\title{
Amyloid beta 4-42 in Alzheimer's disease: Target, Therapy, Mechanism
}

\author{
Doctoral Thesis
}

In partial fulfilment of the requirements for the degree

"Doctor of Philosophy (Ph.D.)"

Molecular Medicine Program

Georg-August University Göttingen

Faculty of Medicine

\section{Submitted by \\ Gregory Antonios}

Born in

Tahwitet Al Nahr, Lebanon

Göttingen, 2015 


\section{Members of Thesis Committee:}

Prof. Dr. Thomas A. Bayer (Supervisor)

Division of Molecular Psychiatry

Dept. of Psychiatry

University Medical Center (UMG)

Göttingen

Prof. Dr. Hubertus Jarry (2 ${ }^{\text {nd }}$ Referee)

Dept. of Clinical and Experimental Endocrinology

University Medical Center (UMG)

Göttingen

Prof. Dr. Thomas Dresbach

Dept. of Anatomy and Embryology

University Medical Center (UMG)

Göttingen

\section{Further Members of the Examination Board:}

\section{Dr. Vladimir Pena}

Macromolecular Crystallography group

Max Planck Institute for Biophysical Chemistry

Göttingen

Prof. Dr. Andre Fischer

Dept. For Psychiatry and Psychotherapy

University Medical Center (UMG)

German Center for Neurodegenerative Diseases (DZNE)

Göttingen

Prof. Dr. Christine Stadelmann

Institute for Neuropathology, Neurology Clinic

University Medical Center (UMG)

Göttingen

Date of the oral examination: March 2nd, 2016 


\section{AFFIDAVIT}

I hereby declare that my doctoral thesis entitled "Amyloid beta 4-42 in Alzheimer's disease: Target, Therapy, Mechanism" has been written independently with no other sources and aids than quoted.

Gregory Antonios<smiles>CCC1CC1C</smiles>

Göttingen, December 2015 


\section{List of Publications:}

Antonios, G., Borgers, H., Richard, B. C., Brauß, A., Meißner, J., Weggen, S., Pena, V., Pillot, T., Davies, S L., Bakrania, P., Matthews, D., Brownlees, J., Bouter, Y., \& Bayer, T. A. (2015). Alzheimer therapy with an antibody against N-terminal Abeta 4-X and pyroglutamate Abeta 3-X. Scientific Reports, 5, 17338. http: / / doi.org/10.1038/srep17338

Antonios, G., Saiepour, N., Bouter, Y., Richard, B. C., Paetau, A., Verkkoniemi-Ahola, A., Lannfelt, L., Ingelsson, M., Kovacs, G., Pillot, T., Wirths, O., \& Bayer, T. A. (2013). N-truncated Abeta starting with position four: early intraneuronal accumulation and rescue of toxicity using NT4X-167, a novel monoclonal antibody. Acta Neuropathologica Communications, 1(1), 56. http://doi.org/10.1186/ 2051-5960-1-56

\section{Publications not included in thesis:}

Zhang, W. I., Antonios, G., Rabano, A., Bayer, T. A., Schneider, A., \& Rizzoli, S. O. (2015). Super-Resolution Microscopy of Cerebrospinal Fluid Biomarkers as a Tool for Alzheimer's Disease Diagnostics. Journal of Alzheimer's Disease: JAD, 46(4), 1007-20. http:/ / doi.org/10.3233/JAD-150064 


\section{Table of Contents}

Acknowledgments................................................................. i

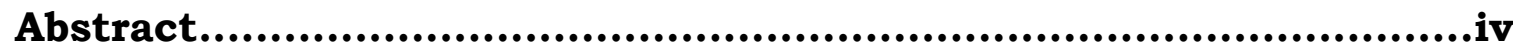

List of Figures .....................................................................vi

List of Tables ............................................................................. viii

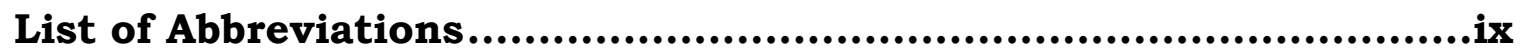

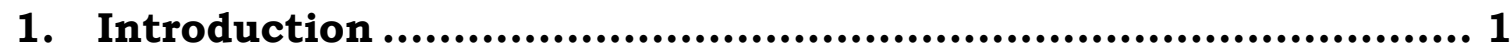

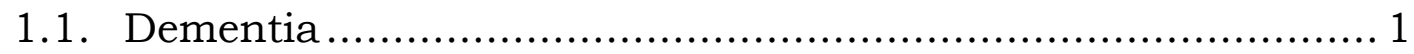

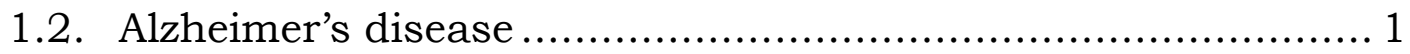

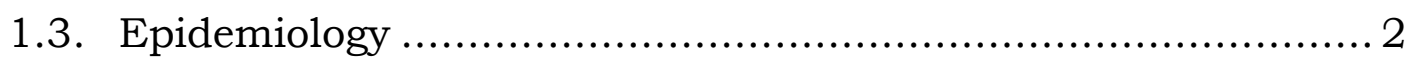

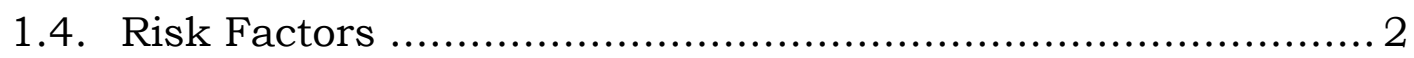

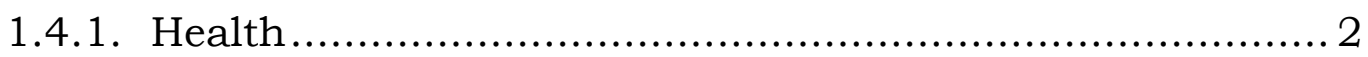

1.4.2. Environmental ........................................................ 3

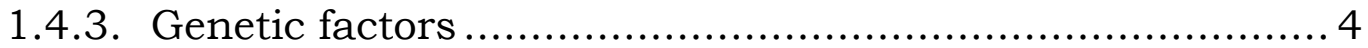

1.4.4. Genome wide association studies ................................ 5

1.5. Neuropathological Hallmarks ........................................... 5

1.5.1. Amyloid deposits ....................................................... 5

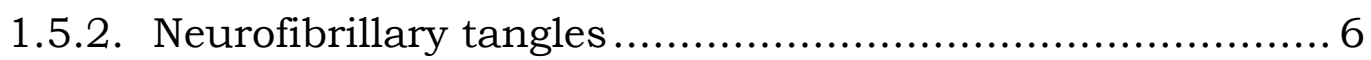

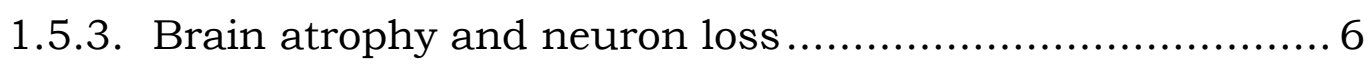

1.6. The Amyloid Precursor Protein ............................................ 7

1.6.1. Amyloidogenic and non-amyloidogenic processing ........... 7

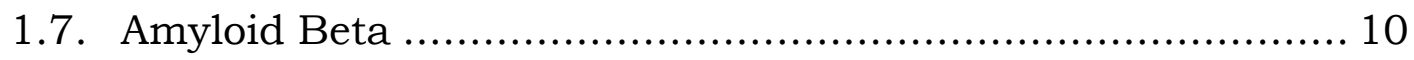

1.7.1. N-truncated amyloid beta........................................ 10

1.7.2. $\mathrm{N}$-truncated $\mathrm{A} \beta$ peptides in murine AD models .............. 11

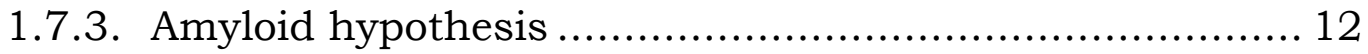

1.7.4. Revised amyloid hypothesis ........................................ 12

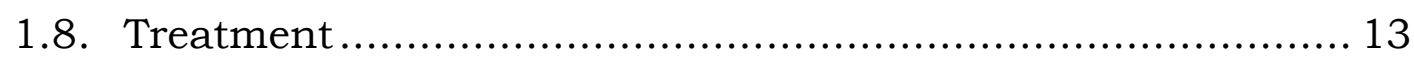

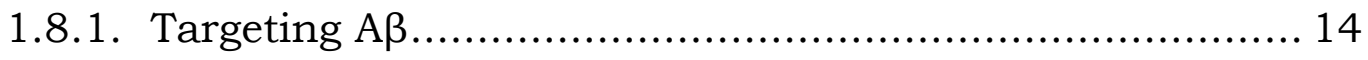

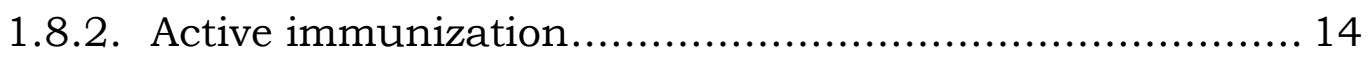

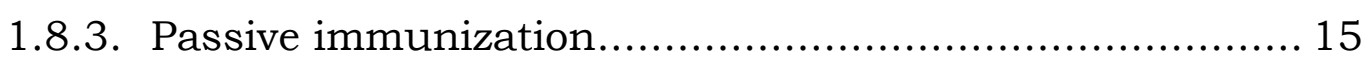

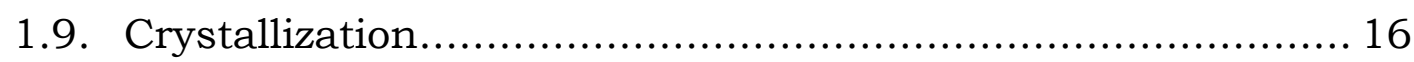

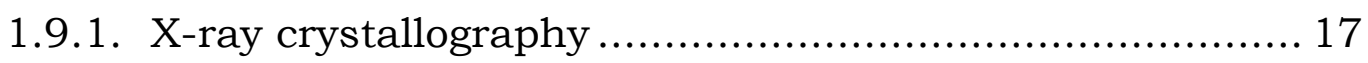

1.9.2. Crystallization of anti-amyloid beta antibodies .............. 17

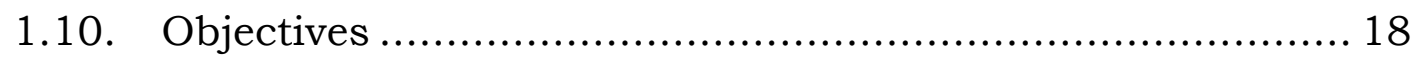

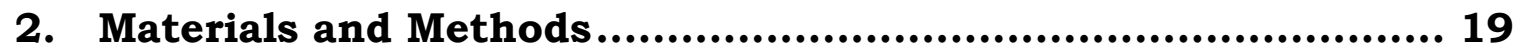

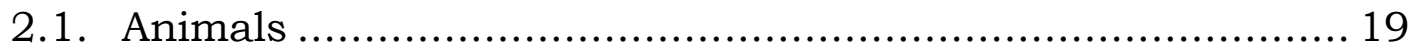




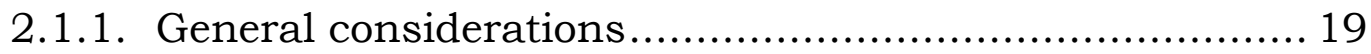

2.1.2. Transgenic mice ….............................................. 19

2.2. Animal Experiments .............................................. 19

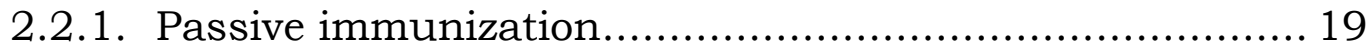

2.2.2. Morris water maze ............................................... 20

2.2.3. Intracerebroventricular injection of soluble $A \beta \ldots \ldots \ldots \ldots \ldots . . . .21$

2.2.4. Y-Maze task ...................................................... 22

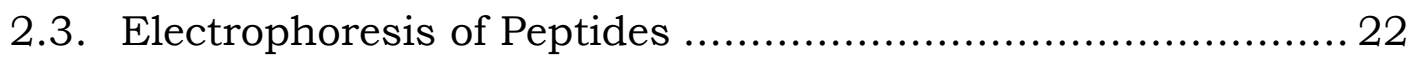

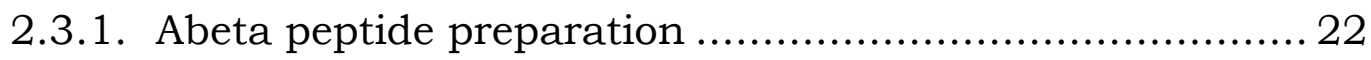

2.3.2. Western blot of synthetic peptides ............................. 22

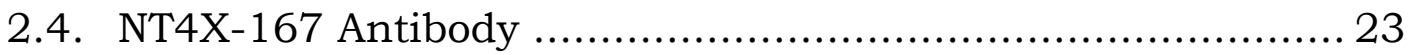

2.4.1. NT4X hybridoma cell culture ..................................... 24

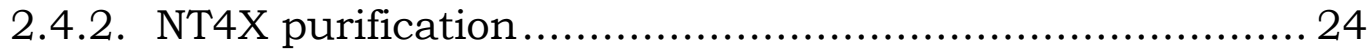

2.4.3. NT4X Fab generation and purification ........................ 24

2.4.4. Antibody storage ................................................... 25

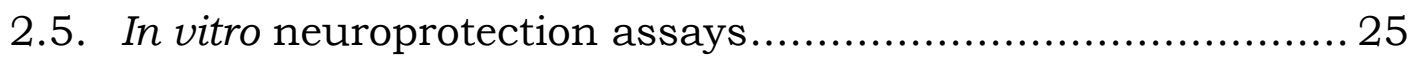

2.5.1. Full-length NT4X antibody neuroprotection assay ......... 25

2.5.2. NT4X Fab fragment neuroprotection assay .................. 26

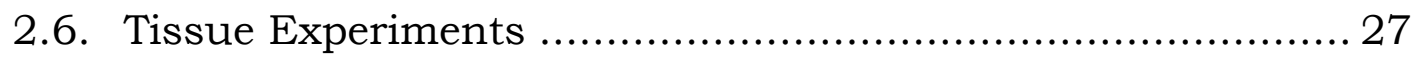

2.6.1. Collection and preservation ................................. 27

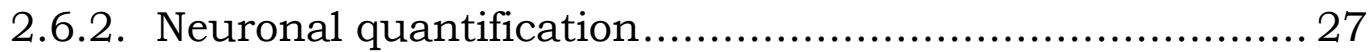

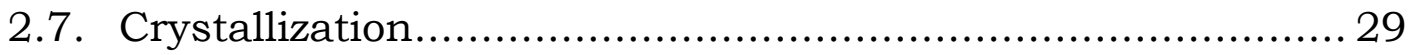

2.7.1. General crystallography setup ................................ 29

2.7.2. Crystallization and diffraction data collection ................ 29

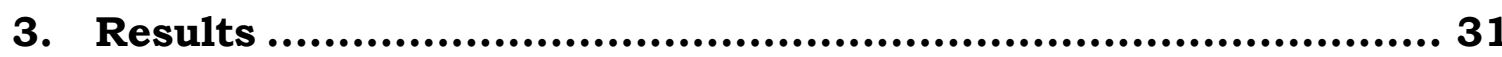

3.1. Full-length NT4X Purification........................................... 31

3.2. NT4X Fab Generation and Purification .............................. 36

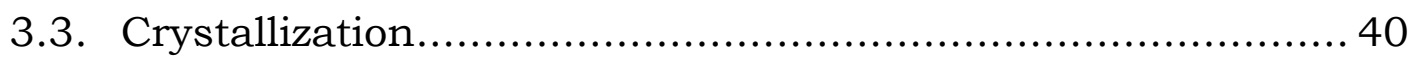

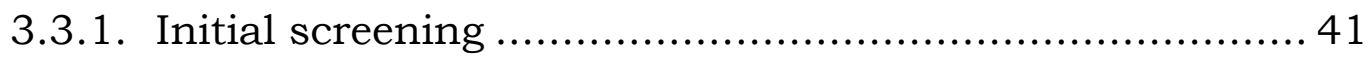

3.3.2. $\mathrm{Fab}+\mathrm{A} \beta_{4-19 \ldots \ldots \ldots \ldots \ldots \ldots \ldots \ldots \ldots \ldots \ldots \ldots \ldots \ldots \ldots \ldots \ldots \ldots \ldots \ldots \ldots \ldots \ldots \ldots \ldots \ldots \ldots \ldots \ldots \ldots \ldots \ldots \ldots \ldots \ldots} 45$

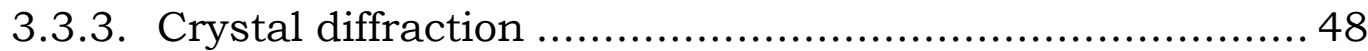

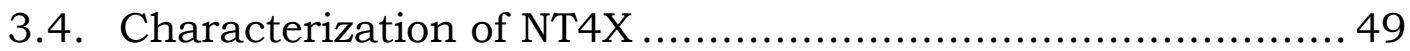

3.4.1. A $\mathrm{B}$ binding properties of NT4X under reducing conditions .49

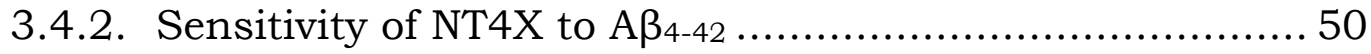

3.5. NT4X and Fab Fragment in vitro Rescue of $A \beta$ Toxicity ........ 50

3.6. NT4X and Fab Fragment in vivo Rescue of $A \beta$ Toxicity.......... 52 
3.7. Spatial Reference Memory Deficits in Homozygous Tg4-42 Mice .54

3.8. Preventative Passive Immunization of Tg4-42hom Mice with

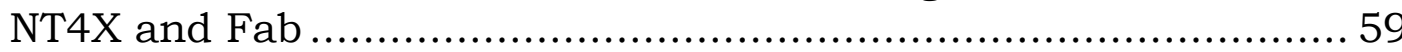

3.8.1. Rescue of spatial reference memory deficits ................. 59

3.8.2. Deceleration of neuron loss ....................................... 61

4. Discussion ....................................................................63 63

4.1. N-Truncated Amyloid Beta 4-x: The Target......................... 63

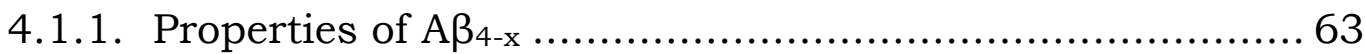

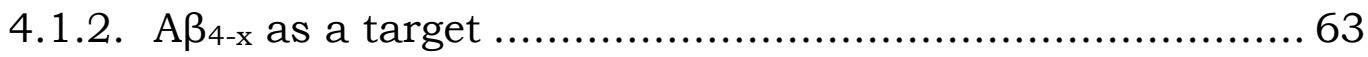

4.1.3. The Tg4-42 model: $A \beta_{4-42}$ in vivo .................................. 65

4.1.4. Neuron loss and spatial reference memory: Age-dependent

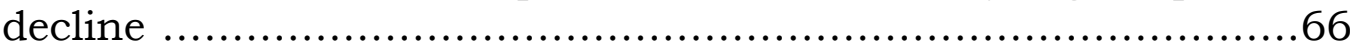

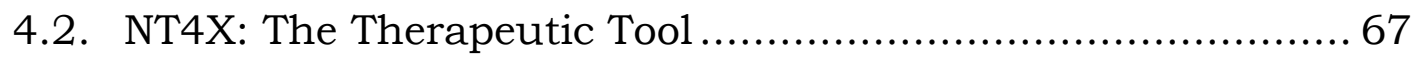

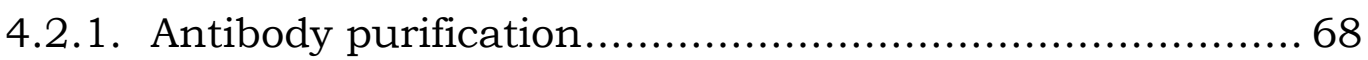

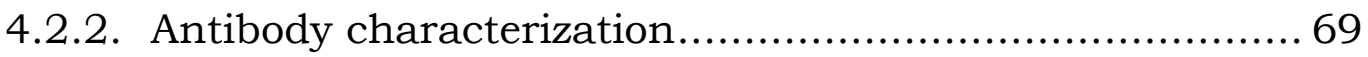

4.2.3. In vitro and in vivo target engagement and rescue ........... 70

4.3. Passive Immunization of the Tg4-42hom AD Model Using NT4X

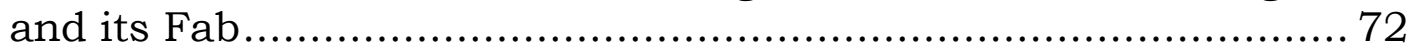

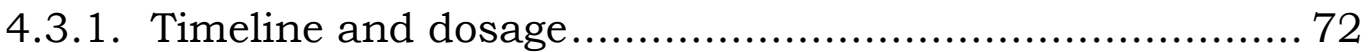

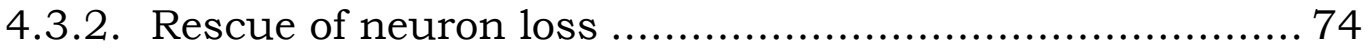

4.3.3. Rescue of reference memory deficits ........................... 75

4.3.4. Mechanism of NT4X passive immunotherapy.................. 75

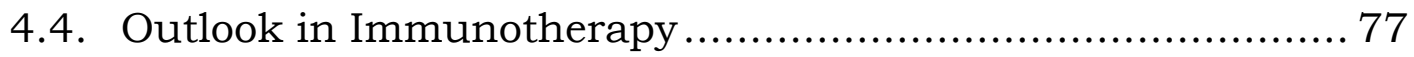

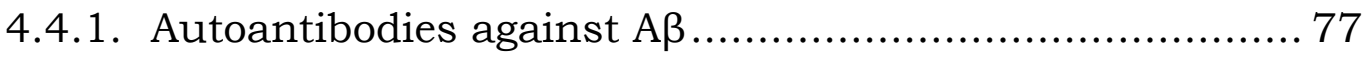

4.4.2. Passive immunotherapy and vascular pathology ............. 78

4.4.3. Intrabodies in immunotherapy .................................... 78

4.5. Crystallization of NT4X Fab and Target Peptide .................. 79

4.5.1. Generation of Fab fragment........................................ 79

4.5.2. Fab functional in vitro and in vivo.............................. 80

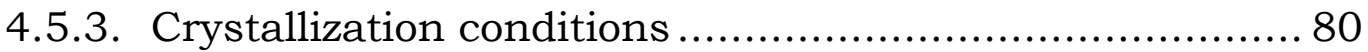

4.5.4. Crystallization of clinically relevant antibodies............... 82

5. Summary \& Conclusions ....................................................... 84

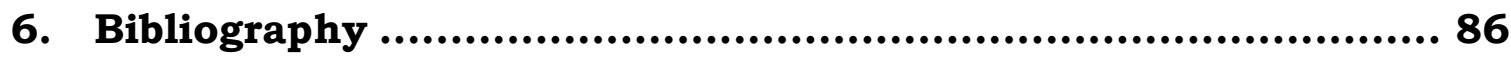

7. Curriculum Vitae .........................................................110 


\section{Acknowledgments}

I'd initially like to acknowledge my supervisor Prof. Dr. Thomas Bayer, for the opportunity to work at the Molecular Psychiatry group these past years and the chance to grow as a scientist. He has always encouraged us to actively participate in scientific meetings and conferences and offered the fiscal support enabling us to do so.

Along those lines, I thank Dr. rer. nat. Oliver Wirths for discussions and insight. I acknowledge past and current members of the working group for an interesting time these past years.

I would like to thank Prof. Dr. Hubertus Jarry and Prof. Dr. Thomas Dresbach for being on my thesis committee and following up on my work.

To Frau Yvette Heise, I owe gratitude for patience and constant help. I would like to also thank Petra Tucholla for introducing me to the working environment.

Meli, I'm glad our paths crossed at this point in life. Though it will carry us to different places in life; I'm certain the memory of all this period will stay on. I wish you all the best, dear friend, and hope that one day you will find what you're looking for.

Meike and Adrianna; you will both do well, of that I am very sure. Believe in yourself first, and others will follow.

To Bernhard, I owe thanks and appreciation for help in tough times when I first arrived. I hope you find contentment in all you seek. 
Anika, you're one of the strongest women I have had the pleasure to know. I hope our paths remain parallel, and that I get to see Ellie grow into the intelligent and beautiful person I know she will be.

When in Göttingen, I was adopted by a lab at Max Planck and spent a significant amount of time there. To Dr. Vlad Pena, I offer sincere gratitude for opening his lab and offering all its resources, and to all the members of the Macromolecular Crystallography group my genuine thanks for making me feel at home.

Ilya, in hopes that our paths cross again, I wish you luck in your pursuits. There's always light, believe it is there against all odds and you shall prevail.

Csaba and Judit, may you always have goodness in you for it has reminded me that your kind still exists, rare as they might be.

To those titans who have carried the weight of educating us all when we were younger; Rita Zgheib, Joseph El Helou, Michel Shbeir. We are a testament of the prospects you made us and are eternally in your debt.

Maya, words cannot begin to express the gratitude I have for the support you have given me. Thank you for pushing me through the door when I was standing right at the entrance, and thank you for always reminding me of what I can do.

Sam, I have had the privilege of calling you "brother" for almost 15 years now. You are to me, an indispensable part of who I am. One day, when we're old, I hope to look back and say; we have done it all, we have crossed the distance and can now rest. I'm certain though, that we will never entirely rest. 
Joelle, for who you are, and for the person Sam has grown into with you, I will forever be thankful.

Joe, life has laid us apart it's been many years now. You have remained, throughout, a support to me. Thank you for setting an example. I hope that one day we shall be reunited.

Noel, thank you for knowing who I am.

$\mathrm{B}$, thank you for being who you are. It has meant the world to me that you have been there during the tough times. You are a wonderful person and I hope to see you achieve all you desire.

To my family, Nadim, Therese, Anna and Mady, I am eternally indebted for their support throughout all I have been through. Not just these past years, but from the beginning.

To my grandmother, Marie; I know that you are with me always. The light you have shown, shall light the path ahead. Till we meet again. 


\section{Abstract}

Targeting $A \beta$ has recently been the main objective in Alzheimer's disease therapeutic approaches. Passive immunization trials have encountered undesirable side effects but the therapy remains a promising option. $A \beta_{4-\mathrm{x}}$ has not been previously considered as a target for AD immunotherapy. Tg4-42 mouse model has been recently established and validated as an advantageous research tool in AD. The current work deals with $A \beta_{4-42}$ and explores its potential as a target, while elucidating therapeutic mechanism and crystallizing the NT4X Fab in complex with $A \beta_{4-19}$ aiming to further reveal the structural basis of antibody: target affinity.

In the present work, the novel monoclonal antibody NT4X specifically reacts with $\mathrm{N}$-truncated $\mathrm{A} \beta$ at position 4 of $A \beta$. It binds $\mathrm{N}-$ truncated $A \beta$ under native and denaturing conditions and rescues in vitro toxicity of $A \beta_{4-42}$ and that of pyroglutamate $A \beta_{\mathrm{PE} 3-42}$. The Fab fragment of the antibody was also able to prevent the in vitro toxicity caused by $A \beta_{4-42}$ in rat primary cortical neuron cultures.

$A \beta_{4-42}$ intracerebroventricular injection into wildtype mice induced a behavioral deficit, shown as a reduction in alteration rate in a Y-Maze, which was prevented using the NT4X. The Fab fragment of the antibody, at a higher dosage, was also able to prevent the in vivo behavioral deficit in a replicate experiment.

The Tg4-42 homozygous mouse model, expressed $A \beta_{4-42}$ and allows for is intraneuronal accumulation. At 6 months of age, the model already exhibits $50 \%$ neuronal loss in the CA1 region of the hippocampus and severe reference memory deficits in a Morris water maze. Preventative passive immunotherapy with the NT4X antibody and its Fab fragment was able to mitigate neuron loss significantly and rescue spatial memory deficits as compared to an isotype control group.

Crystallization of the NT4X Fab in complex with $A \beta_{4-19}$ has been successful. Diffraction data has been collected at $2.8 \AA$. Efforts to 
resolve the crystal structure of the complex are ongoing. Issues with antibody-target engagement in terms of affinity, species and conformation of $A \beta$ bound may be dealt with before going to a clinical setting, with the help of information arising from the crystal structure of the NT4X Fab: A $\beta_{4-19}$ complex. 


\section{List of Figures}

Figure 1.1. Brain atrophy in Alzheimer's disease.

Figure 1.2. APP processing and imbalance in age-related neurodegeneration.

Figure 1.3. Cleavage sites of enzymes potentially involved in generation of $\mathrm{N}$-truncated $\mathrm{A} \beta$ peptides.

Figure 1.4. Adjustable parameters for crystallization include precipitant or additive concentration, $\mathrm{pH}$ and temperature.

Figure 3.1. NT4X antibody purification from hybridoma cell line DSM ACC3162 using immobilized protein A.

Figure 3.2. Coomassie stained SDS-PAGE gel (non-reducing) tracking NT4X antibody purification.

Figure 3.3. Coomassie stained SDS-PAGE gel (non-reducing) tracking NT4X antibody purification following size-exclusion chromatography.

Figure 3.4. Validation of antibody presence during purification process.

Figure 3.5. NT4X antibody digestion using papain

Figure 3.6. Mono S purification chromatogram

Figure 3.7. Mono S purification fractions SDS-PAGE.

Figure 3.8. Modified antibody digestion protocol.

Figure 3.9. Flowchart describing intended process of crystallization.

Figure 3.10. Initial screening for crystallization conditions using NeXtal tube suits.

Figure 3.11. Different concentrations used in screening for crystallization conditions of the NT4X Fab fragment.

Figure 3.12. Representative images from initial crystals of Fab fragment 
Figure 3.13. Verification that crystals grown were consistent with Fab fragment

Figure 3.14. Crystals from initial hits of $\mathrm{Fab}+\mathrm{A} \beta_{4-19}$ complex.

Figure 3.15. First diffraction quality crystals from Fab+A $\beta_{4-19}$ complex.

Figure 3.16. Crystals from Fab+A $\beta_{4-19}$ complex using seeding.

Figure 3.17. Crystal diffraction.

Figure 3.18. SDS-PAGE Western blot analysis of IC16, 1-57 and NT4X antibodies.

Figure 3.19. SDS-PAGE Western blot analysis of $A \beta_{4-42}$ for sensitivity testing of NT4X

Figure 3.20. NT4X protection of $A \beta_{\mathrm{pE} 3-42}$ and $A \beta_{4-42}$ induced toxicity in primary rat neuronal cultures.

Figure 3.21. Cellular toxicity of N-truncated $A \beta_{4-42}$ peptides and treatment effect of NT4X Fab fragment.

Figure 3.22. Full-length and Fab fragment of NT4X rescue A $\beta_{4-42}$ induced working memory deficits in wildtype mice.

Figure 3.23. Cued training of the 6 months homozygous Tg4-42 water maze.

Figure 3.24. Acquisition training of the Morris water maze reveals that 6 months Tg4-42hom mice perform inferior to WT controls.

Figure 3.25. Spatial reference memory deficits in 6 months old Tg442 hom mice shown in the probe trial of the Morris water maze.

Figure 3.26. Cued training of the water maze reveals that Tg4-42 treatment groups exhibit intact eyesight and motor abilities.

Figure 3.27. Spatial learning was assessed in the acquisition training of the Morris water maze.

Figure 3.28. Passive immunization rescues spatial reference memory deficits in NT4X and Fab treated Tg4-42hom mice shown in the probe trial of the Morris water maze. 
Figure 3.29. NT4X and Fab mitigate neuron loss in Tg4-42hom mice.

Figure 4.1. Passive Immunization timeline of Tg4-42.

\section{List of Tables}

Table 2.1. X-ray diffraction data collection parameters.

Table 4.1. Conformational binding properties of some clinically relevant $A \beta$ antibodies. 


\section{List of Abbreviations}

Ach: acetylcholinesterase

AD: Alzheimer's disease

AICD: APP intracellular domain

APOE: Apolipoprotein E

APP: Amyloid precursor protein

$\mathrm{A} \beta$ : amyloid beta

BACE: Beta secretase

BBB: blood-brain barrier

C99: C-terminal 99-residue fragment

CA1: Region I of hippocampus proper

CAA: Cerebral amyloid angiopathy

CTF: ABP Carboxy-terminal fragment

ELISA: Ezyme-linked Immunosorbent Assay

EOAD: early onset Alzheimer's disease

FW: flow-through

GWAS: genome-wide association studies

HRP: horseradish peroxidase

ICV: intracerebroventricular

LOAD: late onset Alzheimer's disease

MRI: magnetic resonance imaging

MWCO: molecular weight cut-off

NaOAc: Sodium Acetate

NFT: Neurofibrillary tangles

NMDA: N-methyl-D-aspartate receptor

PBS: Phosphate buffered saline

PCBs: polychlorinated biphenyls

PEG: polyethylene glycol

PFA: paraformaldehyde

PHF: paired helical filaments

PS-1: Presenilin 1

PS-2: Presenilin 2 
$\mathrm{RT}$ : room temperature

SDS-PAGE: sodium dodecyl sulfate polyacrylamide gel electrophoresis

TBS-T: Tris- buffered saline supplemented with Tween-20

TRH: thyrotropin releasing hormone

WHO: World Health Organization 


\section{CHAPTER 1}

\section{Introduction}

\subsection{Dementia}

The clinical syndrome referred to as "Dementia" encompasses a wide range of underlying pathologies. Most commonly these include Alzheimer's disease (AD), Lewy body dementia, vascular dementia and frontotemporal dementia. The common grounds underlying the aforementioned diseases is a progressive deterioration in cognitive ability and capacity for independent living, brought on via a slow process of neurodegeneration (Sousa et al., 2009, 2010). Attention, problem solving, language, memory and visual-spatial are the most common areas affected by the resulting neurodegeneration (Lee, 2011). In the initial stages of dementia, manifestations of the symptoms are very subtle and often go unnoticed.

Accounting for around 60 - 80\% of dementia cases, Alzheimer's disease is the most common form of dementia (Alzheimer's Association, 2012).

\subsection{Alzheimer's disease}

Senile dementia, before the term Alzheimer's disease was coined at the turn of the previous century following the description of Auguste Deter's case, was well known, dating back to the ancient Greek and Roman philosophers and physicians. However, the histological findings and concepts presented by early researchers of $\mathrm{AD}$, most notably Dr. Alois Alzheimer, were a turning point for the understanding of dementia (Berchtold \& Cotman, 1998). Estimates in France, Sweden, the United States and the Netherlands, consider Alzheimer's disease the most costly disease for society after the age of 65. The epidemiology of $\mathrm{AD}$ is closely linked with the increase in human life span (Bonin-Guillaume et al., 2005). 


\subsection{Epidemiology}

The World Health Organization (WHO) projected that in 2005, $0.379 \%$ of people worldwide had dementia, and that the prevalence would increase to $0.441 \%$ in 2015 and to $0.556 \%$ in 2030 . A more recent WHO study estimates that in $2010,47.5$ million people had dementia, 35 million people of whom had Alzheimer's disease (WHO, 2010, 2015). In line with the previous, another study estimates that by 2050 , the prevalence of AD will quadruple, by which time 1 in 85 persons worldwide will be living with the disease (Brookmeyer et al., 2007).

The death attributable to Alzheimer's disease and other dementias, seems to be correlated to both yearly income (World Bank income categories) and living region (WHO region). Where the lowincome category contributes to $0.41 \%$ of deaths as compared to $2.84 \%$ for the high-income category. Correspondingly, the Eurozone contributes to $2.04 \%$ of $\mathrm{AD}$ and other dementias related deaths as compared to $0.1 \%$ for Africa, 1.47 for the Americas and $0.42 \%$ for Eastern Mediterranean countries (WHO, 2006).

\subsection{Risk Factors}

\subsubsection{Health}

Data from cross-sectional and longitudinal studies relating health risk factors to the risk of developing Alzheimer's disease have mostly remained inconsistent.

Hypertension has been suggested to increase the risk of $A D$ through protein extravasation into brain tissue, caused by a decrease of the vascular integrity of the blood-brain barrier (BBB) (Kalaria, 2010). Likewise, Types 2 diabetes, in observational studies, has been linked to almost doubling the risk of $\mathrm{AD}$ (Leibson et al., 1997; Luchsinger, 2001). 
On the other hand, a lower risk of $\mathrm{AD}$ has been associated with case-control studies examining smoking (Ferini-Strambi et al., 1990; Tyas, 1996). Other health risk factors studied have been cerebrovascular disease (Weishaupt, 2003), body weight (Gustafson et al., 2009; Razay, 2005), plasma lipid levels (Kuo et al., 1998; Michikawa, 2003; Muckle \& Roy, 1985) and traumatic brain injury (Mayeux et al., 1995; Rasmusson et al., 2009).

\subsubsection{Environmental}

Some studies have examined the influence of toxic chemical exposures on the risk of dementia, Alzheimer's disease and eventually, cognitive decline.

Cognitive function including, verbal memory/learning, language, visual memory and more importantly visual spatial/motor functions, have been recently shown do be adversely affected by low-level additive exposure to lead outside of the work setting (Shih et al., 2006).

The potential role of aluminum in Alzheimer's disease has been controversial since 1965. The relevance of a recent laboratory observation to actual real-life conditions has yet to be established since the prediction of aluminum absorption is not mainly extrapolated from the quantity of aluminum ingested. The study had found that a nano-molar amount of aluminum was able to induce gene expression, which promotes inflammation and cell death, similar to observed in AD. The study however, was conducted ex vivo on human neural cells (EFSA, 2008; Lukiw et al., 2005).

Moreover, evidence has begun to develop regarding studies implicating pesticides, polychlorinated biphenyls (PCBs) and particulate air pollution to AD. 


\subsubsection{Genetic factors}

Alzheimer's disease may be classified into early onset $A D$ (EOAD, onset $<65$ years), and late-onset $A D$ (LOAD, onset $\geq 65$ years) that accounts for more than 95\% of cases. Less than 1\% of AD cases are those of EOAD, with the majority of cases belonging to the category of LOAD (Blennow et al., 2006).

While clinically indistinguishable from LOAD, EOAD is generally associated with a more rapid rate of progression and a Mendelian pattern of inheritance.

\subsubsection{Early onset Alzheimer's disease}

The Amyloid precursor protein (APP) as the name entails, is involved in the generation of amyloid beta $(A \beta)$. Mutations in presenilin 1 and 2 (PS-1, PS-2) proteins results in an increase in production of full-length $A \beta_{1-40 / 42}$. They have been firmly implicated in the pathology of EOAD through mutations in the gene encoding their proteins. Considered diagnostic biomarkers of EOAD, these mutations exhibit autosomal dominant inheritance and eventually lead with certainty to $A \beta$ aggregation and an early onset of the disease (Reitz \& Mayeux, 2014; Waring \& Rosenberg, 2008).

\subsubsection{Late onset Alzheimer's disease}

Apolipoprotein E (APOE) is a lipid-binding protein and is expressed in humans as three common isoforms coded for by three alleles, $A P O E \varepsilon 2, \varepsilon 3$, and $\varepsilon 4$. Located on chromosome 19q13, the $A P O E \varepsilon 4$ allele is the only clearly recognized susceptibility gene in Alzheimer's disease. While inhering a single copy of the $A P O E \varepsilon 4$ allele increases the risk of developing $\mathrm{AD}$ by $2-3$ fold, and lowering the age of onset by 6-7 years, it does not guarantee it. Having two copies of the $A P O E \varepsilon 4$ allele is associated with an even higher risk of more than 5 fold increase (Corder et al., 1993; Gomez-Isla et al., 1996b; Kuusisto et al., 1994). 


\subsubsection{Genome wide association studies}

More recent genome-wide association studies (GWAS) have found 19 areas in genes that appear to affect the risk of developing AD. These genes include: CASS4, FERMT2, INPP5D, MS4A, PICALM, NME8, CD2AP, CELF1, HLA-DRB5, EPHA1, ZCWPW1, ABCA7, MEF2C, CLU, SORL1, BIN1, SlC24A4, PTK2B and CR1 (Lambert et al., 2013).

\subsection{Neuropathological Hallmarks}

\subsubsection{Amyloid deposits}

Consisting of folded $\beta$-sheet structures, amyloid depositions are complex mosaic accumulations of protein. Referred to as amyloid plaques, they may be classified into either neuritic or diffuse plaques depending on size, shape and composition (Small, 1998; Yamaguchi et al., 1988).

Neuritic plaques, as the name suggests, are extracellular depositions of fibrillar amyloid beta enclosed by dystrophic neurites. Dystrophic neurites are accumulations of enlarged axons and dendrites amongst others enlarged lysosomes and numerous mitochondria. Ranging in size between 10 to $120 \mu \mathrm{m}$, in AD patients neuritic plaques contain many other proteins such as Tau, ubiquitin and the amyloid precursor protein (Norfray \& Provenzale, 2004; Selkoe, 1989; Su et al., 1998).

Diffuse plaques, on the other hand, are not enclosed by dystrophic neurites and may vary in size from $50 \mu \mathrm{m}$ to a couple of hundred $\mu \mathrm{m}$. They consists of amorphous and non-fibrillar $\mathrm{A} \beta$ depositions and were thought to represent the precursors of neuritic plaque generation (Dickson, 1997).

Cerebral amyloid angiopathy (CAA) is another form of amyloid beta deposition, where $A \beta$ accumulates inside the walls of blood vessels, and is often observed in AD patients (Alafuzoff et al., 2008). 


\subsubsection{Neurofibrillary tangles}

Neurofibrillary tangles (NFT) are constituted of filament pairs, roughly $10 \mathrm{~nm}$ in width, wound into paired helical filaments (PHF) whose composition consists of hyperphosphorylated tau protein (Grundke-Iqbal et al., 1986; Kidd, 1963; Lee et al., 1991). Tau is primarily expressed in axons of the central nervous system. The hyperphosphorylation of tau leads to its dissociation from microtubules, where its primary function is their promotion and stabilization, thus aggregating into PHFs and destabilizing axons (Alonso et al., 2001; Hirokawa et al., 1996). NFTs are used for postmortem staging of $\mathrm{AD}$, although they are acknowledged to be downstream amyloid pathology, yet they correlate better with clinical stages as compared to neuritic plaques (Braak \& Braak, 1991).

\subsubsection{Brain atrophy and neuron loss}

Being a neurodegenerative disease, another characteristic hallmark of $\mathrm{AD}$ pathology is brain atrophy. At the macroscopic level, this is exhibited via the enlargement of the ventricles, widening of the sulci and shrinkage of the gyri (Blennow et al., 2006). Marked by reduction in both volume and weight, magnetic resonance imaging (MRI) may be used to detect this alteration that is noticeable predominantly in the entorhinal cortex, amygdala and hippocampus (Bottino et al., 2002). Studies have shown that hippocampal volume and brain volume are correlated with neuron number, thus pointing towards neuron loss as the driving factor behind brain atrophy (Kril et al., 2004).

The underlying cause driving the progression and severity of neuron loss in $\mathrm{AD}$ is a highly debated matter. While correlations have been made between neuron loss and NFTs (Gomez-Isla et al., 1997), more recently other groups have proposed that the key role is rather neurotoxicity induced by intraneuronal A $\beta$ (Bayer \& Wirths, 2010; Haass \& Selkoe, 2007). Regardless of the reason, analysis of AD cases 
using unbiased stereology have shown significant neuron loss in the entorhinal cortex (Gomez-Isla et al., 1996a), while later studies have also shown neuron loss in the superior temporal gyrus, amygdala, substantia nigra, supramarginal gyrus and region I of hippocampus proper (CA1) (Fig. 1.1) (Duyckaerts et al., 2009).
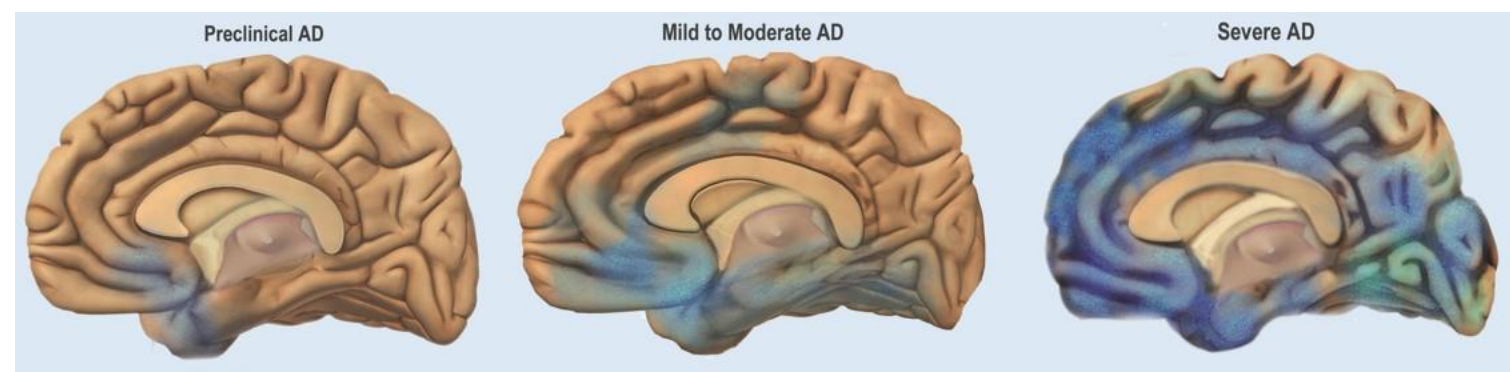

Figure 1.1. Brain atrophy in Alzheimer's disease. Progressive brain atrophy in $\mathrm{AD}$ as compared to a preclinical stage. (Image modified from the National Institute of Health, Open Access source).

\subsection{The Amyloid Precursor Protein}

The gene for the amyloid precursor protein (APP), in humans, is located on chromosome 21 (Yoshikai et al., 1990). It encodes an integral membrane protein whose primary function is yet unknown, yet has been proposed to be involved in iron export (Duce et al., 2010), neural plasticity (Turner et al., 2003) and synapse formation (Priller et al., 2006). As a precursor molecule, its subsequent pathological cleavage results in the generation of beta amyloid, a key player in Alzheimer's disease.

\subsubsection{Amyloidogenic and non-amyloidogenic processing}

In the normal physiological "non-amyloidogenic" pathway, asecretases that are membrane-bound and predominantly active at the cell surface (Sisodia, 1992), cleave APP around the middle region of the $A \beta$ sequence (between amino acids 16 and 17 , both Leucine). This leads to the release of the soluble sAPPa fragment into the extracellular space (Anderson et al., 1991; Sisodia et al., 1990). 
Thereafter, $\mathrm{Y}$-secretase cleaves the remaining $\mathrm{C}$-terminal fragment (C83), thus producing the P3 fragment, which in contrast to $A \beta$ is rapidly degraded, simultaneously producing the APP intracellular domain (AICD) that is thought to be a transcriptional regulator (Haass et al., 1993; Hartmann, 1999).

However, in the pathological "amyloidogenic" pathway, APP is rather cleaved upstream of the $\alpha$-secretase cleavage site by $\beta$ secretase. This consequently releases a soluble $\mathrm{N}$-terminal fragment (sAPP) and a longer C-terminal 99-residue fragment (C99), which remains membrane associated. $\gamma$-secretase then proceeds to cleave $\mathrm{C} 99$ at various sites within the transmembrane domain, generating $A \beta$ peptides ranging from 37 to 43 amino acids in length. This also results in the production of the AICD fragment (Citron et al., 1995; De-Paula et al., 2012) (Fig. 1.2).

It is of worth to note that the main constituent of amyloid plaques is $A \beta$ containing 42 amino acids, while under normal biological conditions mainly $A \beta$ containing 40 amino acids is generated and represents the major portion of the total $A \beta$ (Zhang et al., 2011). 


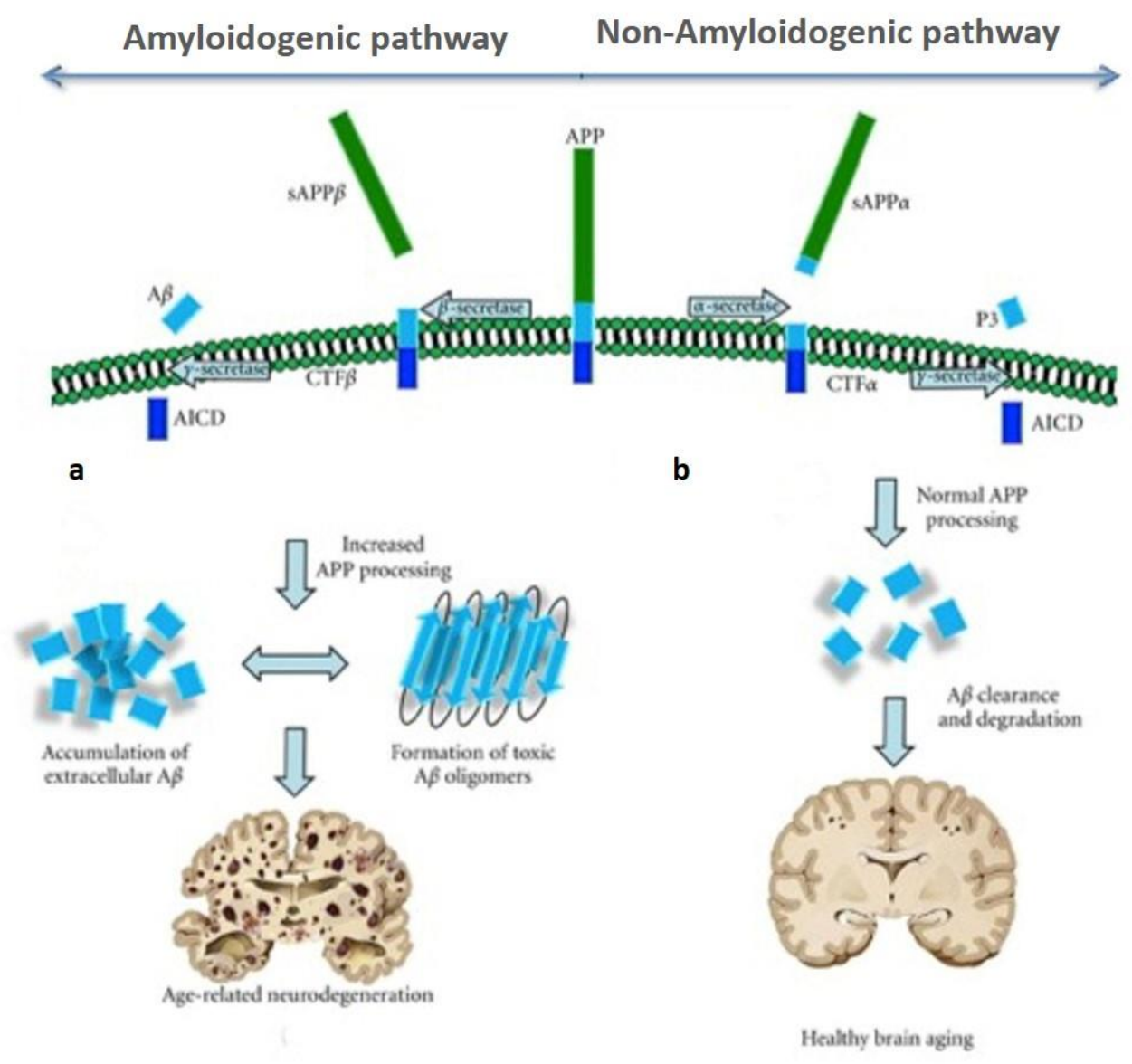

Figure 1.2. APP processing and imbalance in age-related neurodegeneration. The amyloid precursor protein is processed either by an amyloidogenic pathway (left) or a canonical pathway (right). (Left) Beta secretase (BACE) cleaves APP resulting in increased amounts of ABP Carboxy-terminal fragment (CTF $\beta$ ) and $A \beta$ peptide (light blue) being secreted outside the cell. The increased extracellular accumulation of toxic $\mathrm{A} \beta$ species, particularly $A \beta_{42}$, results in the formation of $A \beta$ oligomers. (Right) Normally, most APP is cleaved by the $a$-secretase, secreting SAPP $a$. CTF $a$ is endocytosed and then processed by $\gamma$-secretase, resulting in formation of the p3 peptide, which is secreted, and releasing the AICD into the cytosol. BACE processing of APP does occur to generate A $\beta$ (blue), but these are degraded and cleared. While few small plaques may accumulate with aging, they are much smaller and fewer in number than those associated with disease (Figure and legend modified from (Webb \& Murphy, 2012), Open Access source). 


\subsection{Amyloid Beta}

As previously mentioned, amyloid beta $(A \beta)$ is generated by the sequential cleavage of beta and gamma secretase resulting in the production of peptides varying in length. Apart from so called "full length" $A \beta$ consisting of $A \beta_{1-40}$ and $A \beta_{1-42}$ several truncated versions have been reported such as C-truncated $A \beta_{1-17}, A \beta_{1-38}$ and $A \beta_{1-39}$ (Portelius et al., 2012; Wiltfang et al., 2002). New data has even described peptides similar to $A \beta$, which span amino acids 663-711, before the beta and gamma secretase cleavage sites (Kaneko et al., 2014). Different $A \beta$ isoforms, whether $C$ - or $N$-truncated, possess a carrying degree of aggregation, stability and structure and neurotoxic activity (Bouter et al., 2013; Jarrett et al., 1993; Pike et al., 1995; Wirths et al., 2010). Of particular interest lately in AD therapy have been $\mathrm{N}$-truncated $\mathrm{A} \beta$ peptides.

\subsubsection{N-truncated amyloid beta}

The enzymatic activities that lead to $\mathrm{N}$-terminal truncations are not fully understood. In some cases the question arises if the truncation has occurred after $A \beta_{1-42}$ release or if it is an independent event. Meprin- $\beta$ has recently been proposed to be responsible for generation of $A \beta_{2-x}$ peptides through cleavage of APP (Bien et al., 2012). Neprilysin (NEP) cleaves between Arg-2 and Glu-3 or between Glu-3 and Phe-4, to generate N-truncated $A \beta$ peptides (Howell et al., 1995; Leissring et al., 2003). Furthermore, $\beta$-secretase, the enzyme responsible for the generation of $A \beta_{1-x}$ peptides, can also generate $\mathrm{A} \beta_{11-\mathrm{x}}$ peptides, through between Tyr-10 and Glu-11 (Vassar et al., 1999). An overview of further proteases thought to be involved in $\mathrm{N}$ truncated $A \beta$ generation are seen in Figure 1.3. 


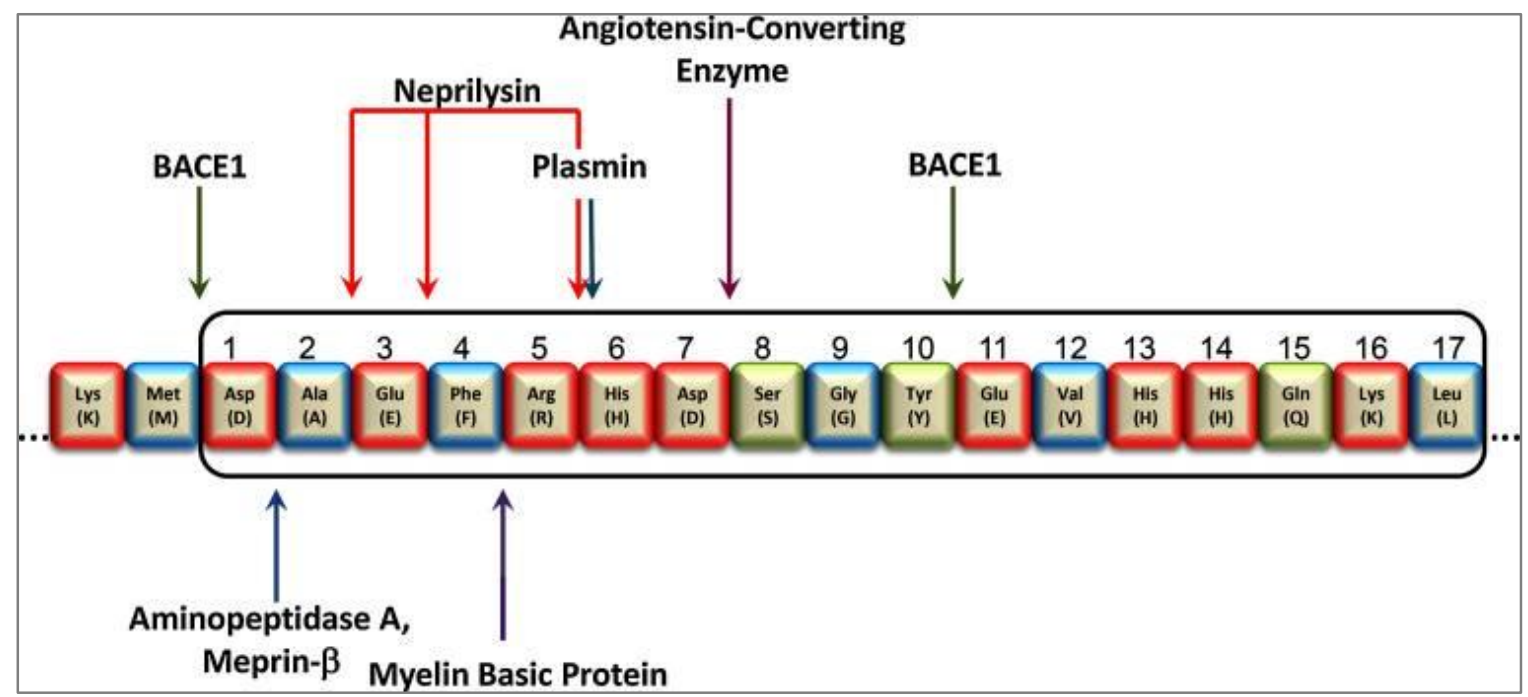

Figure 1.3. Cleavage sites of enzymes potentially involved in generation of $\mathbf{N}$-truncated $\mathbf{A} \boldsymbol{\beta}$ peptides. Sequence of the first 17 amino acids of the N-terminus of human $A \beta$ is shown in three-letter and one-lettercode. Amino acids (AA) with charged polar side-chains are shown in red, AA with uncharged polar side-chains in green and hydrophobic non-polar AA in blue. (Figure adapted from (Bayer $\&$ Wirths, 2014), Open Access source)

\subsection{2. $\quad \mathrm{N}$-truncated $A \beta$ peptides in murine $A D$ models}

The relative amount of $\mathrm{N}$-truncated $\mathrm{A} \beta$ in human $\mathrm{AD}$ is much higher than levels reported in $\mathrm{AD}$ mouse model (Rüfenacht et al., 2005). Nonetheless, several $\mathrm{N}$-truncated forms of $A \beta$ have been reported in murine models. The APP/PS1 KI model has measureable levels of $A \beta_{4 / 5-x}$ and $A \beta_{\mathrm{pE} 3-\mathrm{x}}$ (Casas et al., 2004). Another study assessed the levels of $A \beta_{\mathrm{pE} 3-\mathrm{x}}$ in the 5XFAD, Tg2576, APP/PS1 $1 \triangle \mathrm{E} 9$ and 8 other models (Frost et al., 2013). $A \beta_{5-42}$ has also recently been reported in both the 3xTg and 5XFAD models (Guzman et al., 2014).

To further elucidate the toxicity of $\mathrm{N}$-truncated $\mathrm{A} \beta$ peptides, 2 models expressing only the $A \beta_{\mathrm{pE} 3-\mathrm{x}}$ (TBA42) (Wittnam et al., 2012) and $\mathrm{A} \beta_{4-42}$ (Tg4-42) (Bouter et al., 2013), led to the intracellular accumulation of the respective peptides, accompanied by neuron loss and behavioral deficits. 


\subsubsection{Amyloid hypothesis}

Initial explanations of the pathogenesis of Alzheimer's disease arose from the amyloid cascade hypothesis that pointed the finger towards $A \beta$ deposition as the causative factor in the etiology of AD. This thereby linked $A \beta$ deposition to the eventual pathology in $A D$, claiming it lead to neuron and synapse loss, brain atrophy and eventually leading to dementia (Hardy \& Higgins, 1992). Plaque formation caused by the accumulation of $A \beta_{40}$ and $A \beta_{42}$, caused by increased $A \beta$ production or lack of its clearance, triggered the cascade (Pimplikar, 2009).

Although the theory was heavily supported by a stream of evidence, mostly from familial AD cases studies (Bertram et al., 2010), murine AD models based on familial AD mutations (Duyckaerts et al., 2008), down syndrome and triplication of the APP gene (Rumble et al., 1989; Schupf \& Sergievsky, 2002), the hypothesis had major flaws. The most important indication that the hypothesis was faulty came from evidence showing that cognitively normal individuals, showing no signs of dementia, had shown strong plaque deposition (Pimplikar, 2009). Furthermore, both in human studies (Snowdon, 2003) and in AD mouse models (Walsh \& Selkoe, 2007), plaque load does not correlate consistently with cognitive deficits/dementia.

\subsubsection{Revised amyloid hypothesis}

In contrast to the classical amyloid hypothesis, a revised version dependent on the accumulation of intracellular $A \beta$ peptides has been proposed. It proposes that intracellular $A \beta$ could be secreted and reup taken from cells. Thus elevating levels of intracellular accumulation, is causative in downstream events such as neuronal and synaptosomal dysfunction leading to AD (Wirths et al., 2004). This is supported by several observations, such as, in Down Syndrome intracellular $A \beta$ is detectable at a young age and accumulates less with age as plaques begin to develop (Gyure et al., 
2001). Furthermore, classical AD mouse models, most of which carry a familial $\mathrm{AD}$ mutation and harbour strong plaque pathology, reflect human AD inflammatory pathology, but lack neuron loss (Wirths et al., 2004). To this end, recent mouse models such as the 5XFAD (Oakley et al., 2006), the APP/PS1KI (Casas et al., 2004) and the Tg442 mouse model (Bouter et al., 2013) exhibit an early accumulation of intracellular $A \beta$ and a correlation of behavioral deficits with neuron loss. This implies that $A \beta$ oligomers, soluble intracellularly and extracellularly, play a pivotal role in the development and progression of early AD.

\subsection{Treatment}

Current drugs designed to alleviate the clinical symptoms of $\mathrm{AD}$ mostly rely on neurotransmitter regulation. Since reduction in the activity of cholinergic neurons in $\mathrm{AD}$ has been extensively studied, 4 drugs are acetylcholinesterase (Ach) inhibitors employed to slow down the rate of degradation of Ach (Birks \& Harvey, 2006; Bullock et al., 2005). These are galantamine, rivastigmine, donepezil and tacrine, which are marketed under different commercial names. The $5^{\text {th }}$ drug is an N-methyl-D-aspartate receptor (NMDA) antagonist that blocks the glutamatergic system overstimulation by glutamate (Lipton, 2006). The benefit from their use is very limited and none of the drugs delays the progression of the disease or halts the clinical symptoms (Birks \& Harvey, 2006). Observational studies suggest that combination treatment may increase the time before patients require nursing home care (Lopez et al., 2009). 


\subsubsection{Targeting $A \beta$}

Targeting $A \beta$ has recently been the main target in therapeutic approaches. Drugs have been aimed at either decrease the production of $A \beta$ or enhance its clearance. The primary research focus has been on enzymes involved in $A \beta$ production and their inhibition. $\beta$ - or $\gamma$ secretase inhibition has been attempted with limited success and side effects, as it has been difficult to develop drugs that penetrate the $\mathrm{BBB}$, and precisely inhibit $\beta$ - or $\gamma$-secretase. Unwanted side effects have been the cleavage of alternative substrates such as sodium channel subunits and Notch (Citron, 2010; De Strooper et al., 2010). Research focus has been on immunization approaches to reduce $A \beta$ levels and enhance clearance (Lannfelt et al., 2014).

\subsubsection{Active immunization}

Initial pre-clinical trials in active immunization were a breakthrough, using PDAPP transgenic mice, immunization with preparations of full length $A \beta_{42}$ resulted in the clearance of amyloid plaques (Schenk et al., 1999). Other studies using different mouse models were similar in results and even lead to the amelioration of behavioral symptoms in the mice (Dodart et al., 2002; Janus et al., 2000). Given the previous results, clinical trials in humans were approved hurriedly. Using $\mathrm{A} \beta$ preparations in $\mathrm{AD}$ patients initially reported no adverse effects (Schenk, 2002). However, the clinical phase 2A trials were subsequently halted due to the development of symptoms of central nervous system inflammation, in some patients, and some deaths due to pulmonary embolism (Ferrer et al., 2004; Gilman et al., 2005; Nicoll et al., 2003). The field afterwards turned to passive immunization as a means to overcome the negative side effects caused by active immunization. 


\subsubsection{Passive immunization}

As with any form of therapy that is taken from the bench to bedside application, passive immunization offers both advantages and disadvantages. The major disadvantage of passive immunization lies in the fact that repeated infusions of antibody over the lifetime of a patient would be necessary to maintain a desired therapeutic effect. The therapy however, offers a precise delivery of target specific antibodies to patients and the opportunity to rapidly decrease antibody titer if side effect should develop (Lannfelt et al., 2014).

The first evidence of success in passive immunotherapy in an AD mouse model was demonstrated by Bard and colleagues in 2000. Wherein the systemic administration of the N-terminus 3D6 monoclonal antibody eventually resulted in a decreased plaque burden (Bard et al., 2000). The humanized version of 3D6, Bapineuzumab, proceeded in phase I, II and III clinical trials but terminated after phase III trials did not achieve significant clinical efficiency (Lannfelt et al., 2014). A recent version of the antibody, AAB-003, engineered to reduce risk of vasogenic edema and microhaemorrhage, is now in phase I study.

Other humanized antibodies currently still in various stages of clinical trials are Crenezumab (Genentech), BAN2401 (Biogen), LY3002813 (Eli Lilly \& Co), SAR228810 (Sanofi) and Solanezumab (Eli Lilly \& Co) (Clinicaltrials.gov).

Although passive immunization trials have encountered undesirable side effects, and their long-term cost to the healthcare system is highly debated, the therapy remains a promising option. 


\subsection{Crystallization}

Crystallization is, a feature of precipitation, wherein the process of formation of solid crystals is driven through precipitation from a solution or gas. The two major events of crystallization are nucleation and crystal growth. The clustering of solute molecules, dispersed in the solvent, is a nanometer scale event referred to as nucleation. Conditions such as temperature, supersaturation, $\mathrm{pH}$ and more, will determine whether a cluster the critical size in order to become a stable nucleus (Fig. 1.4). Supersaturation is the driving force of crystal growth, with either nucleation or growth being predominant thus affecting the different sizes and shapes of crystals obtained. Crystallization is complete once supersaturation is drained and the solid-liquid system reaches equilibrium.

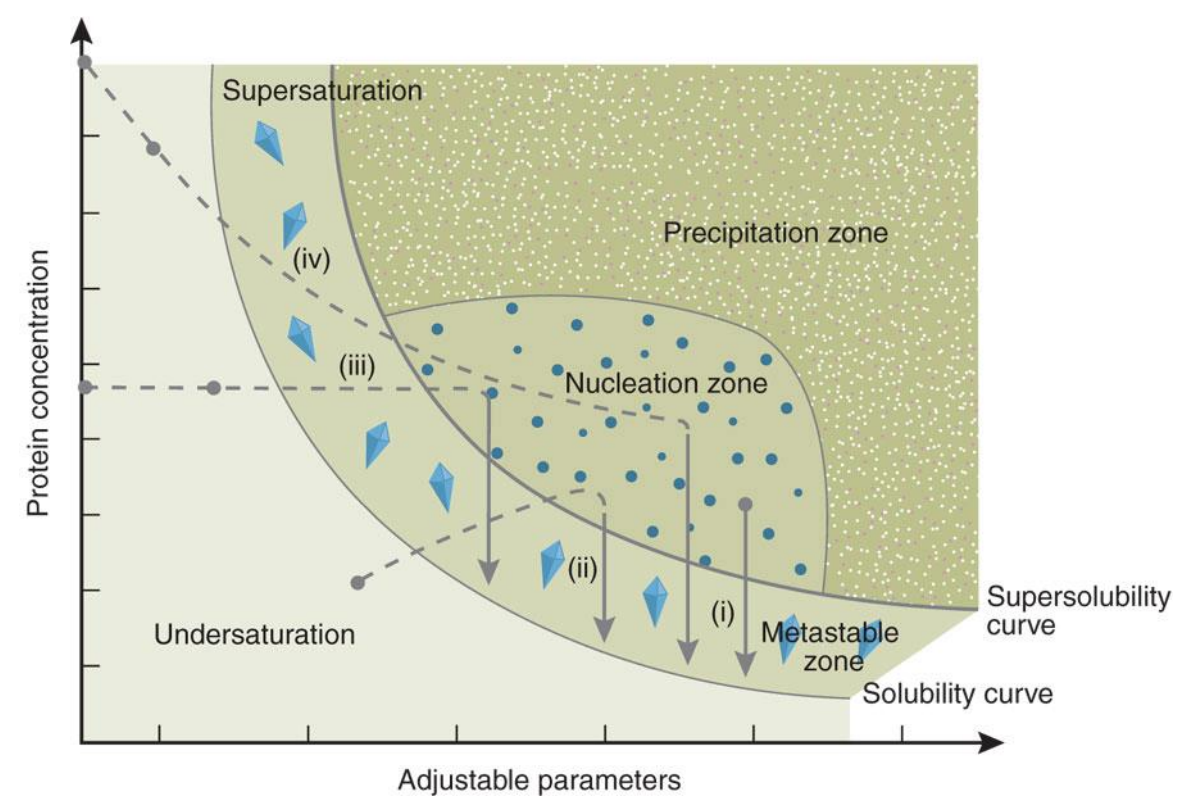

Figure 1.4. Adjustable parameters for crystallization include precipitant or additive concentration, $\mathbf{p H}$ and temperature. The four major crystallization methods are represented: (i) microbatch, (ii) vapor diffusion, (iii) dialysis and (iv) FID. Each involves a different route to reach the nucleation and metastable zones, assuming the adjustable parameter is precipitant concentration. The filled black circles represent the starting conditions. Two alternative starting points are shown for FID and dialysis because the undersaturated protein solution can contain either protein alone or protein mixed with a low concentration of the precipitating agents. The solubility is defined as the concentration of protein in the solute that is in equilibrium with crystals. The supersolubility curve is defined as the line separating conditions under which spontaneous nucleation (or phase 
separation or precipitation) occurs from those under which the crystallization solution remains clear if left undisturbed. Figure and legend taken from (Chayen \& Saridakis, 2008), used with permission from Nature Publishing Group, license number 3770641097789).

\subsubsection{X-ray crystallography}

Is an experimental technique that is used to determine the three dimensional structure of a substance (e.g. protein, RNA, DNA, small molecules). It exploits the fact that periodically arranged atoms in the substance crystal diffract X-rays. Based on the resulting diffraction patterns, the electron density can be reconstructed and the structural model describing position of every atom of the substance can be built. Macromolecular crystallography is a technique used to study biological molecules such as nucleic acids and proteins to a resolution higher than $5 \AA$ A. It allows for the elucidation of protein structure and function and may also demonstrate interaction between 2 or more proteins. The crystallographic analysis of antigen-antibody complexes has been demonstrated (Edmundson et al., 1996).

\subsubsection{Crystallization of anti-amyloid beta antibodies}

Alzheimer's disease researchers have come to believe that the success of $A \beta$ antibodies, currently in clinical development, in terms of eventual success in therapeutic trials, may be correlated with the precise spatial details of how the antibodies engage their antigen. A growing collection of crystal structures are building a knowledge base, in hopes of improving therapeutic outcome and minimize collateral activity such as vasogenic edema. Each of the clinical anti-A $\beta$ antibodies targets specific parts of the notorious peptide, though some of the binding profiles overlap. Some of the published crystal structures include that of Bapineuzumab (Crespi et al., 2014; Feinberg et al., 2014b; Miles et al., 2013), Solanezumab (Crespi et al., 2015), Ponezumab (La Porte et al., 2012) and Gantanerumab (Bohrmann et al., 2012). 


\subsection{Objectives}

Targeting $A \beta$ has recently been the main objective in Alzheimer's disease therapeutic approaches. Passive immunization trials have encountered undesirable side effects but the therapy remains a promising option. Amyloid beta $4-\mathrm{x}$ has not been previously considered as a target for $\mathrm{AD}$ immunotherapy.

The current work's objectives are the following:

- The characterization of a novel antibody (NT4X-167) which recognizes $\mathrm{N}$-truncated amyloid beta

- The large scale purification of the NT4X antibody and its respective Fab fragment

- The characterization of NT4X binding specificity and sensitivity

- The investigation of NT4X in vitro and in vivo rescue of amyloid beta

- The validation of $\mathrm{Tg} 4-42$ as a valid $\mathrm{AD}$ model for therapeutic intervention

- The passive immunization of Tg4-42 with NT4X and determination of the mechanism of target engagement 


\section{CHAPTER 2}

\section{Materials and Methods}

\subsection{Animals}

\subsubsection{General considerations}

Murine lines were maintained in the central animal facility of the University Medicine Göttingen under standard housing conditions. For behavioral analysis, mice were kept under constant $12 \mathrm{~h} / 12 \mathrm{~h}$ dark/light conditions and supplied with food and water ad libitum.

Animal experiments were approved by the local animal protection authorities (Niedersächisches landesamt für Verbraucherschutz und Lebensmittelsicherheit) under the approval number $14 / 1450$.

All experiments were conducted in accordance with the approved protocols.

\subsubsection{Transgenic mice}

Tg4-42 mice express human $A \beta_{4-42}$ fused to the murine thyrotropin releasing hormone (TRH) signal peptide under the control of the neuronal Thy- 1 promoter on a $\mathrm{C} 57 \mathrm{Bl} / 6 \mathrm{~J}$ genetic background (Bouter et al., 2013).

For this study only homozygous Tg4-42 mice were used (Tg442hom).

\subsection{Animal Experiments}

\subsubsection{Passive immunization}

The potential therapeutic effects of NT4X-167 were studied using a passive immunization approach in Tg4-42 hom. Passive 
immunization was performed by intraperitoneal injections of the $A \beta$ specific monoclonal antibody NT4X (against the N-terminus of A $\beta_{4-x}$ ) or its Fab fragment and compared to control groups using antibody of the same immunoglobulin class as NT4X (IgG2b).

Tg4-42hom mice were immunized by injections of the NT4X antibody, $10 \mathrm{mg} / \mathrm{kg}$ body weight, diluted in sterile Phosphate buffered saline (PBS) ( $\mathrm{pH}$ 7.4). Mice received weekly injections beginning at 3 months of age. Each mouse received a total of 12 injections. Behavior testing started between the $10^{\text {th }}$ and the $11^{\text {th }}$ injection. Animals were sacrificed after the last injection.

Control groups comprised of $\mathrm{Tg} 4-42 \mathrm{hom}$ mice received intraperitoneal IgG2b antibody (10mg/kg body weight) diluted in PBS. Control mice were treated exactly the same as the NT4X group receiving 12 injection of the respective control solution starting at 3 months of age. Furthermore, a non-treated Tg4-42hom group served as an additional control.

\subsubsection{Morris water maze}

Spatial reference memory in Tg4-42hom mice was evaluated using a modified version of the Morris water maze (Morris, 1984).

Briefly, mice learn to use visual spatial cues to locate a hidden platform in a circular pool filled with opaque water. The pool was divided into four virtual quadrants that were defined based on their spatial relationship to the platform: left, right, opposite and target quadrant, which contains the submerged goal platform.

ANY-Maze video tracking software (Stoelting Co.,Wood Dale, USA) was used to record escape latency, swimming speed and quadrant preference.

The experiment began with three days of cued training during which the submerged platform was made visible with a triangular flag that extended upwards. Both the location of the platform and the 
position where mice were introduced into the pool changed between trials. Each mouse received four training trials per day.

Forty-eight hours after the last day of cued training, mice performed five days of acquisition training. For this part of testing, the flag was removed from the submerged platform. Both distal cues, existing in the room, and proximal visual cues attached to the outside of the pool, were used as learning cues. The platform location remained stationary for each mouse throughout training. Each mouse again received four training trials per day.

Twenty-four hours after the last acquisition trial, a probe test was performed to assess long-term spatial reference memory. The platform was removed from the pool, and mice were introduced into the water from a novel entry point. Mice were then allowed to swim freely for one minute while their swimming path was recorded.

Mice were sacrificed 24-48 hours after the probe trial.

\subsubsection{Intracerebroventricular injection of soluble $A \beta$}

12-week-old male C57BL/6J mice (Janvier, Le Genest-St-Isle, France) were intracerebroventricularly (icv) injected under anesthetization. Freshly prepared $A \beta_{4-42}$ peptides $(50$ pmol in $1 \mu \mathrm{L}$; $0.1 \mathrm{M}$ PBS (pH 7.4)) or freshly prepared 50 pmol $\mathrm{A} \beta_{4-42}$ in combination with the NT4X antibody [1 or 10 pmol respectively in $1 \mu \mathrm{L} ; 0.1 \mathrm{M}$ phosphate-buffered saline $(\mathrm{pH}$ 7.4)] was injected into the right ventricle, with stereotaxic coordinates from the bregma (AP $-0.22, \mathrm{~L}-$ 1.0 and D 2.5 in $\mathrm{mm})$. Vehicle (0.1M phosphate-buffered saline) or vehicle in combination with 1 or 10 pmol NT4X respectively were injected into the right ventricle as a control. ICV injections were made using a 10- $\mu 1$ Hamilton microsyringe fitted with a 26-gauge needle. Four days following ICV infusion of $A \beta$ peptides, working memory was assessed using the Y-maze test (Experiments performed by SynAging, Nancy, France). 


\subsection{4. $\quad$ Y-Maze task}

Immediate spatial working memory performance in icv injected 12-week-old male C57BL/6J wildtype mice was assessed by recording spontaneous alternation behavior in a Y-maze as described previously (Miller et al., 2008; Youssef et al., 2008). The Y-maze task was carried out on day four after $A \beta_{4-42}$ and NT4X application. The maze was made of opaque plexiglas and each arm was $40 \mathrm{~cm}$ long, $16 \mathrm{~cm}$ high, $9 \mathrm{~cm}$ wide and positioned at equal angles. Mice were placed at the end of one arm and allowed to move freely through the maze during a 5 min session. The series of arm entries were recorded visually and arm entry was considered to be completed when the hind paws of the mouse were completely placed in the arm. Alternation was defined as successive entries into the three arms on overlapping triplet sets. The percentage alternation was calculated as the ratio of actual (total alternations) to possible alternations (defined as the number of arm entries minus two), multiplied by 100 (Experiments performed by SynAging, Nancy, France).

\subsection{Electrophoresis of Peptides}

\subsubsection{Abeta peptide preparation}

Stock solutions of synthetic peptides for blotting $(1 \mathrm{mg} / \mathrm{ml}$ in 10 $\mathrm{mM} \mathrm{NaOH}$; PSL, Heidelberg) were prepared, sonicated for $5 \mathrm{~min}$ in water bath (Sonorex RK 100H, Bandelin electronic), snap frozen in liquid nitrogen and stored at $-80^{\circ} \mathrm{C}$.

\subsubsection{Western blot of synthetic peptides}

For Western blot analysis under reducing conditions $7 \mu \mathrm{g}$ peptide per well (mixed with an equal volume of sample buffer) were loaded on 4-12\% Tris-Tricin VarioGels (Anamed) and run at a constant current of $120 \mathrm{~V}$. After electrophoresis, the peptides were 
transferred onto $0.45 \mu \mathrm{m}$ nitrocellulose membranes for 30 minutes per membrane at constant $25 \mathrm{~mA}$ in a semi-dry transfer chamber. Free binding sites were blocked with $10 \%$ (w/v) non-fat dry milk dissolved in Tris- buffered saline supplemented with Tween-20 (TBS-T) (50 mM Tris(hydroxymethyl)- aminomethane (Tris) $\mathrm{pH} \quad 8.0$ supplemented with $0.05 \%(\mathrm{v} / \mathrm{v})$ Tween-20) for one hour at room temperature (RT).

For detection, the primary antibodies IC16 $(1 \mu \mathrm{g} / \mathrm{ml}), 1-57$ (1 $\mu \mathrm{g} / \mathrm{ml})$ and NT4X $(1 \mu \mathrm{g} / \mathrm{ml})$ were dissolved in TBS-T and incubated on a shaker over night at $4{ }^{\circ} \mathrm{C}$. After three, $5 \mathrm{~min}$, washing steps with TBS- $\mathrm{T}$, the secondary rabbit-anti-mouse horseradish peroxidase (HRP)-conjugated antibody was diluted 10000-fold in TBS-T and incubated with the membrane for 2 hours at RT. Blots were developed using Luminata Crescendo Western HRP Substrate (Millipore) and exposed with the ODYSSEY Fc (LI-COR).

\subsection{NT4X-167 Antibody}

The novel oligomeric A $\beta$ specific antibody NT4X (IgG2b; official name of cell line $A \beta_{4-40}$ NT4X-167; DSM ACC3162) was generated by

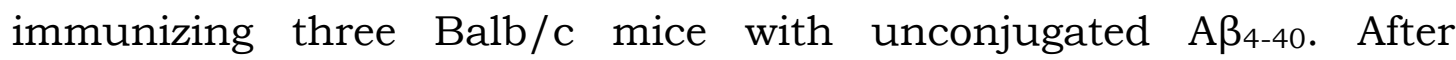
preparation of the lymph nodes they were fused with the myeloma cell line P3-X63-Ag8 for generation of the hybridoma cells. The hybridoma supernatants of mixed clones were screened by Ezyme-linked Immunosorbent Assay (ELISA) and immunohistochemistry and subcloned. The idea behind the generation of novel oligomeric antibodies was that in solution $A \beta_{4-40}$ peptides are forming stable aggregates that can be used as an epitope for antibodies that specifically bind at the $\mathrm{N}$ - terminus of $A \beta_{4-40}$. Therefore $A \beta_{4-40}$ was used for immunizing mice and positive clones were screened in four steps. (Antonios et al., 2013). 


\subsubsection{NT4X hybridoma cell culture}

The NT4X hybridoma cell line was cultured in a serum-free media for hybridoma culture ISF-1 (Biochrom) and maintained in fed batch/continuous perfusion mode at 25\% Oxygen, $5 \% \mathrm{CO} 2$ and $37^{\circ} \mathrm{C}$ in a 3L glass vessel bioreactor (Applikon) controlled using ADI 1030 (Applikon). The cell-culture supernatants were harvested by centrifugation at $500 \mathrm{~g}$ and the antibody containing media was collected.

\subsubsection{NT4X purification}

Media was further centrifuged at $10,000 \mathrm{~g}$ for $30 \mathrm{~min}$ prior to Protein A affinity chromatography and $\mathrm{pH}$ was stabilized by addition of $20 \%(\mathrm{v} / \mathrm{v})$ of PBS buffer. Media was loaded at $5 \mathrm{ml} / \mathrm{min}$ onto HiTrap $^{\mathrm{TM}}$ Protein A HP (GE Healthcare) connected to an AKTAxpress (GE Healtcare). Further column washing and elution was done according to Protein A column manufacturer instructions. The eluted sample was further purified by size-exclusion chromatography using a HiLoad 26/60 Superdex 200 pg run in PBS on an AKTAxpress (GE Healthcare).

\subsubsection{NT4X Fab generation and purification}

Fab fragments were produced utilizing papain digestion of the intact NT4X monoclonal antibody. Papain agarose (Sigma) was preactivated, shaking at $1400 \mathrm{rpm}$, with $10 \mathrm{mM}$ cysteine (Sigma) in PBS for 30 min at room temperature. Previously purified NT4X antibody (in PBS) was incubated for 4 hours at $37^{\circ} \mathrm{C}$ with pre-activated papain agarose (1 $\mathrm{U}$ agarose/5 $\mathrm{mg}$ antibody). Papain agarose was subsequently removed by filtration through a $0.45 \mu \mathrm{m}$ filter. Filtrate was then dialyzed into Buffer A $(20$ mM Sodium Citrate, $20 \mathrm{mM} \mathrm{NaCl}$, $\mathrm{pH}=5.5)$ and afterwards loaded onto a Monos 10/100 GL (GE Healthcare). Column was eluted using 30 column volumes, reaching a 
$10 \%$ gradient of Buffer B (20 mM Sodium Citrate, $1 \mathrm{M} \mathrm{NaCl}, \mathrm{pH}=5.5)$. Column eluate was immediately neutralized using Buffer C (1 M Tris, $\mathrm{pH}=9.0$ ).

Fab Eluate was further purified and buffer exchanged by sizeexclusion chromatography using a HiLoad 26/60 Superdex 75 pg run in PBS or Tris $50 \mathrm{mM}$ buffer on an AKTAxpress (GE Healthcare).

\subsubsection{Antibody storage}

Both full length antibody and Fab fragment were concentrated to $2 \mathrm{mg} / \mathrm{ml}$ with a $10 \mathrm{kDa}$ molecular weight cut-off (MWCO) centrifugal concentrator (Amicon Ultra, Millipore), snap frozen in liquid nitrogen and stored at $-80^{\circ} \mathrm{C}$ until further use.

\subsection{In vitro neuroprotection assays}

\subsubsection{Full-length NT4X antibody neuroprotection assay}

Neurons were prepared from the cortex of 18 day old embryonic $\mathrm{CD}$ rat brains using a papain digestion kit (Worthington, Biochemical Corporation). Cells were plated at $3 \times 10^{5}$ cells $/ \mathrm{ml}$ in 96 well Cell Coat, Poly-D-Lysine coated plates (Greiner) in Neurobasal media with Pen/Strep, L-glutamine and B27 supplement with antioxidants (Gibco, ThermoFisher). The plates were incubated in a humidified incubator at $37^{\circ} \mathrm{C}, 5 \% \mathrm{CO} 2$ for two days prior to adding the antibodies and amyloid peptides. Media was removed from the plates and fresh Neurobasal media containing B27 supplement without antioxidants (Invitrogen) added to perform the assay. Purified antibody stocks (mouse NT4X IgG2b and an isotype control antibody) were diluted in sterile PBS $(\mathrm{Ca} / \mathrm{Mg}$ free) and $10 \mu \mathrm{l}$ added to a total volume of $100 \mu 1$ per well to give a series of dilutions at the required concentration. HFIP treated and dried amyloid peptide aliquots (stored in a desiccator at $-80^{\circ} \mathrm{C}$ ) were dissolved in $100 \mathrm{mM} \mathrm{NaOH}$ and further diluted in Neurobasal media without antioxidants to achieve final peptide 
concentrations of $5 \mu \mathrm{M}$ for both $\mathrm{A} \beta_{\mathrm{pE3}-42}$ and $\mathrm{A} \beta_{1-42}$ and $10 \mu \mathrm{M}$ for $\mathrm{A} \beta_{4-42}$ peptide in the cell assay (Anaspec, Fremont, CA (Eurogentec) and California Peptide Research, San Francisco). The plates were incubated for seven days prior to LDH measurement with the CytoTox96 Non-Radioactive cytotoxicity assay kit (Promega). The LDH assay was performed on $50 \mu \mathrm{l} /$ well culture supernatant in fresh 96 well assay plates (Costar). The plates were read at $490 \mathrm{~nm}$ on a Tecan Safire II plate reader. The inhibition assay was repeated $n=2$ to 3 for each peptide with the two antibodies detailed. (Experiment performed by MRC Technology, London, United Kingdom)

\subsubsection{NT4X Fab fragment neuroprotection assay}

Cortical neurons from embryonic day 16-17 Wistar rat fetuses were prepared as previously described (Pillot et al., 1999). In brief, dissociated cortical cells were plated at 50,000 cells/well in 48-well plates precoated with $1.5 \mathrm{mg} / \mathrm{mL}$ polyornithine (Sigma). Cells were cultured in a chemically defined Dulbecco's Modified Eagle's/F12 medium free of serum (Gibco) and supplemented with hormones, proteins and salts. Cultures were kept at $35^{\circ} \mathrm{C}$ in a humidified $5 \%$ CO2 atmosphere, and at 6-7 DIV, cortical population was determined to be at least $97 \%$ neurons by immunostaining as previously described (Youssef et al., 2008). At 6 DIV, the medium was removed and cortical neurons were incubated for $24 \mathrm{~h}$ with vehicle (cell culture medium) or $A \beta$ peptides (dissolved in cell culture medium) at the indicated concentrations. Following a $24 \mathrm{~h}$ incubation of primary cortical neurons with $A \beta$ peptides, cell viability was determined using a calcein-AM assay (Invitrogen, Molecular Probes).

Briefly, cells were washed twice with PBS and incubated protected from light for $30 \mathrm{~min}$ at room temperature in the presence of $2 \mu \mathrm{M}$ calcein-AM solution prepared in PBS. Cells were then washed twice with PBS and incubated for $15 \mathrm{~min}$ at room temperature in PBS containing $1 \%$ Triton X-100 (v/v). The level of calcein fluorescence was 
monitored by fluorescence emission at $530 \mathrm{~nm}$ after exciting at 485 nm, using a Fluostar microplate reader (BMG-Lab technologies, France). (Experiment performed by SynAging, Nancy, France)

\subsection{Tissue Experiments}

\subsubsection{Collection and preservation}

For all intended purposes, mice tissue was collected and preserved after transcardial perfusion of anaesthetised mice.

First mouse is anaesthetised using $10 \mathrm{~mL} / \mathrm{kg}$ intraperitonal injection of $1 \%$ Ketamin (Medistar, Ascheberg, Germany) and 0.1\% Xylazin (Ecuphar, Belgium) in injectable grade water. Following deep anaesthesia, transcardial perfusion is carried out using ice-cold PBS buffer, followed by 4\% paraformaldehyde (PFA) in PBS. Brain hemispheres were carefully divided at the midline. Left hemispheres were post fixed in 4\% PFA overnight followed by $30 \%$ sucrose in PBS overnight. Following day, the tissue is frozen on dry ice and stored at $80^{\circ} \mathrm{C}$ until further processing.

Right brain hemispheres were post fixed in $4 \%$ buffered formalin (Roth, Karlsruhe, Germany) at $4^{\circ} \mathrm{C}$ before the tissue was embedded in paraffin by dehydration in a series of ethanol of $50 \%, 60 \%, 70 \%, 80 \%$, 90\%, and $2 \times 100 \%$ ethanol followed by Xylol treatment. Finally, tissue was immersed in liquid paraffin for 2 hours before being embedded in solid paraffin blocks.

\subsubsection{Neuronal quantification}

\subsubsection{Cresyl violet staining}

For neuronal stereology, frozen left hemispheres brains were cut in 10 series of $30 \mu \mathrm{m}$ coronal sections with collection of every $10^{\text {th }}$ section throughout the brain and stored frozen at $-80^{\circ} \mathrm{C}$ until further processing. 
One series comprising every $10^{\text {th }}$ section from each animal was carefully mounted in PBS onto super frost glass slides and left to dry overnight at room temperature.

Sections were washed $2 \times 10 \mathrm{~min}$ in $0.04 \mathrm{M}$ Sodium acetate, $0.1 \%$ acetic acid solution (Solution 1), delipidated $20 \mathrm{~min}$ in $0.025 \%$ Triton X-100; 75\% ethanol, washed $2 \times 10 \mathrm{~min}$ in solution 1 and stained for $2 \times 8 \mathrm{~min}$ in $0.01 \%$ cresyl violet dissolved in solution 1 .

The sections were then washed $3 \times 1 \mathrm{~min}$ in solution $1,3 \mathrm{~min}$ in $100 \%$ ethanol, $10 \mathrm{~min}$ in isopropanol, and $2 \times 5 \mathrm{~min}$ in xylol before being embedded in Roti-Histokitt (Roth) mounting medium.

\subsubsection{Unbiased stereology}

Stereological analysis was performed as previously described (Bouter et al., 2013). Briefly, mice were anaesthetized and transcardially perfused with $4 \%$ paraformaldehyde. Brains were carefully removed from the skull, dissected and post-fixed. The left brain hemispheres were cryoprotected in 30\% sucrose, quickly frozen and cut frontally into entire series of $30 \mu \mathrm{m}$ thick sections on a cryostat (Microm HM550, Germany). Every tenth section was systematically sampled, stained with cresyl violet and used for stereological analysis of the neuron number in the CA1. The hippocampal cell layer CA1 (Bregma -1.22 to $-3.52 \mathrm{~mm}$ ) was delineated on cresyl violet stained sections. Using a stereology workstation (Olympus BX51 with a motorized specimen stage for automatic sampling), StereoInvestigator 7 (MicroBrightField, Williston, USA) and a $100 \mathrm{x}$ oil lens $(\mathrm{NA}=1.35)$, neuronal nuclei were sampled systematically using optical dissector probes, and the total number of neurons was subsequently estimated by the fractionator method using a $2 \mu \mathrm{m}$ top guard zone.

Age and sex-matched mice were analyzed for all groups. Samples were blinded to avoid biased counting. 


\subsection{Crystallization}

\subsubsection{General crystallography setup}

Crystallization of the Fab portion of the NT4X antibody or the Fab bound to respective $A \beta$ peptides was carried out at $20^{\circ} \mathrm{C}$ using the sitting drop vapor diffusion method. Different commercial crystallization reagents were screened to identify initial conditions. Initial crystals were obtained by mixing $60 \mathrm{nl}$ protein solution with 60 $\mathrm{nl}$ reservoir solution in 96-well MRC plates using a Cartesian liquid dispensing robot with 8 channels. For grid screening with seeding, crystals were obtained by mixing $100 \mathrm{nl}$ protein solution, $100 \mathrm{nl}$ reservoir solution, and $20 \mathrm{nl}$ seed stocks/dilutions in 96-well INTELLIPLATEs using the Gryphon liquid handling system (Art Robbins Instruments). For growing larger crystals, manual drops of $1 \mu 1$ protein, $1 \mu \mathrm{l}$ reservoir solution and $200 \mathrm{nl}$ seed stock/dilution were set up in 24-well plates. Crystal growth was monitored by imaging with RockImager (Formulatrix, Bedford, United States).

\subsubsection{Crystallization and diffraction data collection}

Fab-A $\beta$ complex preparation was done as follows. Peptide corresponding to residues 4-19 of the human amyloid beta sequence (FRHDSGYEVHHQKLVF) was purchased from Peptide Specialty Laboratories (Germany) at 95\% purity. Peptide was re-suspended in $50 \mathrm{mM}$ Tris, $150 \mathrm{mM} \mathrm{NaCl}(\mathrm{pH}=7.5)$ and added to Fab in a Fab:A $\beta$ ratio of 1:5 and left on ice for 4 hours to allow for antibody antigen binding. Final Fab concentration used for successful crystallization trials was $5 \mathrm{mg} / \mathrm{ml}$.

Crystal seed stocks were prepared with Seed Bead ${ }^{\mathrm{TM}}$ kit and done according to manufacturer's instructions (Hampton Research, United States). Seeding was attempted by the use of horse's tail hair but was unsuccessful. Direct seeding resulted in diffraction quality crystals, 
where seed stocks or dilutions were directly added to protein + reservoir combination.

X-ray diffraction data were collected at beamline PXII of SLS (Paul Scherrer Institute, Villigen, Switzerland) and beamline 14.2 of BESSY II (HZB, Berlin, Germany). An example of data collection parameters (example) is summarized in Table 2.1 below.

Table 2.1. X-ray diffraction data collection parameters.

\begin{tabular}{|l|l|}
\hline Parameter & Setting \\
\hline Detector distance $(\mathrm{mm})$ & 390 \\
\hline$\Phi / \Delta \Phi\left({ }^{\circ}\right)$ & $360 / 0.5$ \\
\hline Exposure time (s) & 0.3 \\
\hline Beam intensity & 0.2 \\
\hline$\Lambda(\AA)$ & 1 \\
\hline Number of frames & 720 \\
\hline
\end{tabular}




\section{CHAPTER 3}

\section{Results}

\subsection{Full-length NT4X Purification}

Initial NT4X antibody purification was attempted using Ammonium Sulfate precipitation $(50-70 \% \mathrm{w} / \mathrm{v})$. However, due to the use of serum-free culture media, antibody-containing hybridoma supernatant could be loaded onto a Protein A column (GE Healthcare) after pelleting cell debris through centrifugation. Elution with low $\mathrm{pH}$ solution resulted in antibody disengagement from column. Antibody buffer was subsequently exchanged into appropriate storage/usage buffer (Fig 3.1). 


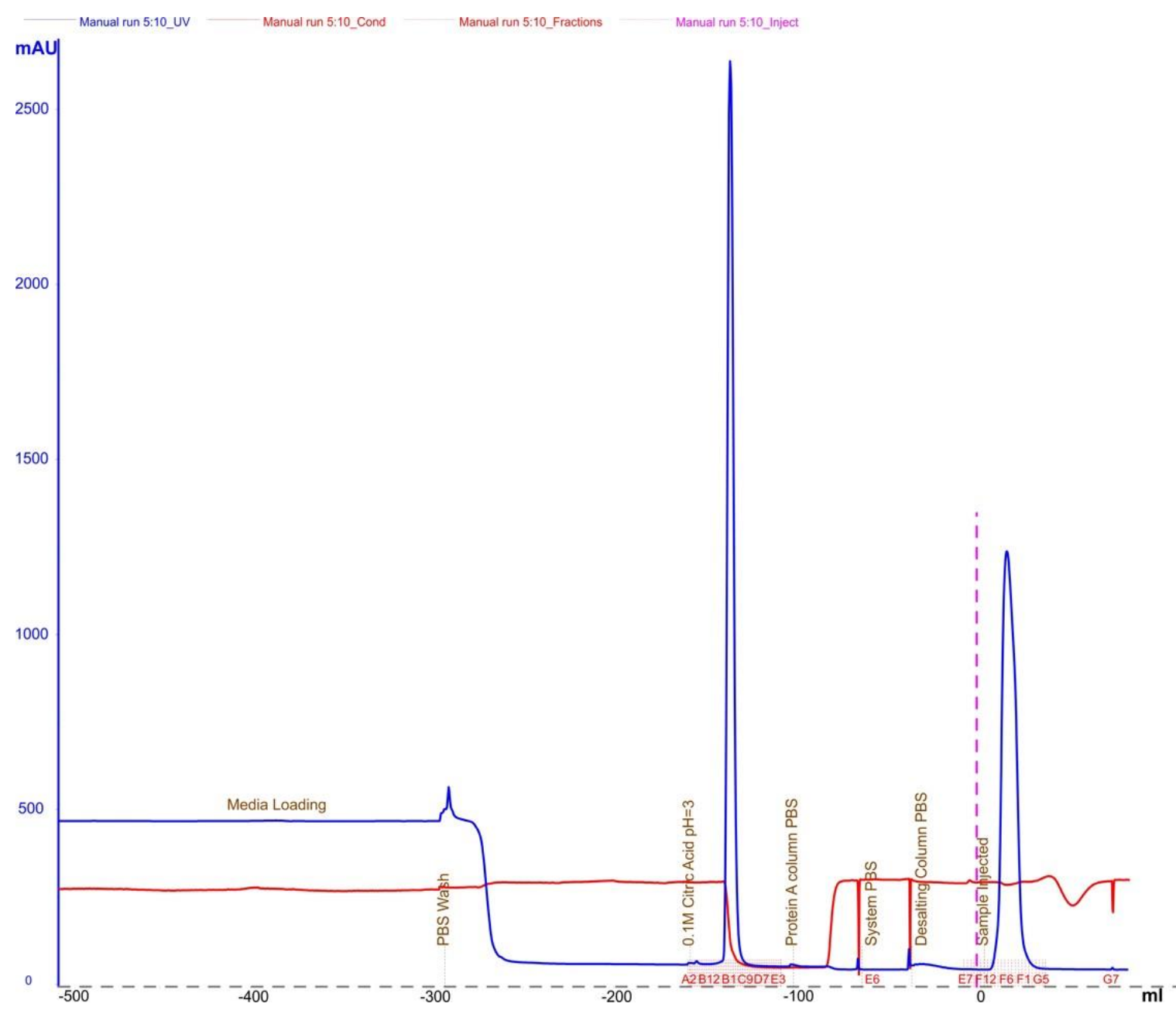

Figure 3.1. NT4X antibody purification from hybridoma cell line DSM ACC3162 using immobilized protein A. Left peak, antibody purification from culture media using protein A. Right peak, antibody buffer exchange using HiPrep 26/10 desalting column (GE Healthcare).

NT4X antibody purification was tracked at various stages of purification through sodium dodecyl sulfate polyacrylamide gel electrophoresis (SDS-PAGE) gels stained either by coomassie or silver staining. Hybridoma media contained antibody and various other proteins that were required for hybridoma cell line maintenance. Following Protein A column, only full antibody and some antibody fragments were collected in eluate. Column flow-through (FW) still contained antibody and was re-loaded on protein A column (2-3 times) until no more antibody was detectable in FW (Fig 3.2). An antibody yield of approximately $50-60 \mathrm{mg} / \mathrm{L}$ of hybridoma media was achievable. 


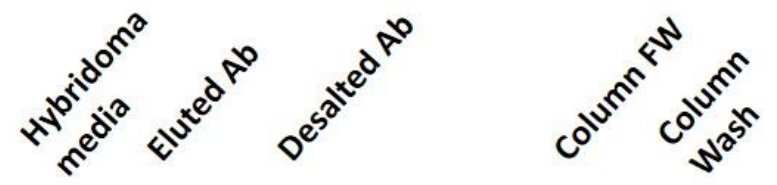

$\mathrm{kDa}$

250

150

100

75

50

37

25

20

15

Figure 3.2. Coomassie stained SDS-PAGE gel (non-reducing) tracking NT4X antibody purification. From left to right: Hybridoma Media collected post centrifugation, Antibody eluted from Protein A column, antibody buffer exchanged, column flow-through showing antibody remaining in media, and Protein A column wash (right).

To further purify the NT4X from smaller antibody fragments that eluted along with full-length antibody, the resulting eluate from the Protein A column was concentrated and injected into a HiLoad 26/60 Superdex 200 pg size-exclusion column in PBS. Fractions from different peaks were analyzed. Peak 1 contained full-length antibody (Fig 3.3). 


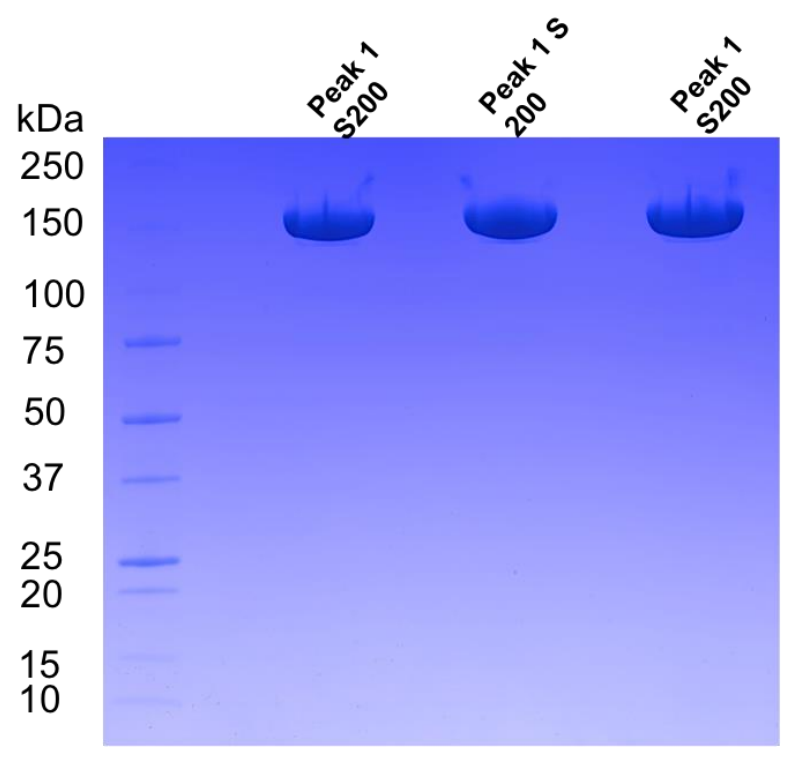

Figure 3.3. Coomassie stained SDS-PAGE gel (non-reducing) tracking NT4X antibody purification following size-exclusion chromatography. Using HiLoad 16/600 Superdex 200 pg. Fractions from Peak 1 are represented on gel demonstrating a high purity antibody preparation.

In order to validate antibody presence in hybridoma media and throughout purification steps; a reducing PAGE-SDS gel was run and either stained by coomassie (Fig 3.4A) or transferred to a nitrocellulose membrane and probed using a mouse secondary antibody (Fig 3.4B). Coomassie gel revealed the presence of heavy and light chains (50 kDa and $25 \mathrm{kDa}$ respectively) and probed membrane identified that antibody chains are murine as is expected. 


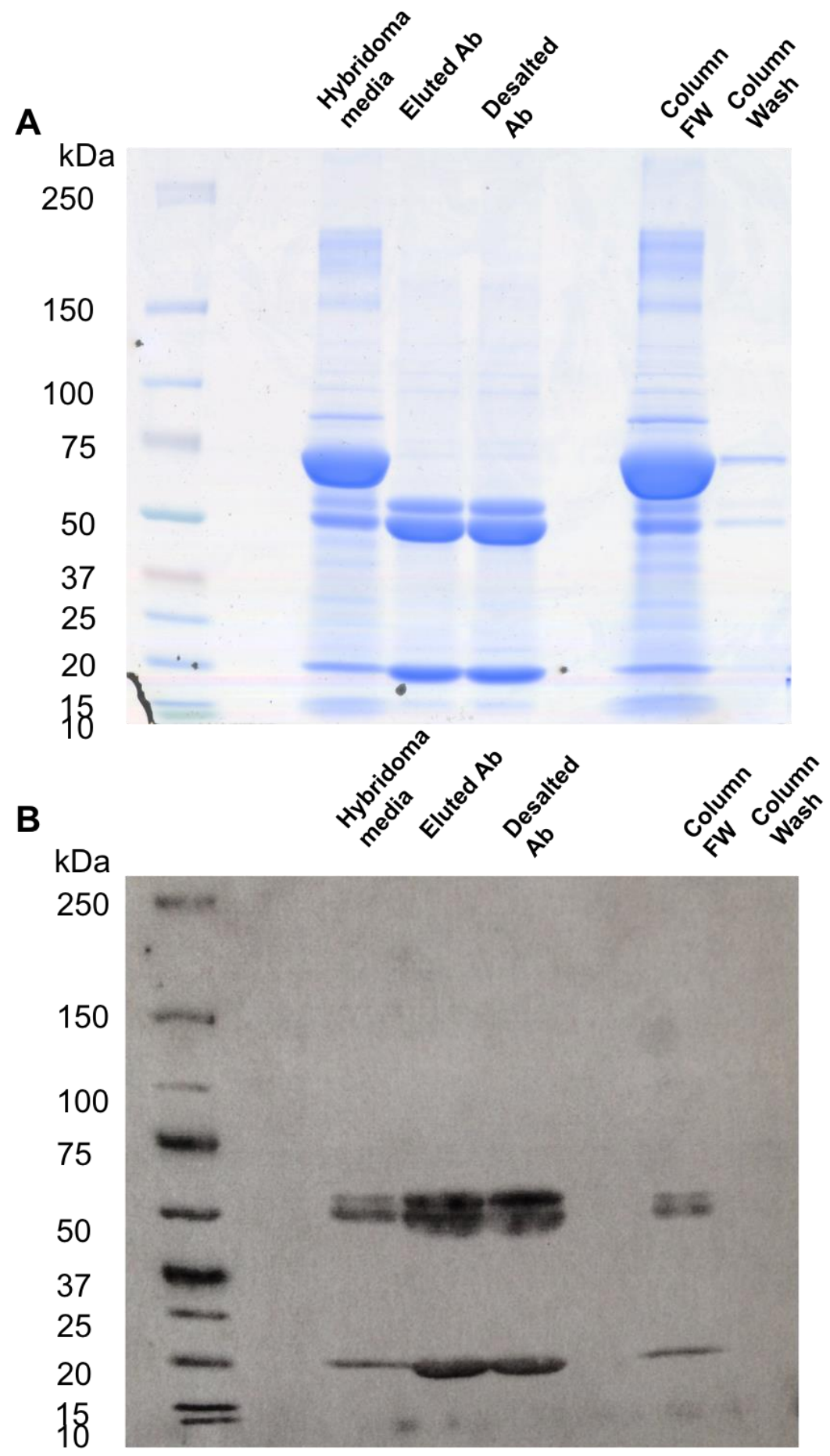

Figure 3.4. Validation of antibody presence during purification process (A) Coomassie stained SDS-PAGE gel (reducing), verifying presence of both heavy-chain and light chain fragments of antibody and (B) Western blot of similar gel using a mouse secondary HRP conjugated antibody, revealed that antibody being purified is murine. 


\subsection{NT4X Fab Generation and Purification}

Antibody was incubated with papain for the duration of the reaction. Papain was initially not pre-activated. Reaction at room temperature (a) resulted in partial digestion of antibody while reaction at $37^{\circ} \mathrm{C}$ resulted in the creation of the fab fragment (at $50 \mathrm{kDa}$ ) within the time frame. Smaller digestion products at $15 \mathrm{kDa}$ and $25 \mathrm{kDa}$ were also noticeable. The constant region of the antibody $\left(\mathrm{F}_{\mathrm{C}}\right)$ was subsequently removed by binding digest on a Protein A column where the $\mathrm{F}_{\mathrm{C}}$ fragment would bind but the Fab would pass in the FW (Fig. 3.5).

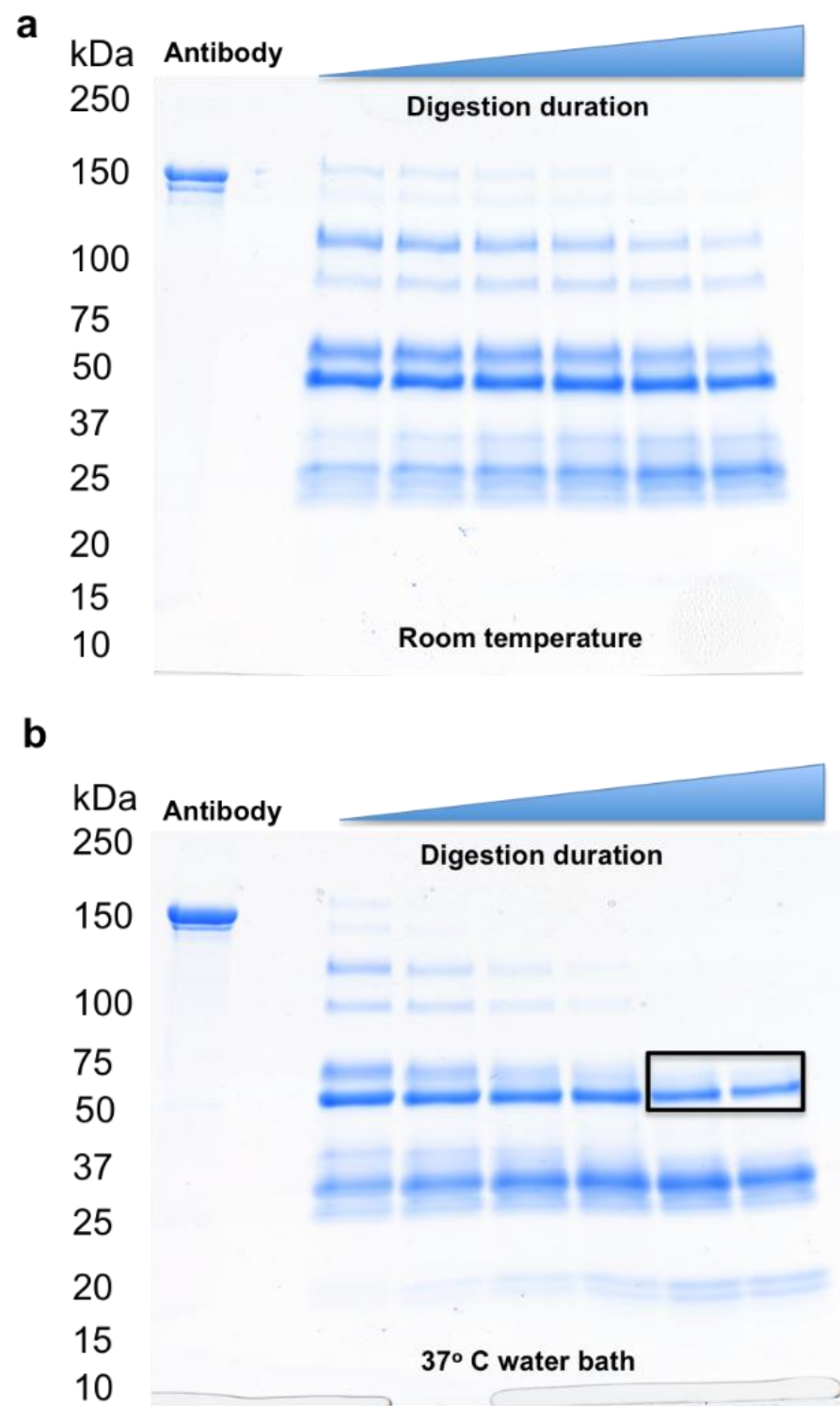

Figure 3.5. NT4X antibody digestion using papain (a) antibody incubated at room temperature for duration of digestion (b) antibody incubated in a $37^{\circ} \mathrm{C}$ water bath for duration of digestion. Time scale: 0-4 hours. 
Numerous purification strategies were tried for the purpose of further purifying the Fab fragment from smaller unwanted digestion products. Size exclusion chromatography was not successful in separating components. Ion exchange chromatography using a strong cation exchanger (Mono S prepacked with MonoBeads) was able to bind products resulting from papain digestion and successfully separated one component (peak 4) using a very shallow gradient. Peaks 1, 2, and 3 overlapped in elution profiles and were not fully separated, this was due to the fact that they eluted at $3.3 \mathrm{mS} / \mathrm{cm}$, $3.45 \mathrm{mS} / \mathrm{cm}$ and $3.6 \mathrm{mS} / \mathrm{cm}$ respectively (Fig 3.6).

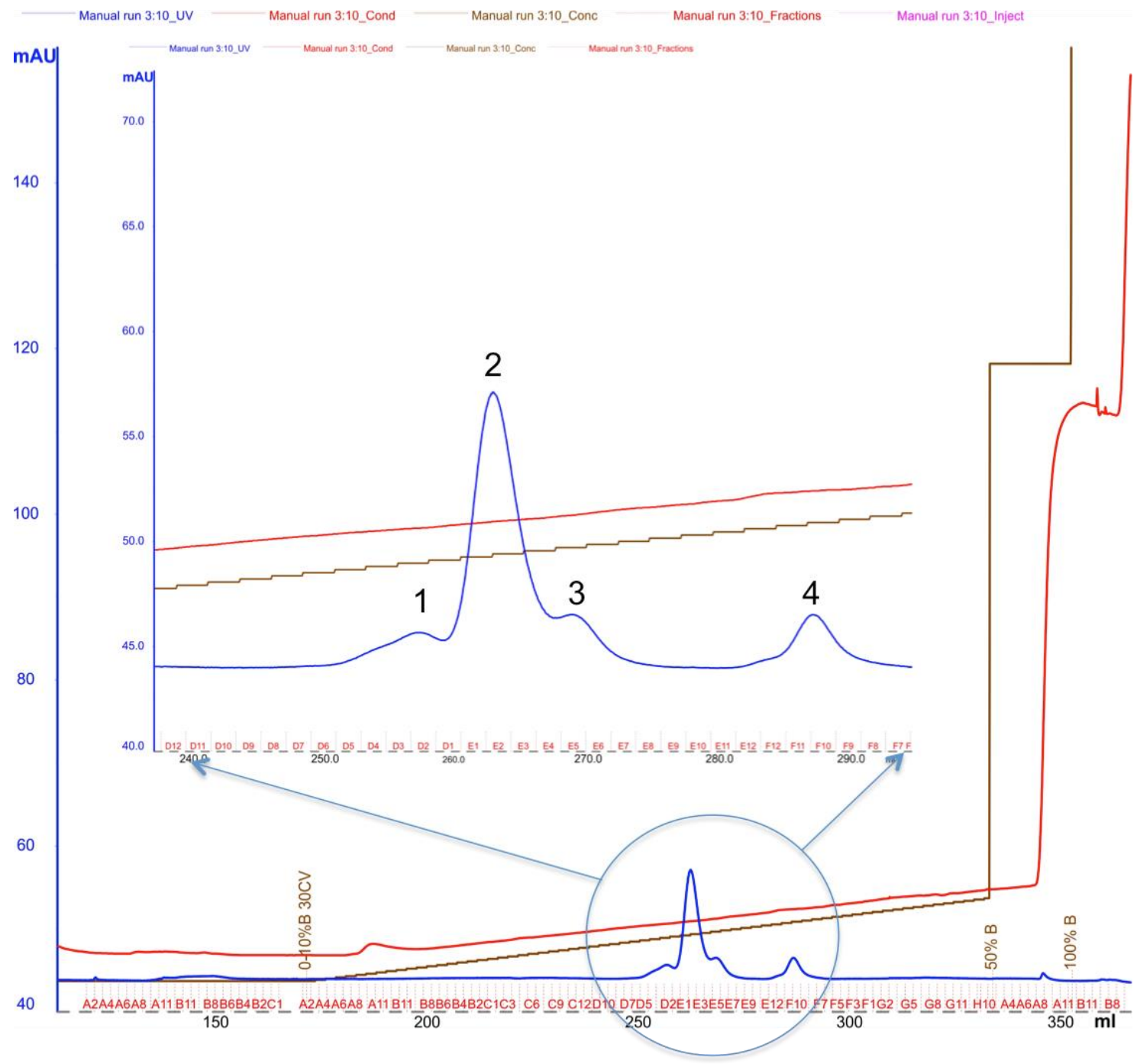

Figure 3.6. Mono $\mathbf{S}$ purification chromatogram showing 2 main eluted components, where peaks (1,2 and 3) overlapped and peak 4 was separate. 
Fractions from Mono S purification were analysed using SDSPAGE and visualized using coomassie. Peak 1 contained two proteins $(50 \mathrm{kDa})$, peak 2 early fractions contained same as peak 1 while fractions that eluted later contained 3 proteins $(50 \mathrm{kDa}, 25 \mathrm{kDa}$ and $15 \mathrm{kDa}$ ), peak 3 contained same proteins as late fractions from peak 2 and finally peak 4 contained a double band of protein (15 kDa) (Fig 3.7). As was apparent from the Mono $S$ purification chromatogram, peaks 1,2 , and 3 were not properly separated while peak 4 was successfully separated from the rest.

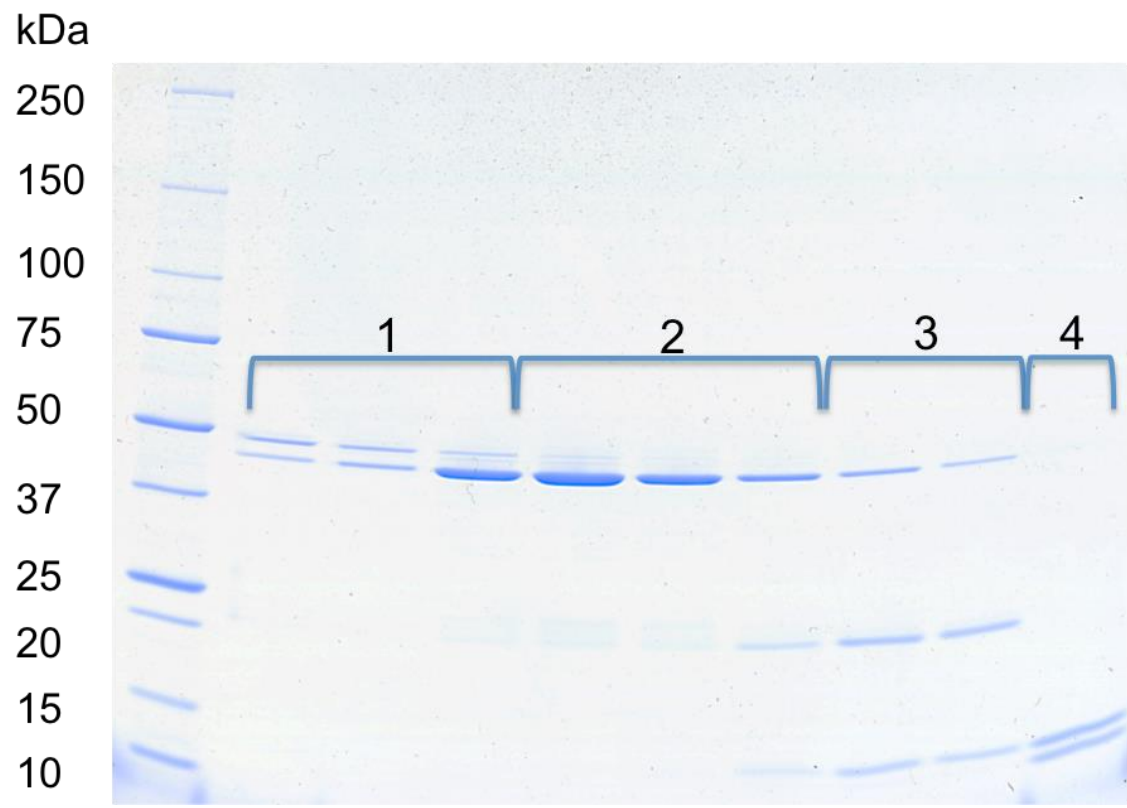

Figure 3.7. Mono $\mathbf{S}$ purification fractions SDS-PAGE. Numbers represent respective peaks in Mono $\mathrm{S}$ purification chromatogram.

A modified digestion protocol using pre-activated papain was eventually used and proved successful in reducing unwanted digestion products. Papain was incubated with cysteine for 30 minutes in order to activate the enzyme. Buffer was then exchanged to one not containing cysteine for the duration of digestion. Digestion products were loaded unto protein A column several times to bind undigested full antibody and $\mathrm{F}_{\mathrm{c}}$ fragments. After $3^{\text {rd }}$ pass on protein $\mathrm{A}$ column, Fab fragment (50 kDa, flow-through 3 and 4) was obtained in higher purity and buffer was exchanged depending on later usage into 
either PBS or Tris buffer. Eluate from protein A column contained undigested $(150 \mathrm{kDa})$, partially digested $(100 \mathrm{kDa})$, and $\mathrm{F}_{\mathrm{c}}$ fragment of antibody (Fig 3.8).

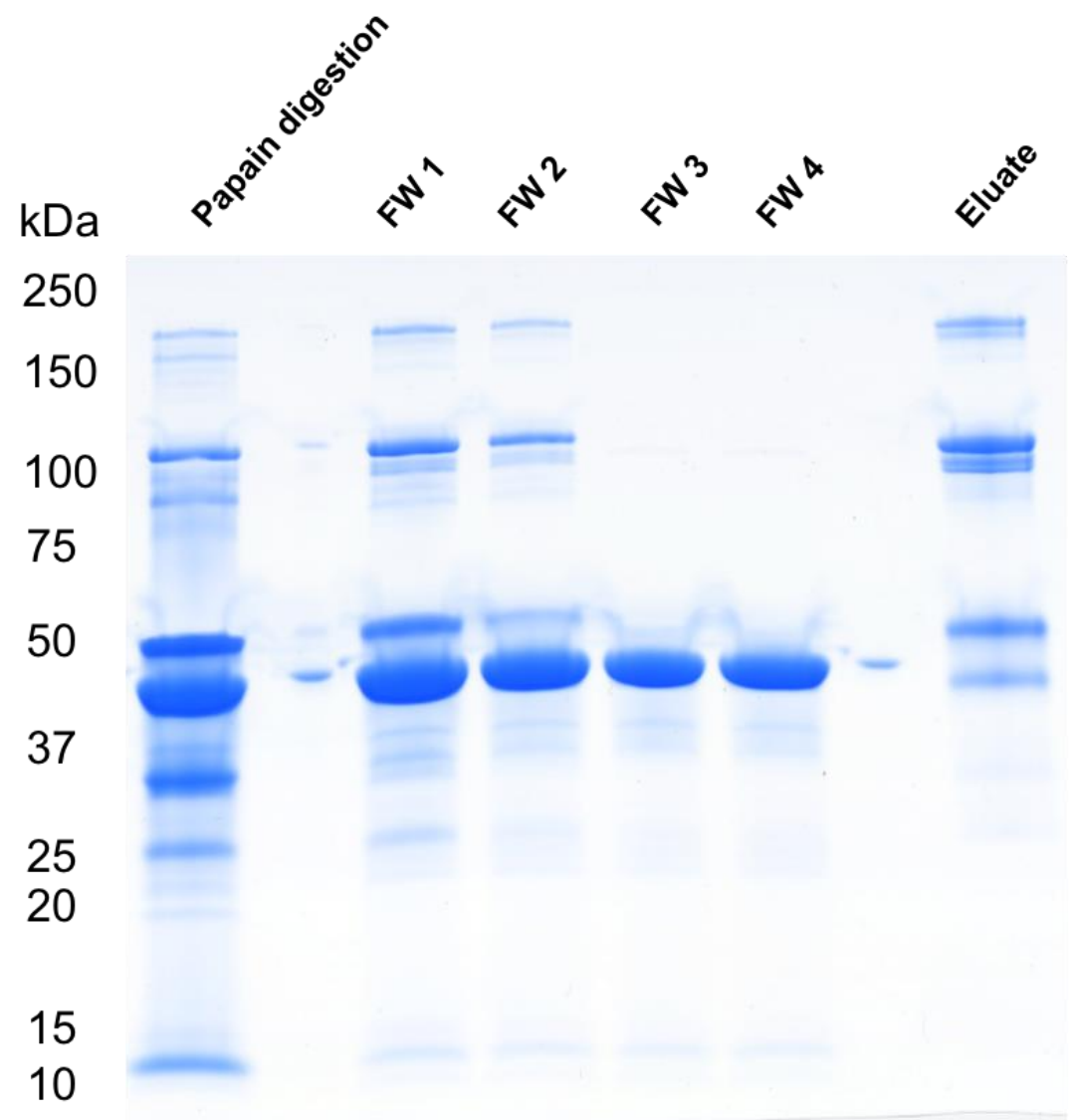

Figure 3.8. Modified antibody digestion protocol. Using pre-activated papain and subsequent purification with protein A column. Left to right. Papain digestion, FWs from successive loading on protein A column (FW 3 and 4 contain pure Fab) and eluate from protein A column showing undigested antibody and $\mathrm{F}_{\mathrm{c}}$ fragment. 


\subsection{Crystallization}

Intended workflow for the purification and crystallization the NT4X Fab fragment and the Fab bound to a respective amyloid beta peptide may be found below. As the previous parts have already described the purification part, this part will deal with the crystallization portion of the work.

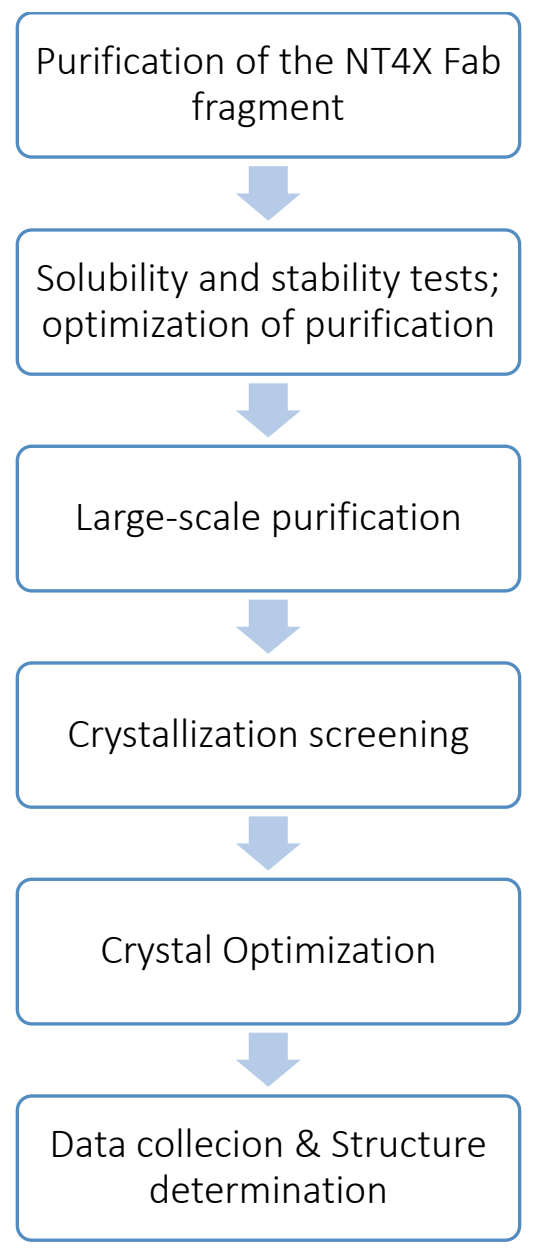

Figure 3.9. Flowchart describing intended process of crystallization. The large scale purification has been described in previous section. Crystallization screening and optimization is described in following section. 


\subsubsection{Initial screening}

Screening for crystallization conditions for the Fab fragment of the NT4X antibody was performed to expose the protein to a variety of agents in order to find "hits" that point to conditions that may result in crystallization. The most common way to adjust crystallization conditions is by varying the concentration of protein, type and concentration of precipitant, and $\mathrm{pH}$ or temperature. In the initial screening, conditions were tested out in various concentrations of the Fab in order to first ascertain the appropriate concentration while simultaneously screening precipitants and buffers.

The primary objective of the screening process was to find conditions in which the Fab either formed crystals, crystalline precipitate or phase separation from the reservoir buffer used. Screening was done in 96 well format plates using the NeXtal tube suits (Qiagen) (Fig 10).

Initial screening included the following suites:

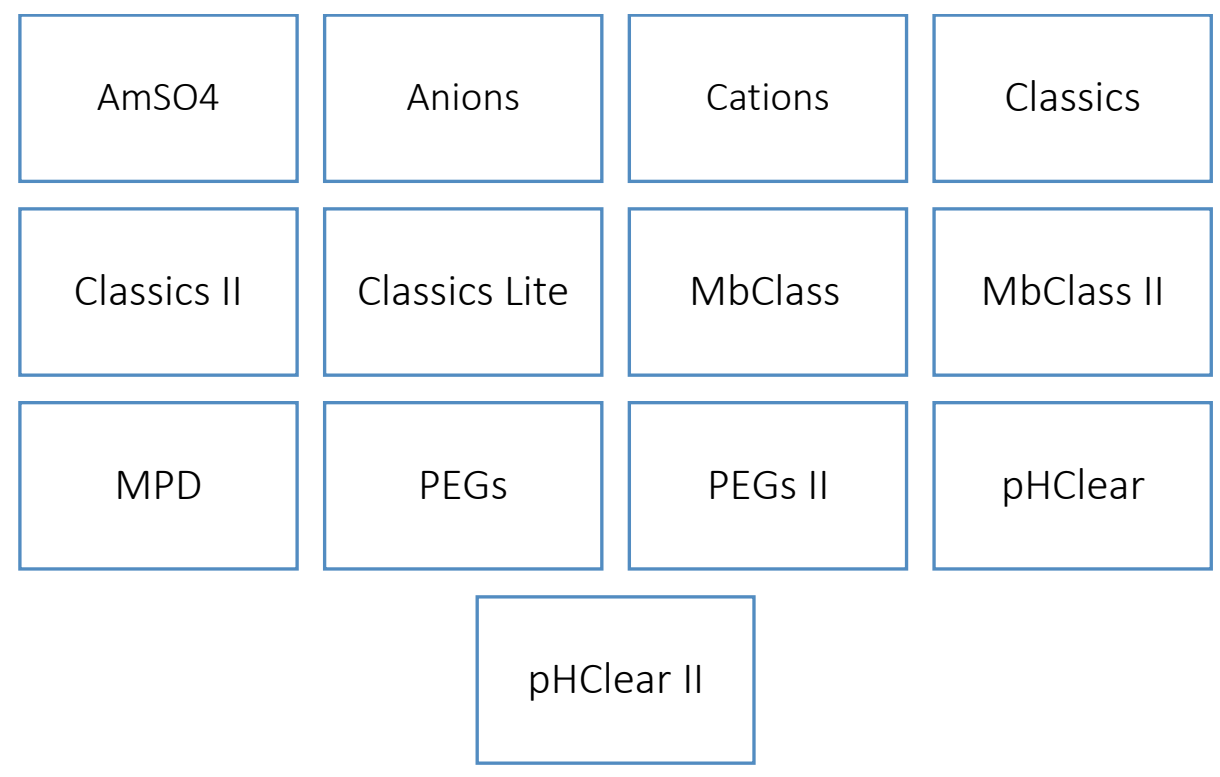

Figure 3.10. Initial screening for crystallization conditions using NeXtal tube suits. 
The vapor diffusion method was used where the protein solution was set up in a sitting drop that equilibrated against crystallizing agents at either higher or lower concentrations than in the drop. This provided a way to sample the crystallization parameter space, as the conditions vary continuously as equilibration proceeds. Screening was performed using 3 concentrations: 5, 13 and $20 \mathrm{mg} / \mathrm{ml}$. Heavy precipitation was noticeable in both the 13 and $20 \mathrm{mg} / \mathrm{ml}$ (Fig $3.11 \mathrm{~b}$ ) screens while light precipitation was noticeable in the $5 \mathrm{mg} / \mathrm{ml}$ (Fig 3.11a) screens. Moreover, screens which contained polyethylene glycol (PEG), of various molecular weights and concentrations, at $5 \mathrm{mg} / \mathrm{ml}$ were the ones that contained initial hits. 
a

Concentration: $5 \mathrm{mg} / \mathrm{ml}$

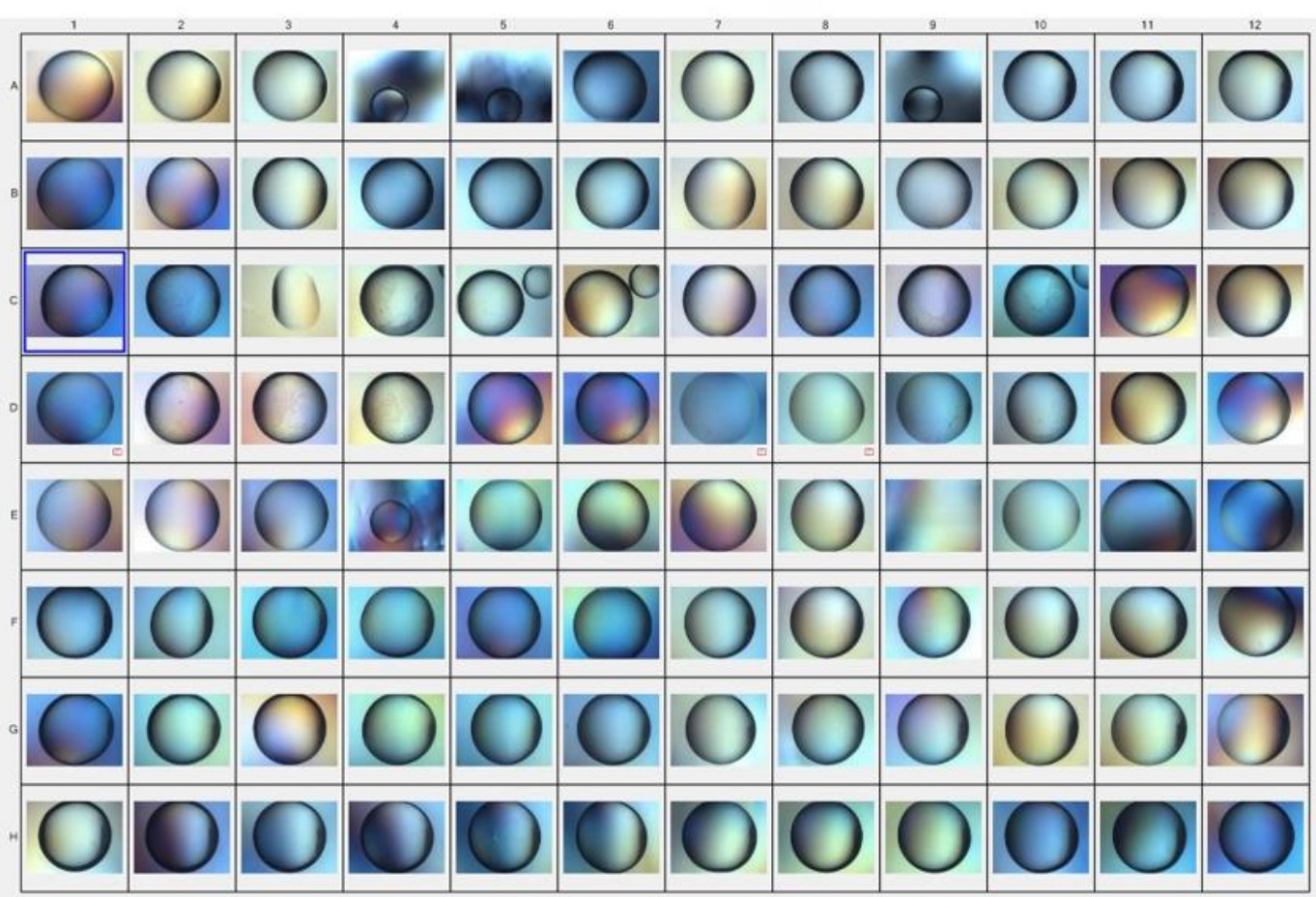

b

Concentration: $20 \mathrm{mg} / \mathrm{ml}$

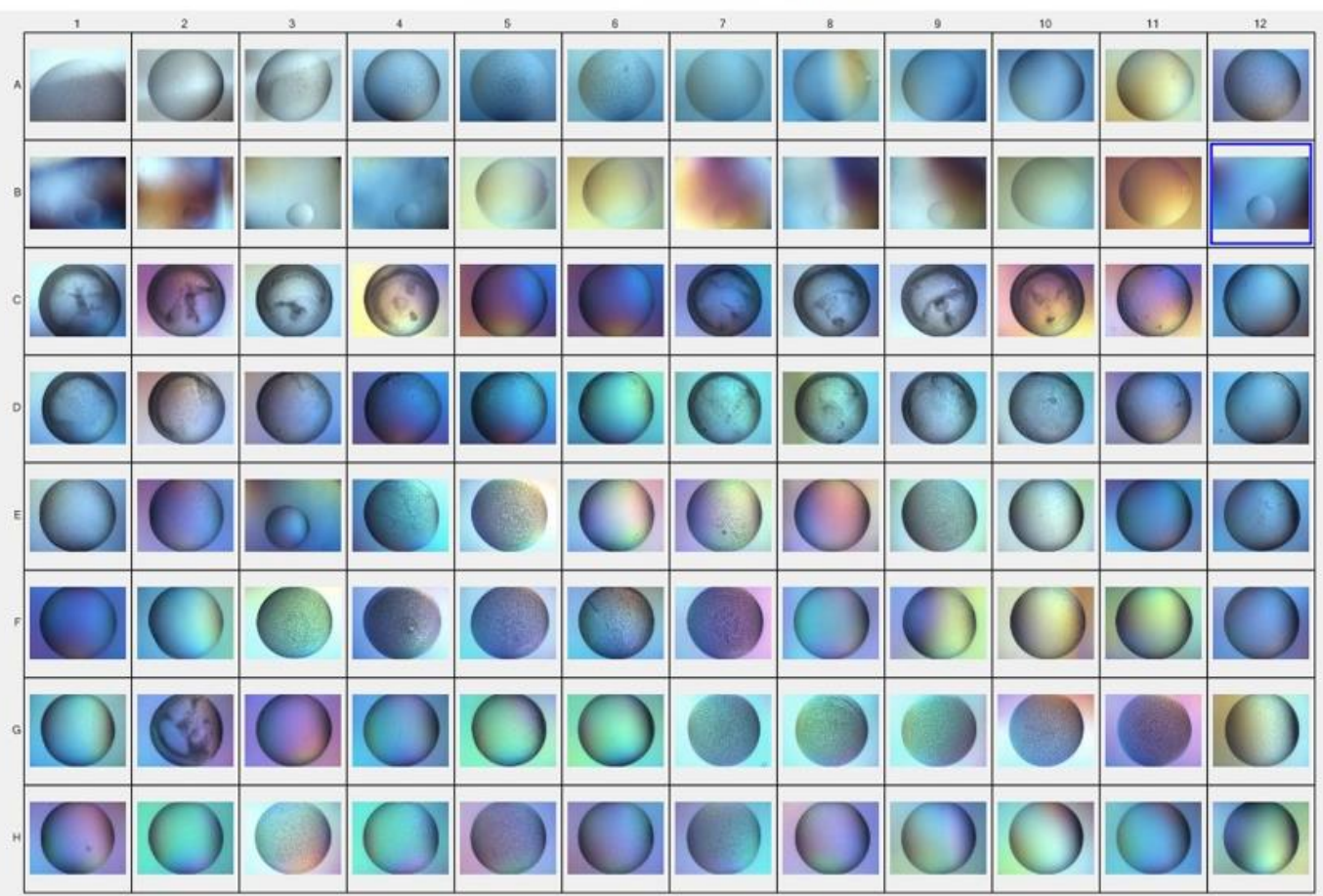

Figure 3.11. Different concentrations used in screening for crystallization conditions of the NT4X Fab fragment. Representative plates from Qiagen PEG screen. Images taken at time zero immediately after setting plates. (a) some protein precipitation (b) immediate heavy protein precipitation. 
Crystals were first obtained in various conditions in which PEG was the main precipitant. Crystal growth was monitored and observed 0-10 days after drops were set. Depending on the crystallization condition in the respective drops, crystals took between 1-3 days to appear. Crystals for the Fab grew in 25\% PEG 3000 and 4000, 0.1 M Tris $\mathrm{HCl}$ reservoir solutions (Fig 3.12).

a

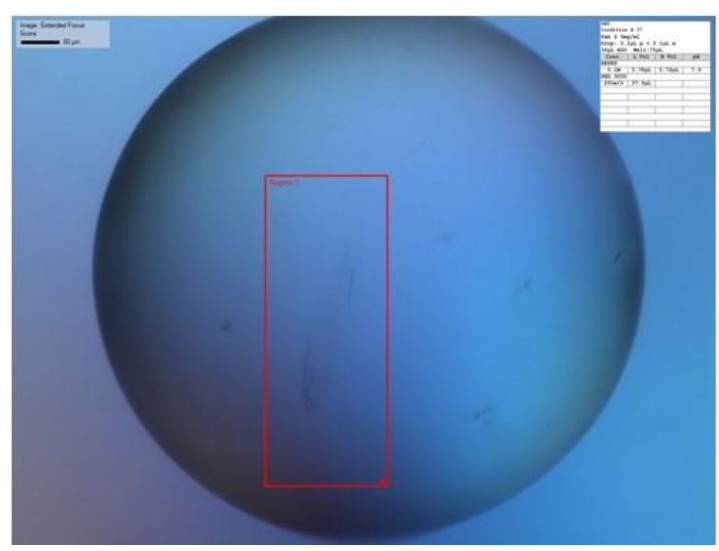

b

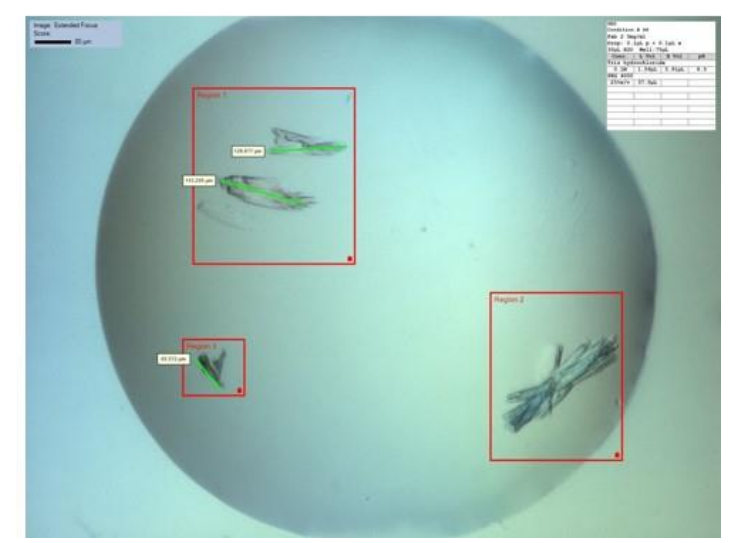

Figure 3.12. Representative images from initial crystals of Fab fragment obtained through screening (a) Crystals may be seen below the surface of the drop (b) several superimposed crystals, amorphous in shape.

To verify that crystals obtained were not salt crystals, best crystals obtained from screening were fished from corresponding drops and soaked/washed in reservoir buffer before being loaded on an SDS-PAGE along with loading buffer (Fig 3.13). Lane (1) demonstrates protein band of crystal visualized using silver staining as compared to lane (2) which contained protein sample used to set up crystallization screens, both of which ran at around $50 \mathrm{kDa}$. This demonstrated that crystals grown were indeed formed by the Fab fragment of the NT4X antibody. 
a

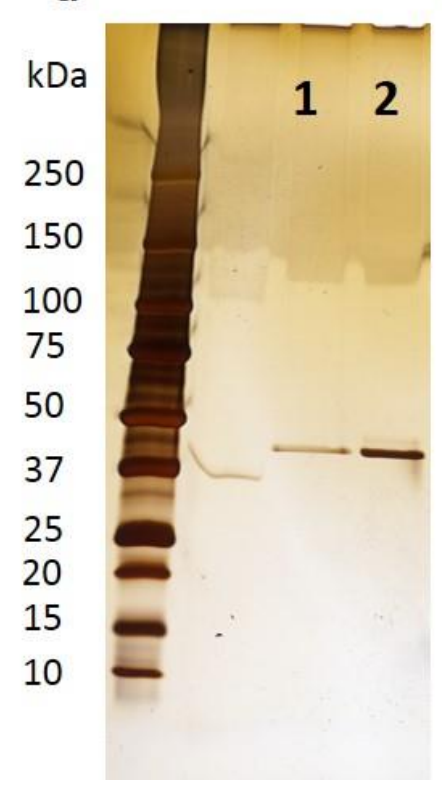

b

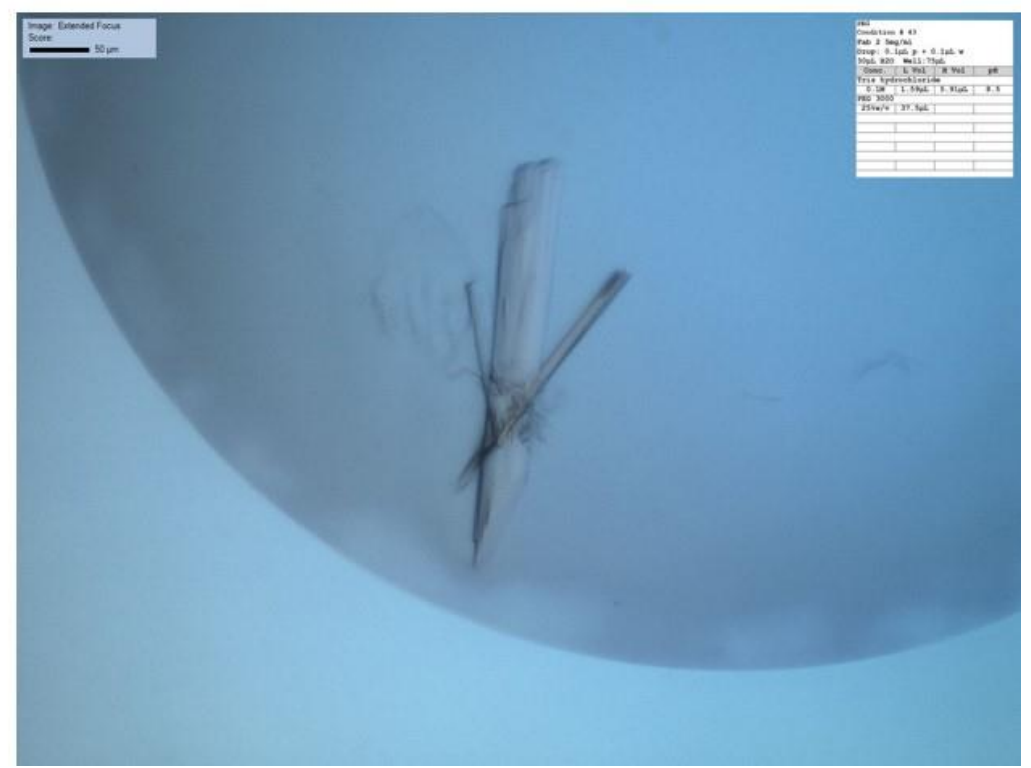

Figure 3.13. Verification that crystals grown were consistent with Fab fragment where crystal from (b) was loaded on gel (a) and visualized using silver staining.

\subsection{2. $\quad F a b+A \beta_{4-19}$}

In order to better study the structural basis for $A \beta$ recognition of the NT4X antibody, the NT4X Fab was co-crystallized together with an $\mathrm{N}$-truncated $\mathrm{A} \beta$ peptide. The $A \beta_{4-19}$ peptide was used as the antibody has the highest affinity to the $N$-terminal part of $A \beta$ starting at position 4. Initial crystals of the Fab bound to the $A \beta_{4-19}$ peptide grew in similar conditions all containing PEG as precipitant. Initial hits were in following reservoir solutions $\left(\mathrm{Fab}+\mathrm{A} \beta_{4-19}: 5.5 \mathrm{mg} / \mathrm{mL}\right)$ :

- 25\% PEG 2000 MME, $0.1 \mathrm{M}$ NaOAc trihydrate pH 4.6 (Fig $3.14 a)$

- 25\% PEG 3000, 0.1 M NaOAc trihydrate pH 4.6 (Fig 3.14b)

- 25\% PEG 3350, 0.1 M NaOAc trihydrate $\mathrm{pH} 4.6$

- 25\% PEG 6000, 0.1 M NaOAc trihydrate pH 4.6 (Fig 3.14c)

- 25\% PEG 8000, 0.1 M NaOAc trihydrate pH 4.6 
a

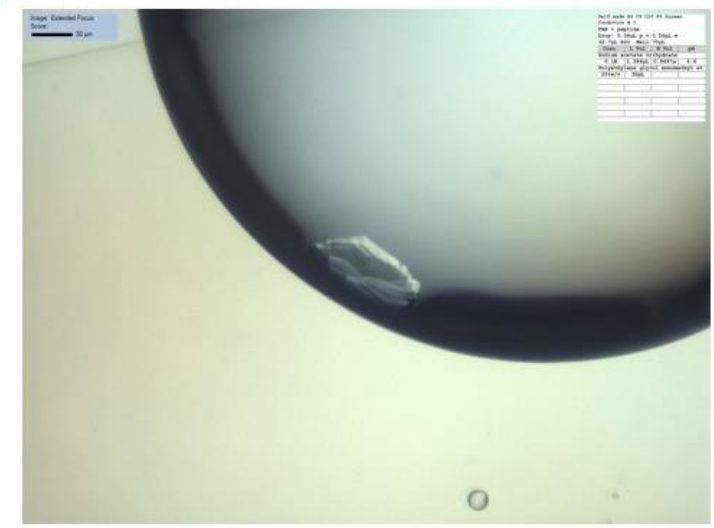

C b

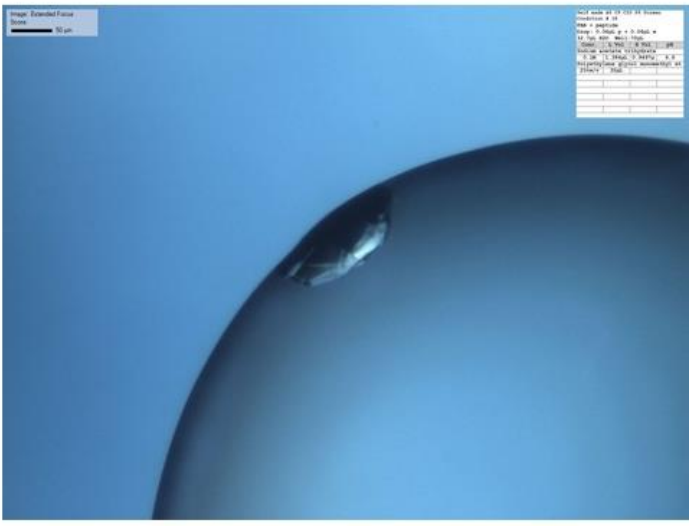

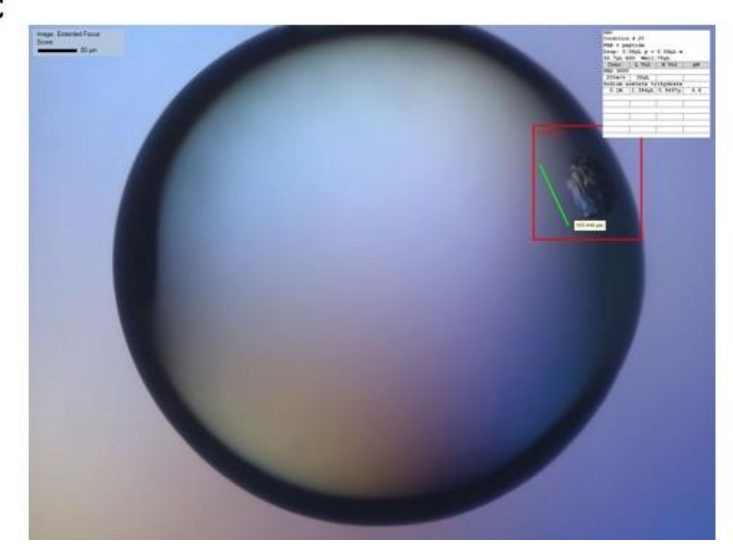

Figure 3.14. Crystals from initial hits of $\mathbf{F a b}+\mathbf{A} \boldsymbol{\beta}_{4-19}$ complex. Crystals grown in reservoir solution containing $0.1 \mathrm{M} \mathrm{NaOAc}$ trihydrate $\mathrm{pH} 4.6$ buffer and (a) 25\% PEG $2000 \mathrm{MME}$ (b) 25\% PEG 3000 (c) 25\% PEG 6000.

\subsubsection{Refinement}

Refinement grids were consequently designed around the conditions where initial hits were observed. Grids varied the concentration of PEG using used (between 20-30\% in small 1\% increments) and the $\mathrm{pH}$ of the $\mathrm{NaOAc}$ trihydrate buffer used (between $\mathrm{pH} 4$ and 5, in $0.1 \mathrm{pH}$ increments). Best crystals obtained were in $25 \%$ PEG $2000 \mathrm{MME}$ and 24\% PEG 8000, both in $0.1 \mathrm{M} \mathrm{NaOAc}$ trihydrate $\mathrm{pH}$ 4.6. Replicates of the conditions were then setup in both 96 and 24 well formats. Best diffraction quality crystals obtained were from 96 well plates. Crystals from PEG $2000 \mathrm{MME}$ reservoirs took 3 days to appear and a total of 10 days to grow and diffracted up to $9 \AA$ (Fig 3.15a). Crystals from PEG 8000 reservoirs took 2 days to appear and a total of 6 days to grow and diffracted up to $5 \AA$ (Fig 3.15a). 
a

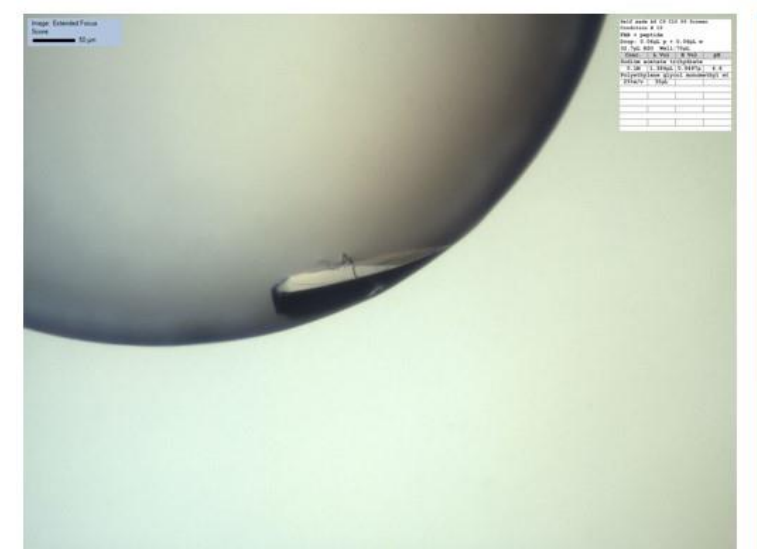

b

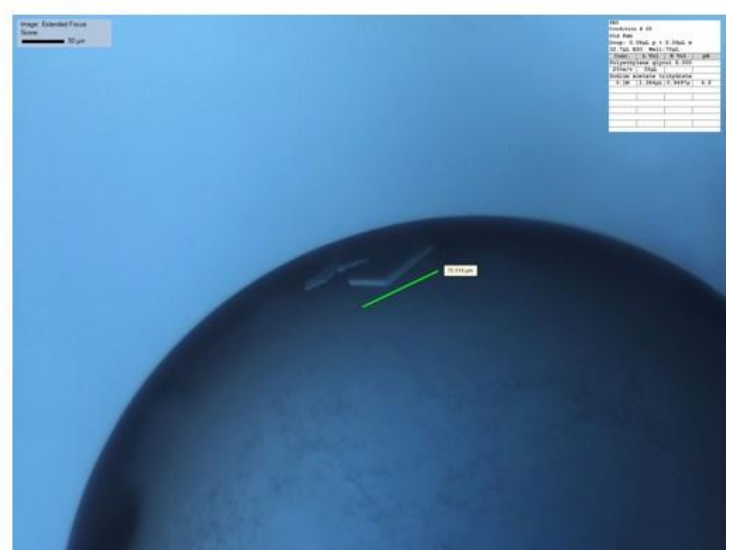

Figure 3.15. First diffraction quality crystals from Fab+A $\boldsymbol{\beta}_{4-19}$ complex. Crystals grown in reservoir solution containing $0.1 \mathrm{M} \mathrm{NaOAc}$ trihydrate $\mathrm{pH}$ 4.6 buffer and (a) 25\% PEG $2000 \mathrm{MME}$, diffracted to $9 \AA$ (b) 24\% PEG 8000, diffracted to $5 \AA$.

\subsubsection{Seeding}

Best crystals grown in PEG 8000 were used to prepare seed stock solutions. Seeding was performed in 96 well format and in 24 well plates. Seeding was done using gradients of different PEGs (3000, 6000, and 8000) and even using commercial PEG I and II screens from Qiagen. Best crystals resulting from seeding were from 23-24\% PEG 3000, and were again used to prepare fresh seed stocks from which replicate plates of 23-24\% PEG 3000, 0.1 M NaOAc trihydrate pH 4.6 were set in both 96 and 24 well format. Seeding was done in this sequential manner several times. Best diffraction quality crystals resulting from seeding, grew in 23.27\% PEG 3000 in both $200 \mathrm{nl}$ (Fig 3.16a) drops and $2 \mu$ drops (Fig 3.16b), both of which diffracted well. Crystals grown in $200 \mathrm{nl}$ drops grew between 50-100 $\mu \mathrm{m}$, while crystals grown in $2 \mu \mathrm{l}$ drops grew up to $200 \mu \mathrm{m}$. 
a

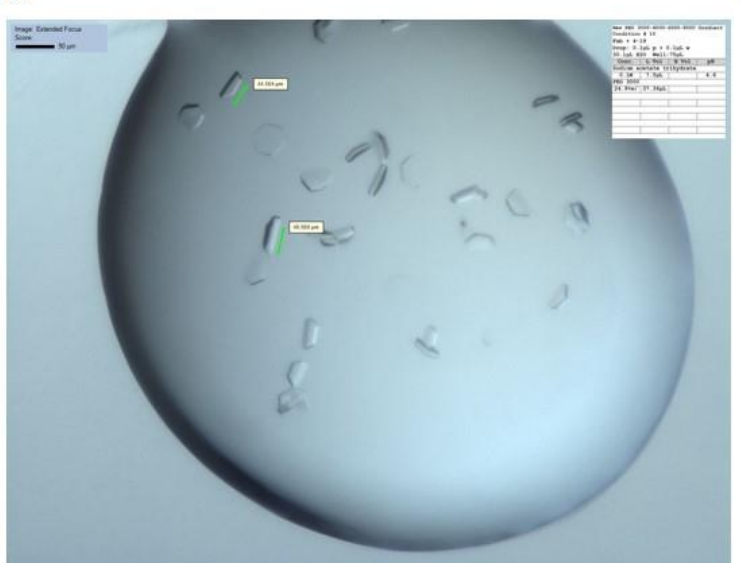

b

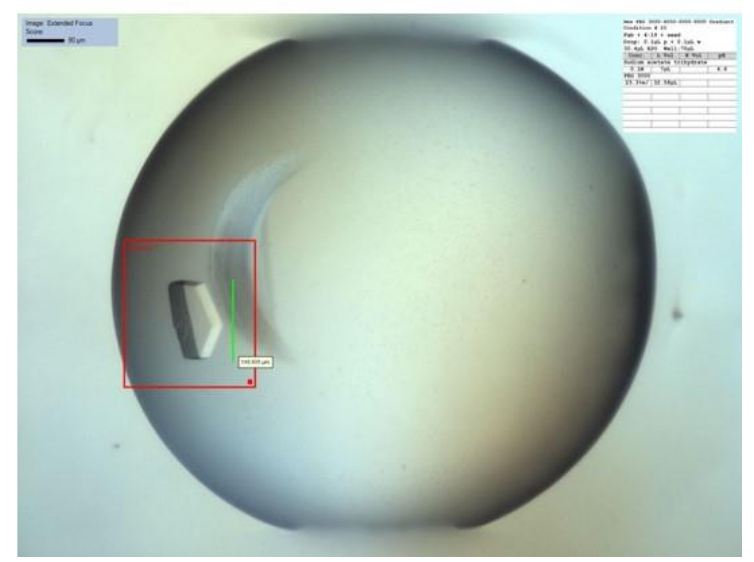

Figure 3.16. Crystals from $\mathbf{F a b}+\mathbf{A} \boldsymbol{\beta}_{\text {4-19 }}$ complex using seeding. Crystals grown in reservoir solution containing $0.1 \mathrm{M} \mathrm{NaOAc}$ trihydrate $\mathrm{pH} 4.6$ buffer and $23.27 \%$ PEG 3000 (a) in $200 \mathrm{nl}$ drops, 50-100 $\mu \mathrm{m}$ (b) in $2 \mu 1$ drops, 200 $\mu \mathrm{m}$.

\subsubsection{Crystal diffraction}

Several complete datasets from crystals diffraction were collected, the best of which was at $2.8 \AA \AA$ (Fig 3.17) and collected from a crystal grown in $2 \mu \mathrm{l}$ drops and cryoprotected using 30\% glycerine in reservoir solution of $0.1 \mathrm{M}$ NaOAc trihydrate $\mathrm{pH} 4.6$ buffer and 23.27\% PEG 3000.

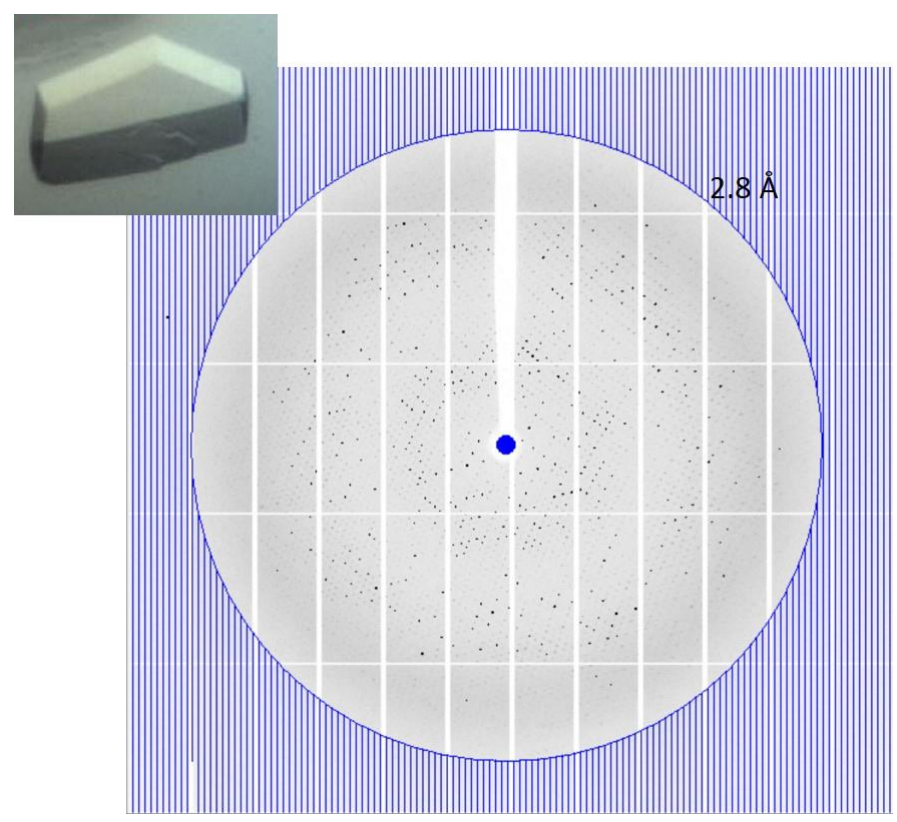

Figure 3.17. Crystal diffraction. Collected at $2.8 \AA$ from crystal grown in 23.27\% PEG 3000, $0.1 \mathrm{M} \mathrm{NaOAc}$ trihydrate $\mathrm{pH}$ 4.6. Cryo: 30\% glycerine. 


\subsection{Characterization of NT4X}

\subsubsection{A 3 binding properties of NT4X under reducing conditions}

Freshly dissolved A $\beta$ peptides were subjected to SDS- PAGE to dissect the binding specificity of the three tested antibodies. Under denaturing conditions NT4X reacted with both N-terminally truncated $A \beta_{\mathrm{pE} 3-\mathrm{X}}$ and $A \beta_{4-\mathrm{X}}$ variants, but not with $\mathrm{A} \beta_{1-\mathrm{x}}$. In addition to monomers and dimers, trimers and tetramers of $A \beta_{\mathrm{pE} 3-42}$ and $A \beta_{4-42}$ were recognized. $A \beta_{\mathrm{PE}-40}$ and $A \beta_{4-40}$ produced primarily monomers and dimers. Antibody $1-57$ stained only $A \beta_{\mathrm{pE} 3-40}$ and $A \beta_{\mathrm{pE} 3-42}$, but no other bands as previously demonstrated. IC16 recognized the N-terminus of full-length $A \beta_{1-40}$ and $A \beta_{1-42}$, but not any of the N-truncated peptides (Fig 3.18).

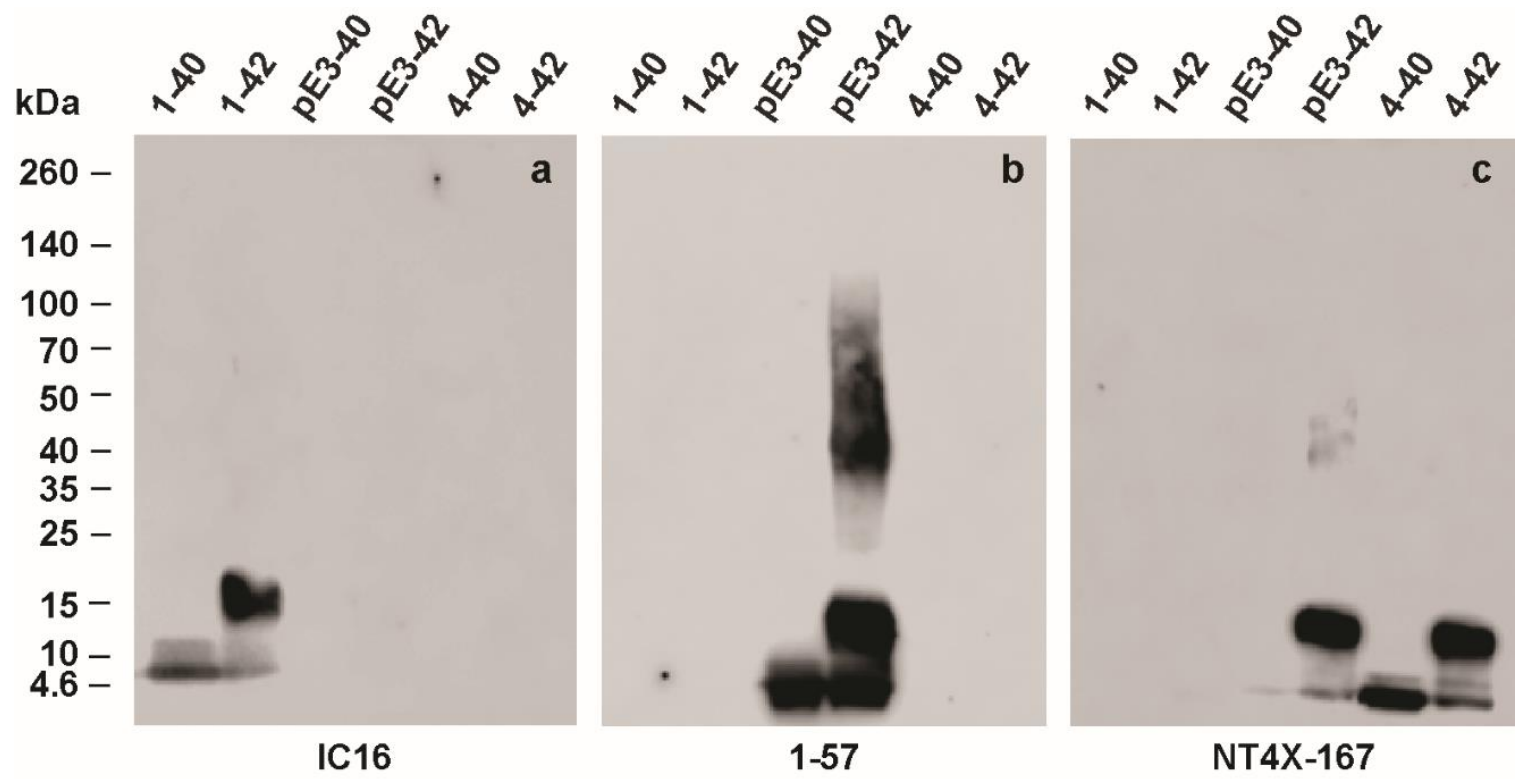

Figure 3.18. SDS-PAGE Western blot analysis of IC16, 1-57 and NT4X antibodies. Freshly dissolved synthetic $A \beta$ variants were probed to a membrane. (a) IC16 detects $A \beta_{1-40}$ and $A \beta_{1-42}$ monomers and low molecular weight aggregates. (b) 1-57 recognizes $A \beta_{\mathrm{PE} 3-40}$ and $A \beta_{\mathrm{PE} 3-42}$ monomers, low molecular weight and larger aggregates of $A \beta_{\mathrm{pE} 3-42}$. (c) NT4X recognizes monomers and low molecular weight aggregates derived from $\mathrm{A} \beta_{\mathrm{pE} 3-40 / 42}, \mathrm{~A} \beta_{4-}$ $40 / 42$. 


\subsubsection{Sensitivity of NT4X to $A \beta_{4-42}$}

In order to analyze the sensitivity of NT4X, a dilution series was performed with freshly dissolved synthetic $A \beta_{4-42}$ and the staining was visualized using a Western blot under reducing conditions. NT4X detected monomers and dimers between 1 and $0.03 \mu \mathrm{g}$ corresponding to a minimum of approximately 7 picomoles of $A \beta_{4-42}$ (Fig 3.19).

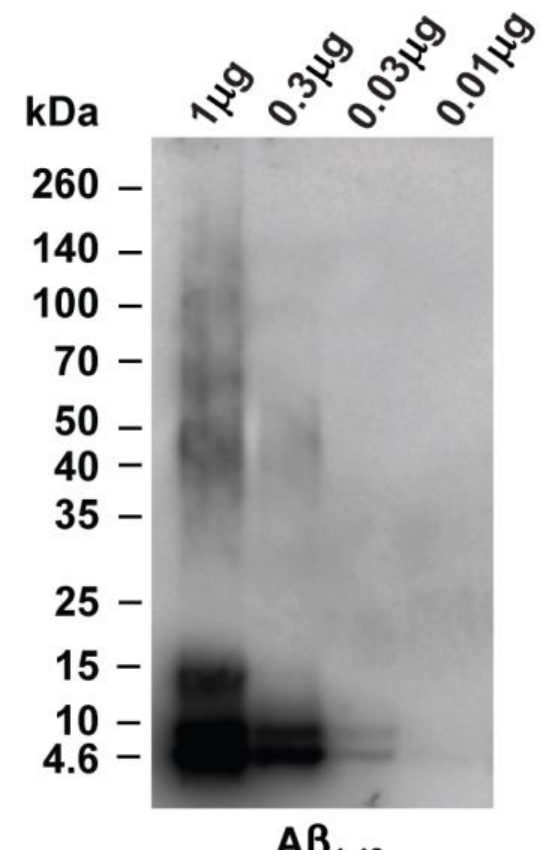

Figure 3.19. SDS-PAGE Western blot analysis of $A \beta_{4-42}$ for sensitivity testing of NT4X using freshly dissolved peptides. NT4X detects monomers and dimers of $A \beta_{4-42}$ up to $0.03 \mu$ peptide.

\subsection{NT4X and Fab Fragment in vitro Rescue of $A \beta$ Toxicity}

In vitro assays were set up using primary rat cortical cultures to investigate the protective properties of the NT4X antibody against the various amyloid peptides. Concomitant with the binding properties of the antibody, NT4X rescues $A \beta_{\mathrm{pE} 3-42}$ and $A \beta_{4-42}$ oligomer induced toxicity but not of full-length $A \beta_{1-42}$ induced toxicity (Fig 3.20). Experiment was performed by MRC Technology (London, United Kingdom). 


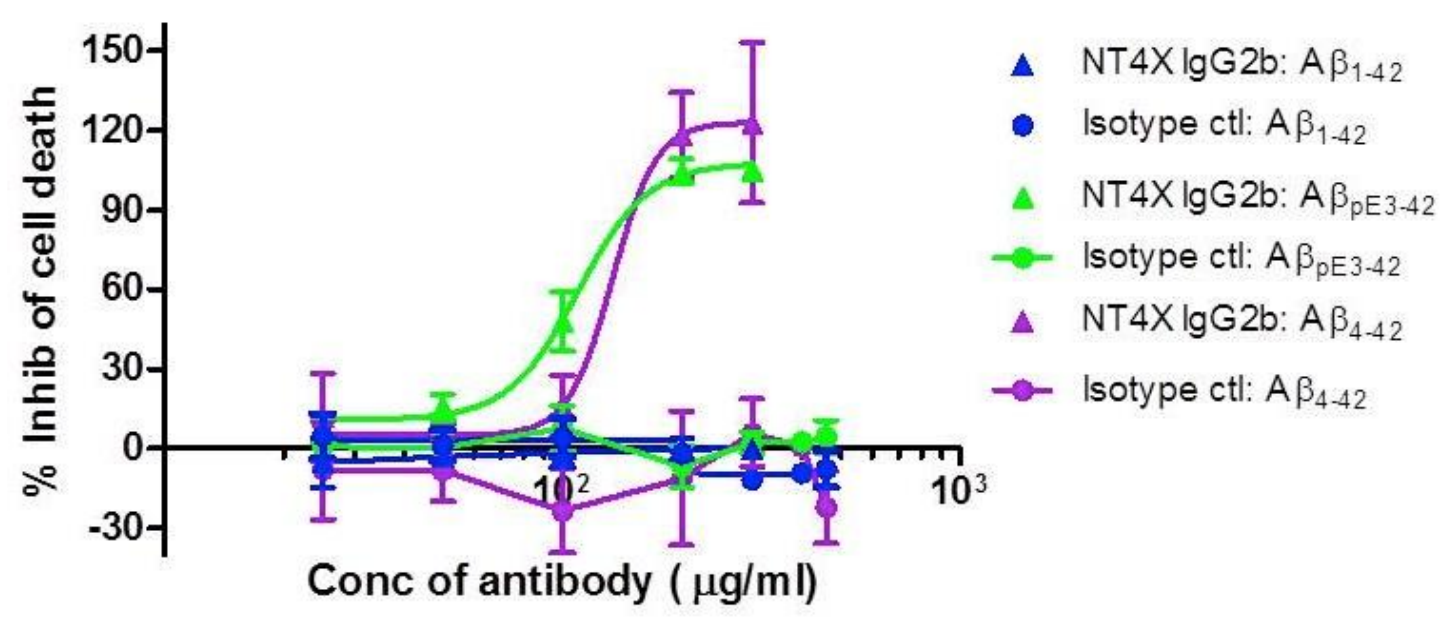

\begin{tabular}{|c|c|c|c|}
\hline \multirow{2}{*}{ Antibody } & \multicolumn{3}{|c|}{ IC50 $(\mu \mathrm{g} / \mathrm{ml})$} \\
\cline { 2 - 4 } & $\begin{array}{c}\mathrm{A} \beta 1-42 \\
(5 \mu \mathrm{M})\end{array}$ & $\begin{array}{c}\mathrm{A} \beta \mathrm{pE}-42 \\
(5 \mu \mathrm{M})\end{array}$ & $\begin{array}{c}\mathbf{A} \beta 4-42 \\
(\mathbf{1 0 \mu M})\end{array}$ \\
\hline NT4X IgG2b & - & 109.5 & 133.7 \\
\hline Isotype ctl & - & - & - \\
\hline
\end{tabular}

Figure 3.20. NT4X protection of $A \beta_{\mathrm{pE3}-42}$ and $A \boldsymbol{\beta}_{4-42}$ induced toxicity in primary rat neuronal cultures. NT4X and an isotype IgG2b control antibody were assayed to assess potential protective properties in an amyloid peptide induced cellular toxicity assay using primary rat cortical cultures. Cellular toxicity was measured using an LDH release assay and results converted to percentage inhibition of cell death compared to control wells $(n=3$ repeats on cell preparations from 3 separate rats). Values plotted are means +/-SEM. The NT4X antibody shows inhibition of $A \beta_{\mathrm{pE} 3-42}$ and $A \beta_{4-42}$ induced toxicity but has no effect on the toxicity induced by full length $A \beta_{1-}$ 42 .

In vitro toxicity rescue of the Fab fragment of the NT4X was also studied in primary neurons using a calcein assay. Treating the cells with freshly prepared $A \beta_{4-42}$ resulted in a dose-dependent reduction in cell viability. NT4X significantly rescued toxicity of $A \beta_{4-42}$ (Fig 3.21). Experiment was performed by SynAging (Nancy, France). 


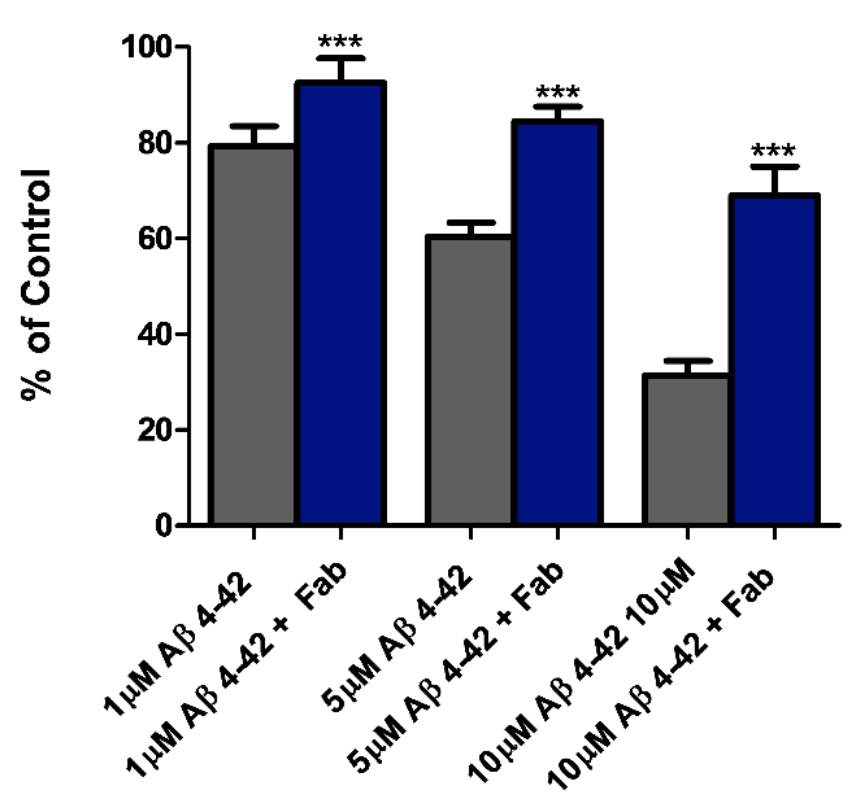

Figure 3.21. Cellular toxicity of $N$-truncated $A \beta_{4-42}$ peptides and treatment effect of NT4X Fab fragment. In rat primary cortical neurons, $A \beta_{4-42}$ peptide induced significant dose-dependent cellular toxicity. NT4X Fab treatment completely rescues toxic effects of freshly dissolved 1, 5 and 10 $\mu \mathrm{M} \quad \mathrm{A} \beta_{4-42}$. (ANOVA, $\mathrm{P}<0.0001, \mathrm{~F}=87.24, \mathrm{dF}=17$ ). After ANOVA, the individual groups were subsequently analysed using Bonferroni multiple comparisons. (Abbreviation: ***, $\mathrm{P}<0.0001$ ).

\subsection{NT4X and Fab Fragment in vivo Rescue of AB Toxicity}

In order to study the therapeutic effects of NT4X and its Fab fragment in wild-type mice, the animals were given an intracerebroventricular (ICV) injection of freshly prepared 50pmol A $\beta_{4-}$ 42 and $A \beta_{4-42}$ in combination with the NT4X antibody or the Fab fragment, respectively. Working memory was assessed using the Ymaze (Fig 3.22). The alternation rate was significantly reduced after injection of $A \beta_{4-42}$ reaching chance level (dashed line). In contrast, mice injected with $A \beta_{4-42}$ and 1 pmol NT4X antibody behaved like vehicle controls and learned well (compared to $A \beta_{4-42}$ injection; one-way ANOVA: $\mathrm{p}$ <0.05). The alternation rate in mice treated with $10 \mathrm{pmol}$ NT4X further increased (compared to $A \beta_{4-42}$ injection; one-way ANOVA: $\mathrm{p}<0.01)$. Furthermore, mice treated with $A \beta_{4-42}$ and 10pmol Fab NT4X also showed no deficits in working memory and behaved like the vehicle control (compared to $A \beta_{4-42}$ injection; one-way ANOVA: $p<0.01$ ). 
Mice treated with only the NT4X antibody or its Fab fragment showed a similar alternation rate than mice treated with the vehicle control alone. Experiment was performed by SynAging (Nancy, France).

Therefore, the NT4X antibody and its Fab fragment were able to rescue the learning deficits induced through $A \beta_{4-42}$ injection in a dosedependent manner.

a

NT4X In Vivo toxicity prevention in WT mice

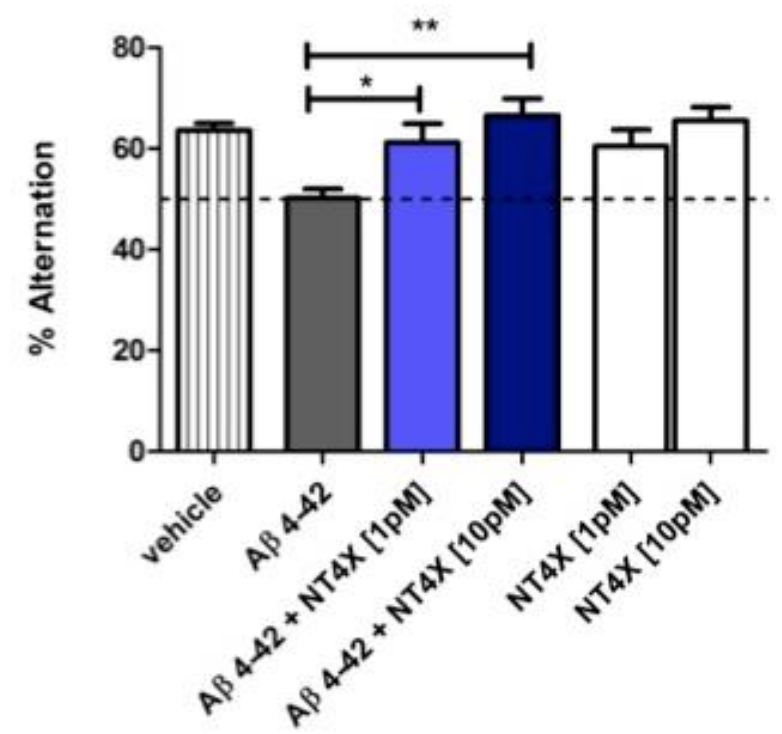

b

Fab In Vivo toxicity prevention in WT mice

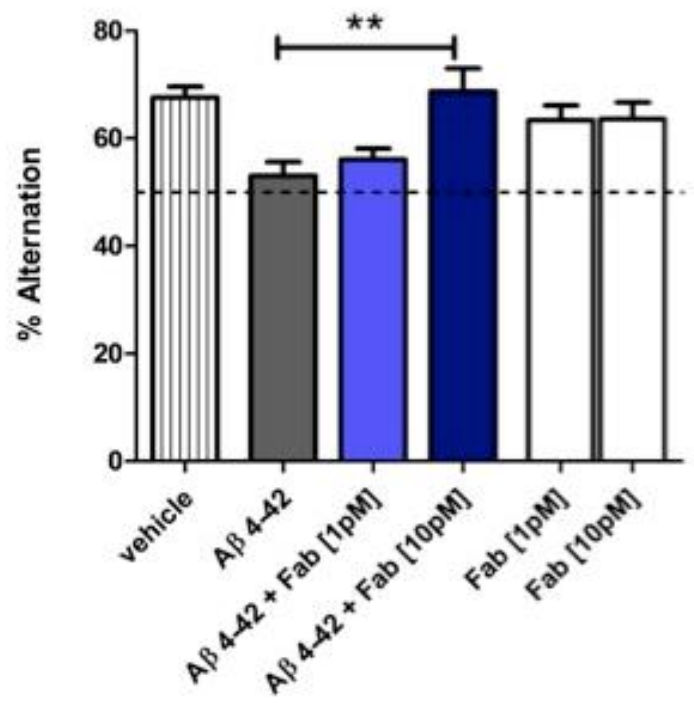

Figure 3.22. Full-length and Fab fragment of NT4X rescue $A \beta_{4-42}$ induced working memory deficits in wildtype mice. $(a, b)$ Working memory deficits were induced by intraventricular injection of $A \beta_{4-42}$ as the mice performing at chance level (dashed line). Both treatment with (a) fulllength antibody and (b) Fab fragment rescued memory deficits in a dosedependent manner. Mice treated with the vehicle control and the vehicle in combination with full-length or Fab fragment of NT4X respectively demonstrated normal working memory performance. One-way analysis of variance (ANOVA) followed by Bonferroni multiple comparisons; $n=6-8$ per group; ${ }^{* *} p<0.01 ;{ }^{*} p<0.05$; data presented as mean \pm S.E.M. 


\subsection{Spatial Reference Memory Deficits in Homozygous Tg4-42 Mice}

Memory deficits have previously been described in homozygous Tg4-42 mice at 8 months of age (Bouter et al., 2013). In order to identify the onset of spatial reference memory deficits Tg4-42hom mice were analysed at six months $(\mathrm{m})$ of age and compared to agematched wild type controls using the Morris water maze.

All mice showed progressively decreased escape latencies over three days of cued training (Fig 3.23a; two-way repeated measures ANOVA, $6 \mathrm{~m}$ Non-treated (NT) and 6m Wild-type (WT): main effect of days: $p<0.00001)$. All mice showed comparable swimming speeds (Fig 3.23b).
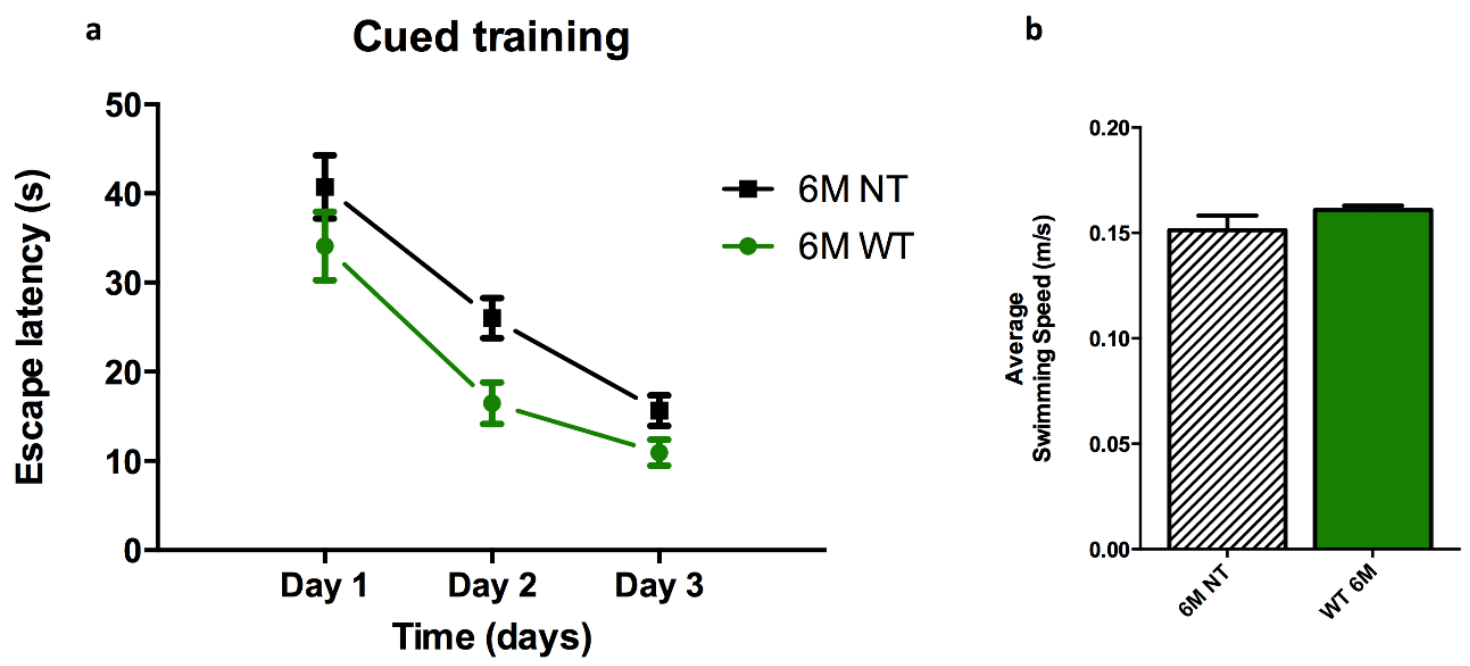

Figure 3.23. Cued training of the 6 months homozygous Tg4-42 water maze. Reveals that Tg4-42 exhibit intact eyesight and motor abilities. Homozygous Tg4-42 mice and WT littermate controls were examined at 6 months of age. All mice showed progressively shorter escape latencies in response to training (main effect of days: $p<0.00001$ ). Swimming speed did not differ between genotypes. Escape latencies and swimming speed: twoway repeated measures ANOVA. $\mathrm{n}=8-9$ per group; data presented as mean \pm S.E.M; $m=$ months. 
Throughout the five days of acquisition training, both Tg442 hom mice and aged-matched WT mice, showed a significant decrease in the escape latencies (Fig 3.24). A significant main effect of days could be found for escape latencies (two-way repeated measures ANOVA, days: $p=0.0291$ ). Also, a significant difference was detected between the genotypes (two-way repeated measures ANOVA, genotype: $p=0.0038$ ). Since a significant difference in average swimming speed was also identified between genotypes (two-way repeated measures ANOVA, genotype: $p=0.0073)$, distance travelled before reaching goal platform was also calculated to ascertain that genotype difference did not arise from swimming speed. Again, a significant effect of days could be found (two-way repeated measures ANOVA, days: $p=0.0123$ ) as well as a significant genotype difference (two-way repeated measures ANOVA, days: $p=0.0206)$. 
a Acquisition Training

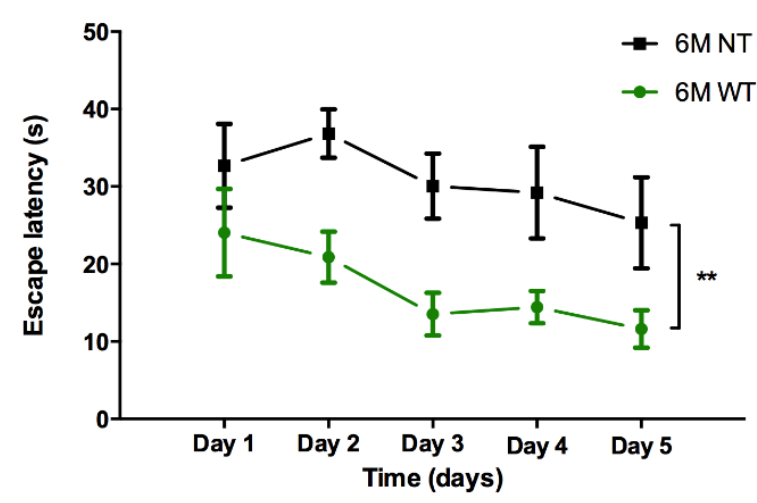

C

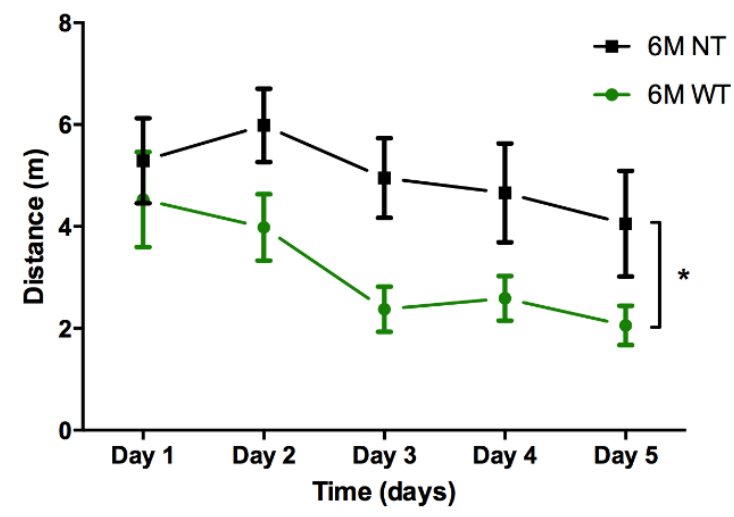

b

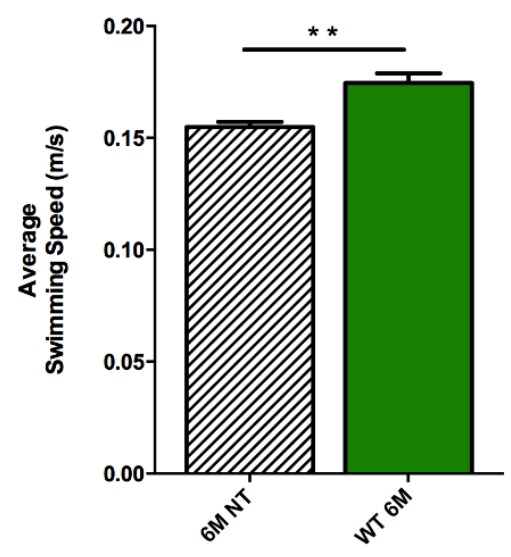

Figure 3.24. Acquisition training of the Morris water maze reveals that 6 months Tg4-42hom mice perform inferior to WT controls. Homozygous Tg4-42 mice and WT littermate controls were examined at 6 months of age. Across the 5 days of acquisition both groups showed a significant decrease in the escape latencies and in distance travelled before reaching platform. (a,c) At 6 months Tg4-42hom performed significantly inferior to WT mice both in escape latency and distance travelled (b) A significant difference in swimming speed was detected between genotypes. (a)-(c). Escape latencies, distance travelled and swimming speed: two-way repeated measures ANOVA, $\left({ }^{* * *} \mathrm{p}<0.001,{ }^{* *} \mathrm{p}<0.01,{ }^{*} \mathrm{p}<0.05 . \mathrm{n}=8-9\right.$ per group; data presented as mean \pm S.E.M; $\mathrm{m}=$ months.)

48 hours after the last acquisition trial, a probe trial was conducted to assess spatial reference memory. Six-month-old Tg442hom mice displayed no significant preference for the target quadrant as compared to WT controls that displayed a significant preference to the target quadrant (Fig 3.25a, one-way ANOVA followed by Bonferroni's multiple comparisons test for WT group, T vs. L, R and 
$\mathrm{O}: \mathrm{p}<0.001)$. Since a significant difference in swimming speed was also identified between genotypes (Fig 3.25b, two-way repeated measures ANOVA, genotype: $p=0.023$ ), distance travelled in all quadrants was also assessed to confirm results. Again 6 months old Tg4-42hom displayed no preference for distance travelled in target quadrant as compared to WT group that preferentially covered more distance in target quadrant (Fig 3.25c, one-way ANOVA followed by Bonferroni's multiple comparisons test for WT group, T vs. L, R and O: $\mathrm{p}<0.001)$. Results are also evident in the group occupancy plots reflecting search strategy during the probe trial (Fig 3.25d) where the WT group shows preference for the target quadrant while 6 months old Tg4-42hom display a random search strategy.

Taken together results indicate severe spatial memory deficits of Tg4-42hom at 6 months of age. 
a

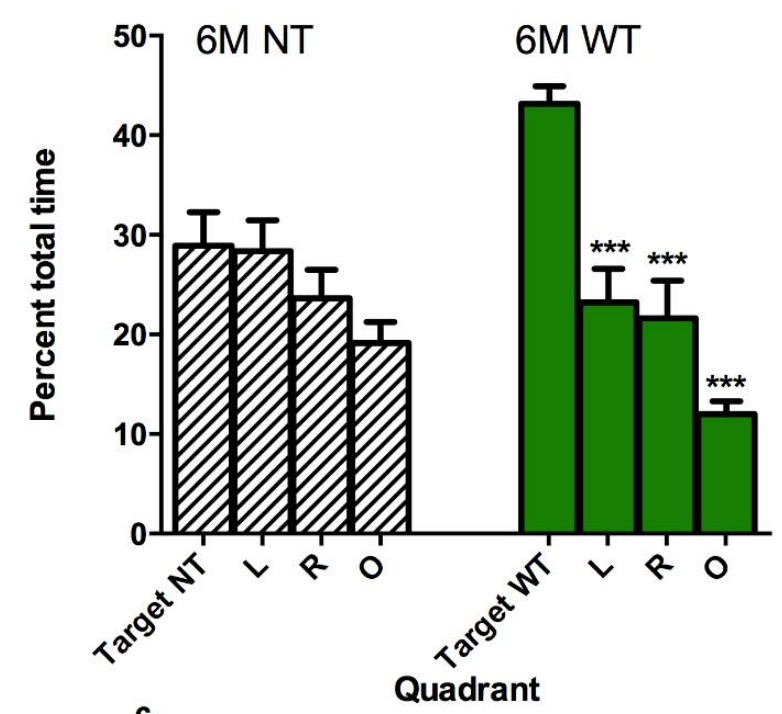

c

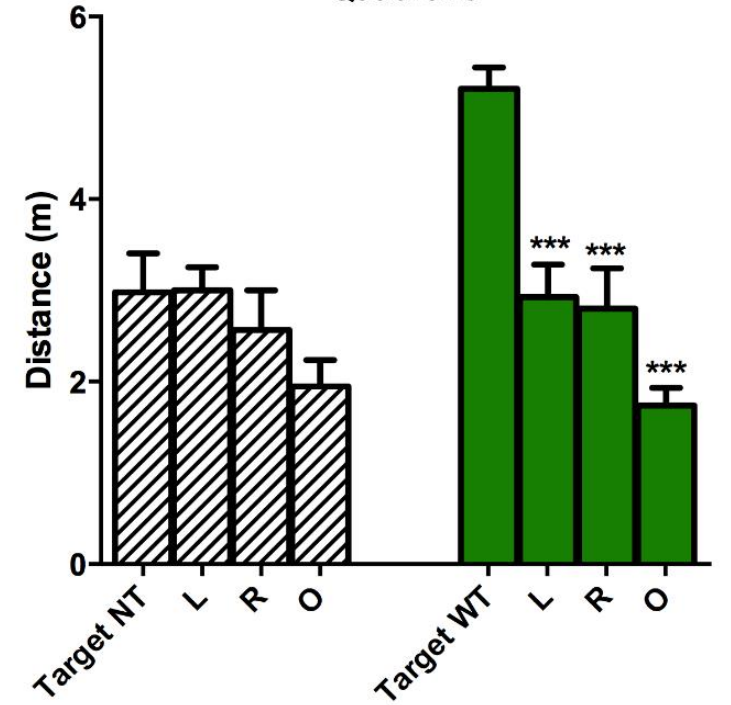

b

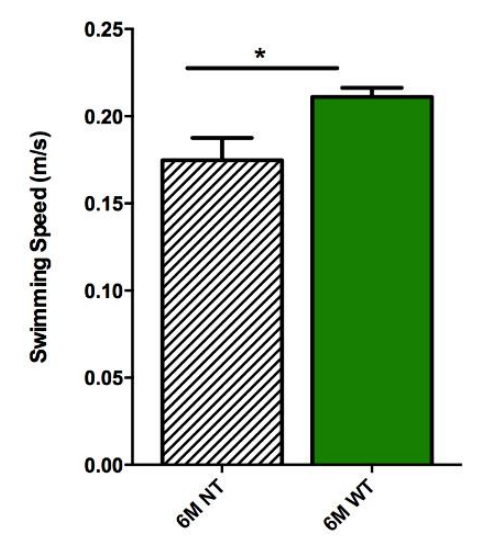

d
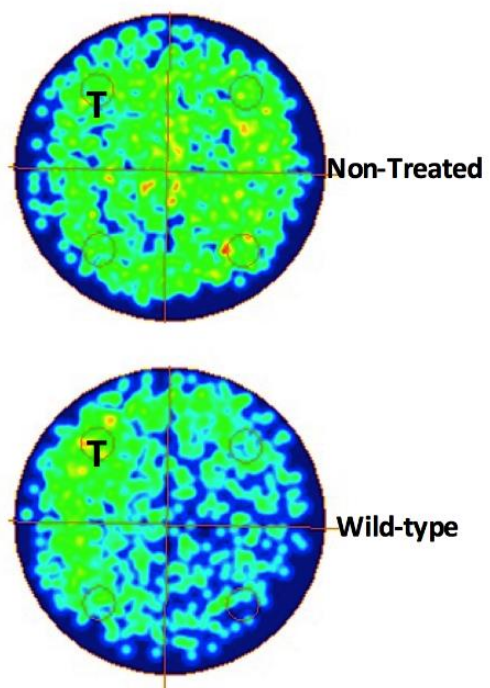

\section{Quadrant}

Figure 3.25. Spatial reference memory deficits in 6 months old Tg442hom mice shown in the probe trial of the Morris water maze. Homozygous Tg4-42 mice and WT littermate controls were tested at 6 months of age. (a) Homozygous Tg4-42 mice did not show a preference for time spent in target quadrant. However, same-aged WT mice had a significant preference for the target quadrant (b) Swimming speed was significantly different between genotypes. (c) Homozygous Tg4-42 mice did not show a preference for distance travelled in target quadrant as compared to WT group that showed preferentially covered more distance in the target quadrant. (d) Group occupancy plots reflecting search strategy during the probe trial. (Abbreviations: $\mathrm{T}=$ target quadrant; $\mathrm{L}=$ left quadrant; $\mathrm{R}=$ right quadrant; $\mathrm{O}=$ opposite quadrant. Quadrant preference: ANOVA followed by Bonferroni multiple comparisons, ${ }^{* * *} p<0.001$. Swimming speed: two-way ANOVA, ${ }^{*} \mathrm{p}<0.05 . \mathrm{n}=8-9$ per group; data presented as mean \pm S.E.M; $\mathrm{m}=$ months.) 


\subsection{Preventative Passive Immunization of Tg4-42hom Mice with NT4X and Fab}

\subsubsection{Rescue of spatial reference memory deficits}

Severe spatial reference memory deficits in Tg4-42hom were detected at 6 months of age. Therefore, 6-month-old Tg4-42hom mice that had received weekly injections with the full-length or Fab of NT4X antibody, and those injected with an IgG antibody control for a period of 12 weeks were assessed using the Morris water maze. All Tg442hom treatment groups showed progressively decreased escape latencies in the cued training. A significant main effect of days could be found for escape latencies (Fig 3.26a, two-way repeated measures ANOVA, days: $\mathrm{p}<0.0001)$. All mice showed comparable swimming speeds (Fig 3.26b).

The cued training revealed that all mice had an intact vision and appropriate motor abilities to swim.
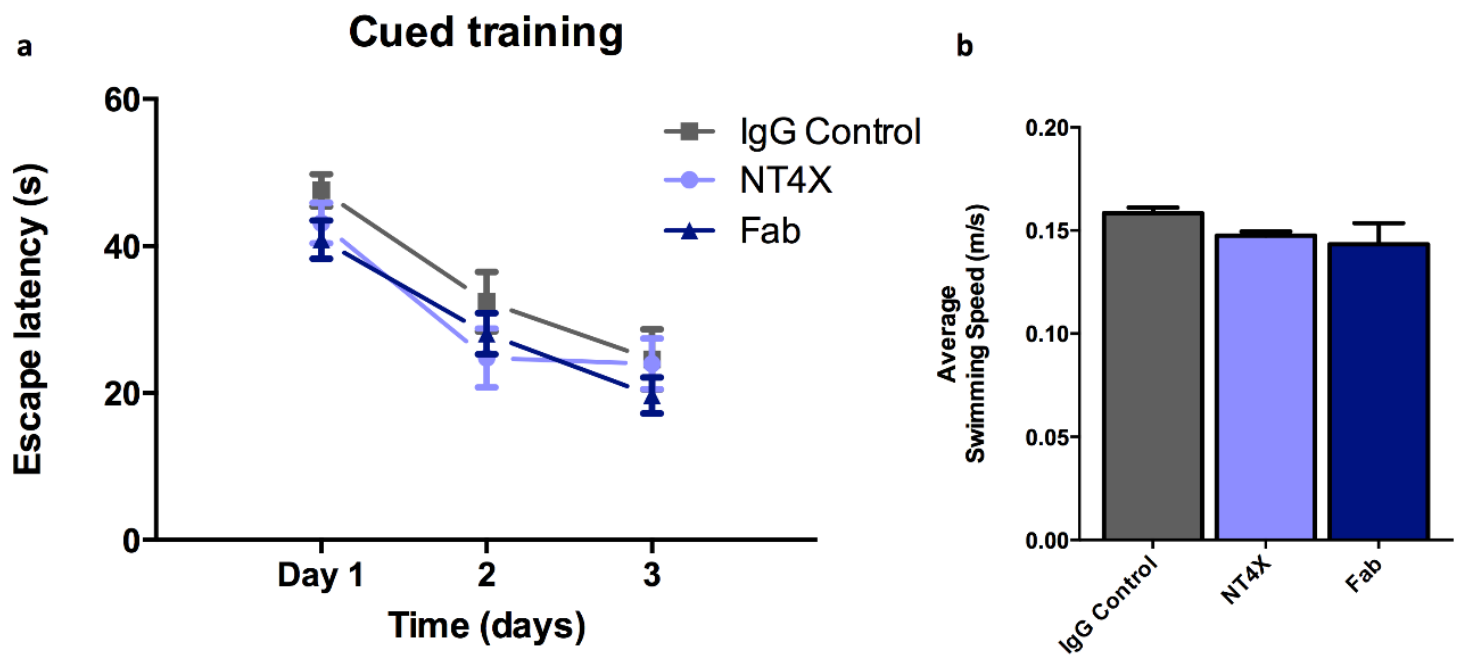

Figure 3.26. Cued training of the water maze reveals that Tg4-42 treatment groups exhibit intact eyesight and motor abilities. Homozygous Tg4-42 treatment groups were examined at 6 months of age. All mice showed progressively shorter escape latencies in response to training. Swimming speed did not differ between treatment groups. Escape latencies and swimming speed: two-way repeated measures ANOVA. $\mathrm{n}=10-13$ per group; data presented as mean \pm S.E.M. 
All groups showed a significant decrease in escape latencies over the five days of acquisition training (Fig 3.27a, two-way repeated measures ANOVA, days: $\mathrm{p}<0.0001)$. Different treatments did not have a significant effect on escape latency. Swimming speed between groups was comparable (Fig 3.27b).

a

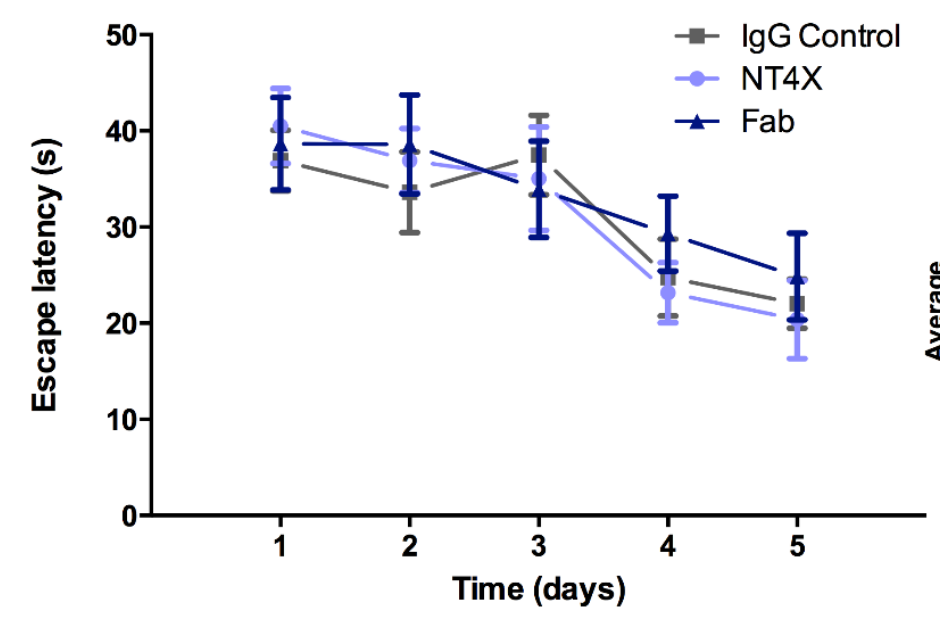

b

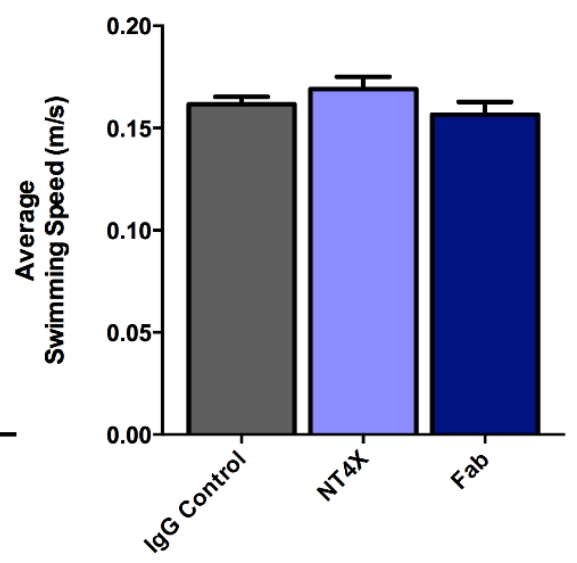

Figure 3.27. Spatial learning was assessed in the acquisition training of the Morris water maze. Tg4-42hom treatment groups were examined at 6 months of age. (a) Across the 5 days of acquisition all groups showed a significant decrease in escape latency. (b) Swimming speed did not differ between treatment groups. Escape latencies: two-way repeated measures ANOVA, effect of days: $\mathrm{p}<0.0001 . \mathrm{n}=10-13$ per group; data presented as mean \pm S.E.M.

48 hours after the last acquisition trial, a probe trial was conducted to assess spatial reference memory. No quadrant preference was found for IgG control treatment group. Both full-length and Fab NT4X immunized Tg4-42hom mice displayed a significant preference for the target quadrant, as indicated by the percentage time spent in different quadrants of the pool (Fig 3.28a, one-way ANOVA, full-length NT4X: $\mathrm{p}<0.01 \mathrm{~T}$ vs. L and O quadrant; Fab: $\mathrm{p}<0.001 \mathrm{~T}$ vs. $\mathrm{L}$ and $\mathrm{O}, \mathrm{T}$ vs $\mathrm{R} p<0.01$ quadrants). Swimming speed did not differ between treatment groups (Fig 3.28b). 
This indicates that both the full-length NT4X antibody and the Fab fragment of NT4X were able to rescue spatial reference memory deficits in 6 months old Tg4-42hom mice.

No significant difference in Cued training, Acquisition training or the Probe trial test were found between the Non-treated 6 months old Tg4-42hom (Fig 3.28) and the IgG control treatment group (Fig 3.28).

a

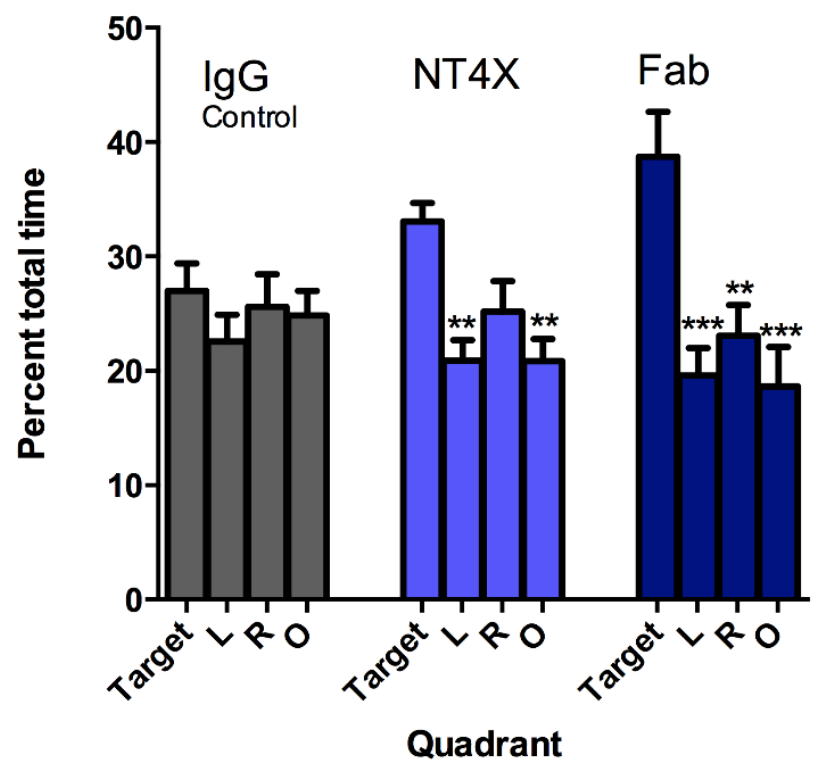

b

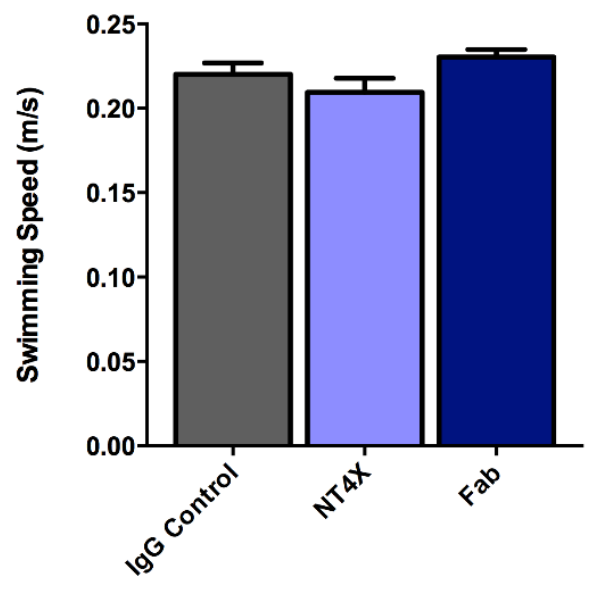

Figure 3.28. Passive immunization rescues spatial reference memory deficits in NT4X and Fab treated Tg4-42hom mice shown in the probe trial of the Morris water maze. Homozygous Tg4-42 mice were tested at 6 months of age. (a) Tg4-42hom IgG treated control mice did not show a preference for the target quadrant. However, NT4X and Fab treated mice showed significant preference for the target quadrant. (b) Swimming speed did not differ between the groups. (Abbreviations: $\mathrm{T}=$ target quadrant; $\mathrm{L}=$ left quadrant; $\mathrm{R}=$ right quadrant; $\mathrm{O}=$ opposite quadrant. Quadrant preference and swimming speed: One-way analysis of variance (ANOVA) followed by Bonferroni multiple comparisons, ${ }^{* * *} \mathrm{p}<0.001 ;{ }^{* *} \mathrm{p}<0.01 . \mathrm{n}=$ 10-13 per group; data presented as mean \pm S.E.M.)

\subsubsection{Deceleration of neuron loss}

In order to study the potential therapeutic effect of NT4X on the observed neuron loss in 6 months old Tg4-42hom the neuron numbers in the CA1 were quantified using design-based stereology. 
The number of neurons was compared between 6-months-old Tg4-42hom immunized with full-length NT4X or Fab NT4X and a control group immunized with an IgG2b antibody control. Stereology revealed a significant treatment effect (Fig 3.29, one-way ANOVA, treatment: $\mathrm{p}=0.0007)$. Following ANOVA, the individual groups were then analysed using Dunnett's multiple comparisons. Compared to IgG control injected mice (mean=136,170; $\mathrm{SEM} \pm 5455$ ), the neuron numbers in $\mathrm{Tg} 4-42 \mathrm{hom}$ were significantly increased after immunization with full length NT4X (mean=160,156; SEM \pm 5096 ) and Fab (mean=165,844; SEM \pm 4717 ) (Fig 3.29; one-way ANOVA: NT4X vs IgG injected: $\mathrm{p}<0.01$; Fab vs IgG injected: $\mathrm{p}<0.001)$.

NT4X immunized Tg4-42 mice displayed $14.97 \%$ more neurons in the CA1 layer of the hippocampus than control IgG treated mice. In comparison, Fab immunized mice displayed $17.89 \%$ more neurons as compared to control IgG treated mice.

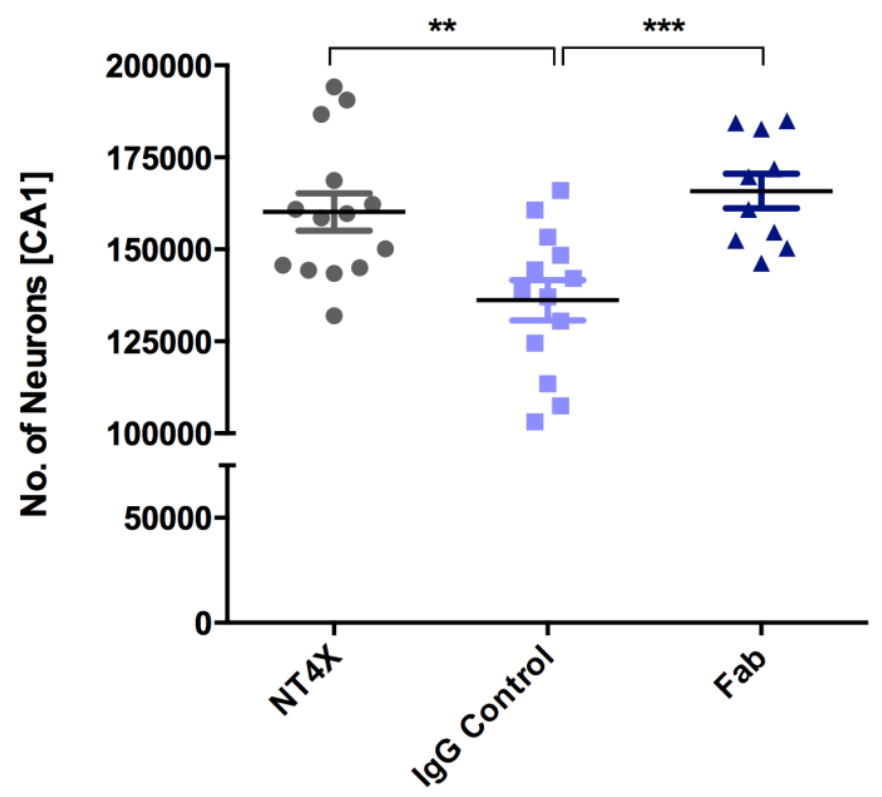

Figure 3.29. NT4X and Fab mitigate neuron loss in Tg4-42hom mice. Quantification of neurons in the CA1 of 6-months-old Tg4-42hom using unbiased stereology. Tg4-42hom mice that received weekly injections with the NT4X antibody or its respective Fab fragment and an IgG control group for a period of 12 weeks were analysed at 6 months of age. Tg4-42hom mice immunized with NT4X full length or Fab fragment both displayed significantly more neurons than age-matched IgG control injected mice. Oneway analysis of variance (ANOVA) followed by Dunnett's multiple comparisons; $\mathrm{n}=10-14 . \quad\left({ }^{* *} \mathrm{p}<0.01 ; \quad{ }^{* * *} \mathrm{p}<0.001 ;\right.$ data presented as mean \pm S.E.M. 


\section{CHAPTER 4}

\section{Discussion}

\subsection{N-Truncated Amyloid Beta 4-x: The Target}

\subsubsection{Properties of $A \beta_{4-x}$}

Part of this work has been dedicated to confirm $\mathrm{N}$-truncated amyloid beta starting at position 4 (phenylalanine) as a viable target in $\mathrm{AD}$ research and therapy. To this end, the aggregation properties of $A \beta_{4-x}$, under reducing conditions, was demonstrated using the $\mathrm{N}$ terminal specific antibody NT4X (Fig 3.18). As previously reported by Jan and colleagues for full length $A \beta$ (Jan et al., 2008), we also mark that the aggregation properties of $\mathrm{N}$-terminally truncated $\mathrm{A} \beta_{\mathrm{pE} 3-\mathrm{x}}$ and $A \beta_{4-x}$ is affected by the carboxyl-terminal length of the peptide. Wherein, under reducing conditions, $A \beta_{\mathrm{pE} 3-40}$ and $A \beta_{4-40}$ migrate as monomers $(4 \mathrm{kDa})$ and dimers $(8 \mathrm{kDa})$, in contrast to $A \beta_{\mathrm{pE} 3-42}$ and $A \beta_{4-}$ 42 , both of which exhibited higher molecular weight aggregations of trimer $(12 \mathrm{kDa})$ and tetramers $(16 \mathrm{kDa})$ in addition to monomers and dimers. We had previously shown that in contrast to full length $A \beta_{1-42}$, which tends to remain in equilibrium with its monomeric state for longer, $A \beta_{\mathrm{pE} 3-42}$ and $A \beta_{4-42}$ tend to form stable oligomers faster (Bouter et al., 2013). It has previously also been reported that the aggregation propensities of $A \beta$ may be directly affected by varying either terminal length of the peptide (Jan et al., 2008; Jarrett et al., 1993; Pike et al., 1995).

\subsection{2. $\quad A \beta_{4-x}$ as a target}

The neurotoxicity of $\mathrm{N}$-terminal truncated variants of $\mathrm{A} \beta$ has been known for over two decades (Pike et al., 1995). First demonstrated by Pike and colleagues, it was later suggested that they may initiate or nucleate the pathological deposition of $A \beta$ into plaques 
(Russo et al., 2002). These observations were recently extended by our lab, showing that $A \beta_{p E 3-42}$ and $A \beta_{4-42}$ have specific structural features that render their soluble aggregates neurotoxic. The stable aggregates formed by $A \beta_{\mathrm{pE} 3-42}$ and $A \beta_{4-42}$ were different in size and morphology than those formed by full length $A \beta_{1-42}$, as shown by far UV CD spectroscopy, dynamic light scattering and NMR spectroscopy (Bouter et al., 2013).

The exact levels of $\mathrm{N}$-truncated $\mathrm{A} \beta$ peptides that comprise a part of the total $A \beta$ pool of $A D$ patient's has been hard to determine. This is mostly due to a variation of methodology and tools used to extract this information. It is in agreement nonetheless, that $\mathrm{N}$-truncated $\mathrm{A} \beta$ peptides appear during Alzheimer disease progression (Bayer \& Wirths, 2014). It is of interest that intraneuronal $A \beta$ has also been reported to be $\mathrm{N}$-truncated and that $A \beta_{4-\mathrm{x}}$, starting with phenylalanine is the variant that is mostly reported in pre-symptomatic $\mathrm{AD}$ cases (Gouras et al., 2000). In good agreement, N-terminal truncated variants (beginning with position 4 "Phenylalanine", position 5 "Arginine", position 8 "Serine", position 9 "Glycine" and position 3 with a pyroglutamyl residue) comprised the first stage of amyloid deposition in non-demented individuals. At this stage all $A \beta$ variants detected were not truncated at their C-terminus $\left(A \beta_{x-42}\right)$ (Sergeant et al., 2003).

Masters and colleagues had first reported that $A \beta_{4-x}$ was a component of amyloid deposits analyzed from human AD brains (Masters et al., 1985). In agreement with these findings, cotton wool plaques in patients with familial $\mathrm{AD}$, were found to harbor high amounts of $A \beta_{4-42}$ (Miravalle et al., 2005). Along those lines, we have also shown that $A \beta_{4-x}$ intraneuronal accumulation precedes that of $\mathrm{A} \beta_{\mathrm{pe3-x}}$ in the established 5XFAD mouse model (Antonios et al., 2013).

To that end, the Tg4-42 mouse model has been recently established (Bouter et al., 2013) and validated as an advantageous research tool in $A D$ research as it exclusively expresses $A \beta_{4-42}$, allows 
for its intraneuronal accumulation, and permits the study of a previously neglected therapeutic option in $A D$; the $A \beta_{4-42}$ peptide.

\subsubsection{The Tg4-42 model: $A \beta_{4-42}$ in vivo}

$\mathrm{N}$-truncated $\mathrm{A} \beta$ peptides have been reported in several $A D$ mouse models. A 2D electrophoresis analysis combined with mass spectrometry, has enabled the detection of a wide variety of $\mathrm{N}$ truncated $A \beta$ variants in $A P P / P S 1 K I$ mice. At 2.5 months $A \beta_{2 / 3-42}$, $A \beta_{4 / 5-42}$ and $A \beta_{8 / 9 / 10 / 11-42}$ were found, and the appearance of $A \beta_{p E 3-x}$ was noticeable from 6 months of age (Casas et al., 2004). Another typical AD mouse model to exhibit $N$-truncated $A \beta$ peptides is the 5XFAD model. Confirmed variants in the 5XFAD model have been $\mathrm{A} \beta_{\mathrm{pE} 3-40 / 42}, A \beta_{4-40 / 42}$ and $A \beta_{5-40}$ (Antonios et al., 2013; Guzman et al., 2014; Jawhar et al., 2012; Oakley et al., 2006; Richard et al., 2015). Other models reported to have $\mathrm{N}$-truncated $\mathrm{A} \beta$ peptides are the PDAPP, Tg2576 and APP23 mouse models, all of which also exhibit intracellular A $\beta$ accumulation (Chapman et al., 1999; Games et al., 1995; Hsiao et al., 1996; Kelly et al., 2003; Masliah et al., 1996; Rijal Upadhaya et al., 2013; Rockenstein et al., 1995; Sturchler-Pierrat et al., 1997).

The disadvantage that had previously accompanied transgenic mouse models of $\mathrm{AD}$ was the fact that they relied overly on the overexpression of APP or the expression of mutations that affected the processing of APP. This has led to models that mostly reflect the familial form of AD from which these models were inspired. They also neglected contributions from $\mathrm{N}$-truncated $A \beta$ forms, which were found in small amounts relative to full length $A \beta_{1-40 / 42}$ in these models. Although highly beneficial for basic research into the etiology of AD disease, the models might not provide perfect tools for therapeutic intervention that may be translated into the clinic.

To this end, our lab has recently developed the Tg4-42 mouse model. Expressing only $A \beta_{4-42}$ under the THY1 promoter, the model 
exhibits some aspects of AD pathology without the reliance on APP overexpression or processing. $A \beta_{4-42}$ intraneuronal accumulation eventually leads to neuron loss and spatial memory deficits, without extracellular $A \beta$ accumulation in the form of plaques (Bouter et al., 2013). This further boosts our previous hypothesis on the importance of intraneuronal $A \beta$ being the trigger for respective downstream pathological events (Wirths et al., 2004).

\subsubsection{Neuron loss and spatial reference memory: Age- dependent decline}

Efforts to model AD-relevant cognitive deficits in mouse models have met with partial success (Kobayashi \& Chen, 2005). The hippocampus is one of the first and most severely touched brain regions in $\mathrm{AD}$ patients. Various mouse models have tried to assess reference memory as this particular memory function is highly specific for the hippocampal region (West, 1993). We have previously shown that at 8 months of age, homozygous Tg4-42 mice have developed severe hippocampus neuron loss and spatial reference memory deficits (Bouter et al., 2013). It was of interest to the current work, to determine the onset of neuron loss and subsequent spatial reference memory deficit in the Tg4-42 homozygous mice.

We show that the Tg4-42hom mice exhibit an age-dependent neuron loss in the CA1 region of the hippocampus where neuron loss starts at 4 months of age and gradually decreases with age to reach $50 \%$ at 6 months of age and $64 \%$ at 8 months of age (Antonios et al., 2015). More importantly, this coincides with age-dependent spatial memory deficits where the mice at 6 months of age have developed a severe spatial reference memory deficit as compared to aged matched WT control mice both in acquisition training and in the probe trial of the Morris water maze (Fig 3.24 and Fig 3.25). In rats, spatial memory impairment has been reportedly linked to bilateral dorsal hippocampal lesions, where the onset of impairment coincided with 
lesions that encompassed $30-50 \%$ of total volume and worsened dramatically as lesion size increased above $50 \%$ of total hippocampal volume (Broadbent et al., 2004). At 5 months of age, the Tg4-42hom mice suffer from a $43 \%$ neuron loss in the CA1 and signs of mild spatial reference memory deficits as compared to 6 months where neuron loss has increased to $50 \%$ and spatial reference memory deficits have become severe (Antonios et al., 2015). This is in agreement with other findings which have shown that a significant neuron loss in the hippocampus may still be compensated as only 20$40 \%$ of the total hippocampus is required for effective spatial learning (Moser et al., 1995).

Other studies have also shown an age dependent reference memory decline in transgenic mouse models of AD. Westerman and colleagues have shown that spatial reference memory deteriorates progressively after 6 months of age, as shown in a Morris water maze, in Tg2576 mice. Severe deficits, however are only apparent after 12 months of age (Westerman et al., 2002). Another study utilized the radial arm water maze to show an age dependent reference memory decline in APP/PS1 KI mice. Again, memory deficits are only observable starting at 11 months of age and become severe at 15 months (Webster et al., 2013).

This goes to show the importance of the Tg4-42hom mice as a tool for AD therapeutic intervention. Since the mice already display tremendous neuron loss and reference memory deficits at 6 months of age, the timeline for therapeutic intervention is drastically cut down as compared to other mouse models.

\subsection{NT4X: The Therapeutic Tool}

Since $A \beta_{4-40}$ peptides were found to form stable aggregates in solution (Bouter et al., 2013), we have used them in order to generate a monoclonal antibody that binds at the N-terminus of $A \beta$. 
The novel oligomeric A $\beta$ specific antibody NT4X was generated by immunizing three Balb/c mice with unconjugated $A \beta_{4-40}$. After preparation of the lymph nodes they were fused with the myeloma cell line P3-X63-Ag8 for generation of the hybridoma cells. After fusion, the hybridoma cells were screened by an enzyme-linked immuneabsorbent assay (ELISA) for an antibody that recognizes $A \beta_{4-10 / 40}$ peptides but not the C-terminal end of amyloid beta, thus not recognizing the $A \beta_{36-40}$ peptide. Positive antibody clones were further screened by IHC staining of human brain sections. The intention of the screening procedure was to find a clone that would not preferentially bind to amyloid plaques thereby identifying NT4X (Antonios et al., 2013).

\subsubsection{Antibody purification}

The hybridoma clone B4C11 was subsequently chosen as it fit all previously mentioned selection criteria for the desired antibody. Although small-scale cultures of the hybridoma cell line were maintained in media containing serum, the need for large-scale antibody purification (Fig 3.1) required the conditioning of the cell line with a serum-free culture media. This was done to achieve higher purity of antibody purified. It is well known that serum containing media would contain high titers of antibody from the host organism thus interfering with purification (Howard \& Kaser, 2013).

For the purpose of this study, large amounts of purified antibody were necessary. Since the small-batch production of milligram amounts of antibody was not sufficient, we turned to culture using bioreactors to improve the amount and efficiency of purification. It has been previously reported that a perfusion culture of hybridoma cells drastically increases the number of viable cells (cells/mL) and thus leads to higher overall amounts of antibody produced (mg/L) per liter of culture media (Tang et al., 2007). Our results are in good agreement with this as we achieved antibody yields 
upwards of $50-60 \mathrm{mg} / \mathrm{mL}$ as compared to $30 \mathrm{mg} / \mathrm{mL}$ from previous purifications using traditional methods.

Tracking of antibody purification reveals a high degree of purity was achievable through the designed purification protocol, while the presence of both heavy and light chains confirm antibody presence (Fig 3.3 and Fig 3.4).

\subsubsection{Antibody characterization}

In order to determine the specificity of the purified NT4X antibody against $A \beta$ species, it was utilized as a primary antibody in western blot analysis of various $\mathrm{N}$-truncated and full length $A \beta$ species. Since the antibody itself was raised against unconjugated $A \beta_{4-40}$, it was no surprise that it detected $A \beta_{4-40}$ and $A \beta_{4-42}$ as shown under reducing conditions (Fig 3.18). The antibody however also recognized the pyroglutamate modified N-truncated $A \beta$ species as well, recognizing both $A \beta_{\mathrm{pE} 3-40}$ and $A \beta_{\mathrm{pE} 3-42}$ peptides under reducing conditions (Fig 3.18). This is further corroborated by results obtained from a similar experiment performed under native conditions where the antibody also recognized $\mathrm{N}$-truncated $\mathrm{A} \beta$ species (Antonios et al., 2013).

It is worth noting that, as compared to the IC16 antibody, the NT4X antibody does not recognize full length $A \beta_{1-40 / 42}$ as we have shown in both reducing and native conditions. This is due to the fact that the antibody binds most strongly to the phenylalanine as position 4 of $A \beta$, as demonstrated by a pepscan analysis, and the additional peptides contained in full length $A \beta$ might be blocking it from binding to its preferred site (Antonios et al., 2013).

Previously characterized antibodies have been raised against pyroglutamate modified N-truncated A $\beta$ species (Frost et al., 2012; Wirths et al., 2010), most have been raised against full length $A \beta$ (Bard et al., 2000; Dodart et al., 2002; Wilcock et al., 2004c) and the NT4X antibody is unique in its ability to recognize both $A \beta_{\mathrm{pE} 3-\mathrm{x}}$ and $A \beta_{4-x}$ species. Moreover, it is highly sensitive and may bind as little as 
$30 \mathrm{ng}$ of $\mathrm{A} \beta_{4-42}$, corresponding to a sensitivity of approximately 7 picomoles under reducing conditions (Fig 3.19).

We further show that the NT4X antibody, as previously selected to be, reacts to a very low extent with extracellular plaques in human AD tissue (Antonios et al., 2013). Our working group has further expanded and recently confirmed the previous result in comparison to the biosimilar antibodies of Bapineuzumab, Crenezumab, Solanezumab in sporadic AD cases and mouse models (Bouter et al., 2015). Similarly, this description has been valid for the confirmation specific $A \beta_{\text {pE3-x }}$ antibody 9D5 (Wirths et al., 2010). In murine tissue the NT4X reacts both with intracellular and extracellular $A \beta$ and we were able to show that in the homozygous 5XFAD model (Richard et al., 2015), that the intraneuronal accumulation of $A \beta_{4-x}$ precedes that of $A \beta_{\mathrm{PE} 3-\mathrm{x}}$, underlying a fact which was not previously presented (Antonios et al., 2013).

\subsubsection{In vitro and in vivo target engagement and rescue}

To further out work in characterizing the NT4X antibody and its therapeutic potential, collaborators at SynAging (Nancy, France) and MRC Technology (London, United Kingdom) have performed in vitro and in vivo target engagement and rescue assays with the NT4X antibody.

To go in parallel with our results showing that the NT4X recognized both $N$-truncated $A \beta_{p E 3-x}$ and $A \beta_{4-x}$ species, but that full length $A \beta_{1-x}$ (Antonios et al., 2013), NT4X was also found to rescue the toxicity resulting from both $A \beta_{\mathrm{pE} 3-42}$ and $A \beta_{4-42}$ in primary rat neuronal cultures (Antonios et al., 2015). Even when antibody concentration is increased well above 1:1 molar ratio (antibody:peptide) the NT4X does not rescue toxicity induced by full length $A \beta_{1-42}$ as measured by an LDH release assay. Not surprisingly, the antibody seems also to rescue $A \beta_{4-42}$ preferably as it requires only $133.7 \mu \mathrm{g} / \mathrm{ml}$ of $\mathrm{NT} 4 \mathrm{X}$ to reach $50 \%$ of cell death inhibition caused by $10 \mu \mathrm{M}$ of $\mathrm{A} \beta_{4-42}$, as compared to $109.5 \mu \mathrm{g} / \mathrm{ml}$ antibody to reach the same level of cell 
death inhibition (50\%) caused by a lesser amount of $5 \mu \mathrm{M} \mathrm{A} \beta_{\mathrm{pE3}-42}$ (Fig 3.20). The molecular mechanism of $A \beta$-induced neuronal cell death is not well understood, though studies have reported the involvement of reactive oxygen species (ROS) in $A \beta$ induced neuronal cell death (Behl et al., 1995). It was more recently determined that $A \beta$ induces neuronal cell death through ROS mediated ASK1 activation, and the authors have proposed ASK1 as a therapeutic target for prevention and treatment of AD (Kadowaki et al., 2005).

It was previously demonstrated that $A \beta$ peptide ICV injection induced short term memory impairment in rats (Stepanichev et al., 2003). Recently, we have shown that $N$-truncated $A \beta$ variants (including $A \beta_{4-42}$ ) induce working memory deficits in wild type mice (Bouter et al., 2013). In order to demonstrate NT4X in vivo target engagement, a similar experimental setup was reproduced. ICV injection of $A \beta_{4-42}$ caused a working memory deficit as demonstrated by a Y-maze, the effect of which is completely rescued by the NT4X antibody in a dose dependent manner (Fig 3.22a). The work is essential in showing that the NT4X is capable of target engagement and rescue of $A \beta_{4-42}$ in vivo, under physiological conditions where the peptide would otherwise be toxic. 


\subsection{Passive Immunization of the Tg4-42hom AD Model Using NT4X and its Fab}

\subsubsection{Timeline and dosage}

Pre-clinical passive immunization studies usually differ in at least one of the following parameters: Dosage/time course, animal model employed and antibody used for immunization. Previous therapeutic and preventative passive immunization trials against $\mathrm{N}$ truncated $A \beta$ peptides have attempted both subcutaneous and intraperitoneal administration and opted for a dosage of $12.5 \mathrm{mg} / \mathrm{kg}$ body weight (DeMattos et al., 2012; Frost et al., 2012). Moreover, mouse models frequently used in immunization studies such as the Tg2576 and PDAPP exhibit a difference in the morphology and stoichiometry of A $\beta$ deposits (Fryer et al., 2003; Hsiao et al., 1996; Sasaki et al., 2002). This goes to reflect the difficulty in comparing different preclinical trials. It also reflects as to why the outcome of clinical studies poorly reflected the results from pre-clinical immunizations (Lannfelt et al., 2014).

At 4 months of age, neuron loss in the CA1 region of the hippocampus in the homozygous Tg4-42 is marked with a $17 \%$ loss, and precedes the appearance of behavioral deficits As the mice are still pre-symptomatic at that stage, still capable of learning and have an intact reference memory till the age of 4 months in a MWM, we opted for the purpose of this study to perform a preventative passive immunization. For early intervention in AD by passive immunization, it would be necessary to identify patients inclined to more likely develop cognitive impairment. Though this is currently not possible, it has driven research into the defining of preclinical biomarkers in $A D$ (Fiandaca et al., 2014).

The dosage, administered intraperitoneally, chosen for this study was $10 \mathrm{mg} / \mathrm{kg}$ body weight to be injected weekly. In this treatment window, mice would be immunized with the NT4X antibody starting 3 months (12 weeks) of age where the animals are pre- 
symptomatic, for the duration of 12 weeks reaching an age of 6 months. This has allowed us to examine the preventative therapeutic effect of the NT4X at an endpoint where the mice usually exhibit reference memory deficits (Fig 4.1).

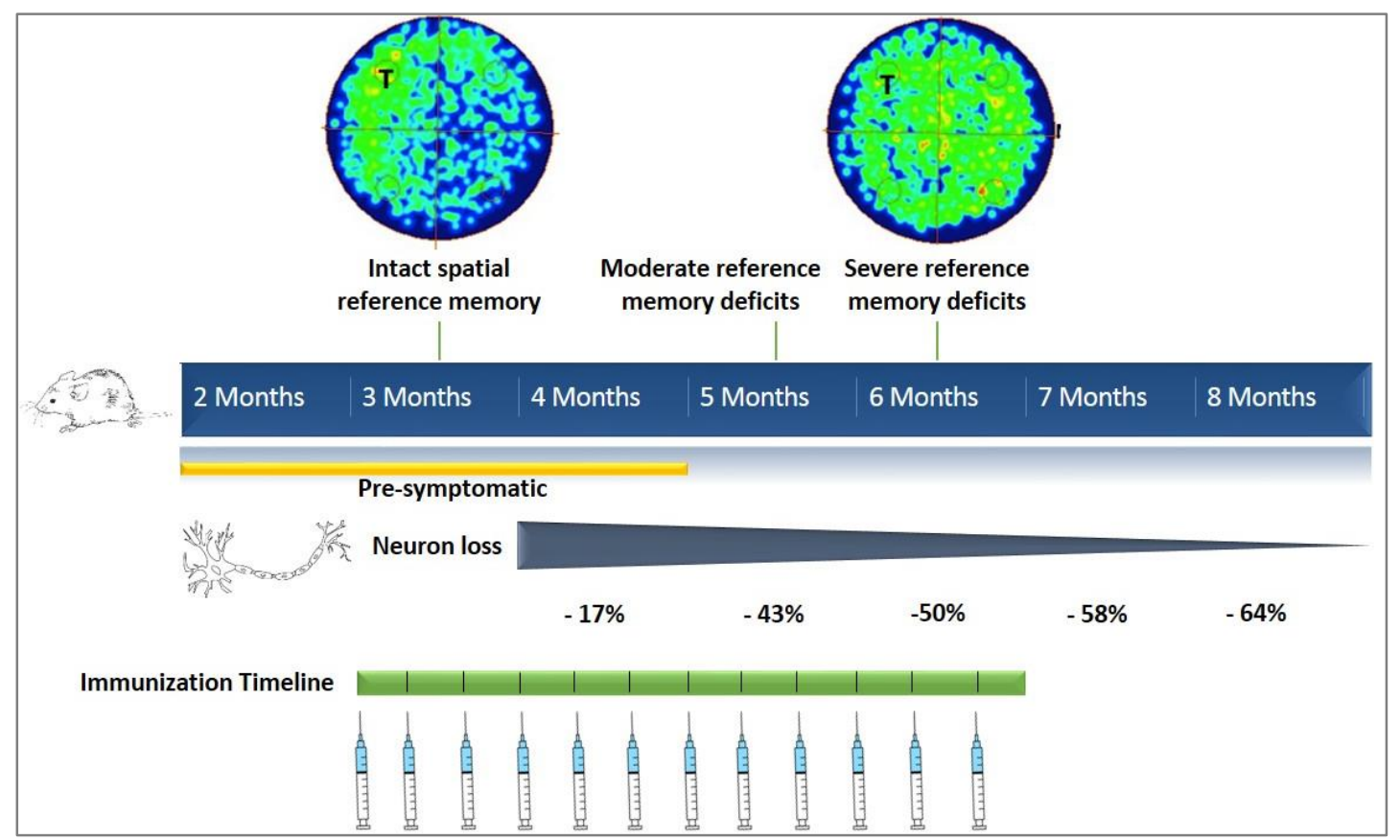

Figure 4.1. Passive Immunization timeline of Tg4-42. Onset and progression of neuron loss and of spatial reference memory decline are displayed. 


\subsubsection{Rescue of neuron loss}

Almost all pre-clinical immunization studies, have relied on $A \beta$ burden as a measurable outcome. While some approaches were therapeutic, with immunization starting after the onset of plaque pathology, other attempted a preventative approach. In therapeutic trials, some studies have reported no clearance of existing plaques (Dodart et al., 2002; Levites et al., 2006), while other report limited clearance (Tucker et al., 2008). Not all trials were unsuccessful however, with several studies suggesting a significant reduction in pre-existing plaques (Frost et al., 2012; Wilcock et al., 2004b). On the other hand, preventative passive immunization has been more successful, with numerous reports of significant inhibition of plaque pathology (Bard et al., 2000, 2003; Bussiere et al., 2004; Frost et al., 2012; Lord et al., 2009).

In spite of the previous, it is well known that $A \beta$ levels do not necessarily correlate with the therapeutic outcome. Reversal of memory deficits in mice, for example, has been shown in an $A D$ mouse model, even though the preclinical passive immunization study did not reduce brain $A \beta$ burden (Dodart et al., 2002). On the other hand, passive immunization of APPswe/PS1 $\triangle \mathrm{E} 9$ transgenic mice with an antibody against the $\mathrm{N}$-terminus of pyroglutamate $A \beta_{3-X}$ significantly reduced total plaque deposition in the hippocampus and cerebellum, without however, affecting $A \beta$ levels as measured by ELISA (Frost et al., 2012).

In this study, we propose a new measurable outcome for the assessment of passive immunization in the homozygous Tg4-42 mice. As previously discussed, the Tg4-42 mice exhibit an early loss of neuron in the CA1 region of the hippocampus. Preventative passive immunization using the NT4X antibody or its Fab fragment, was able to mitigate neuron loss as compared to an IgG control group (Fig 3.29). 


\subsubsection{Rescue of reference memory deficits}

While most passive immunization studies do not tackle the issue of behavioral deficits, most likely due to the fact that results were negative, others have reported findings. The rescue of memory deficits has been reported for a variety of mouse models such as the 5XFAD (Wirths et al., 2010), PDAPP (Dodart et al., 2002) and the Tg2576 (Wilcock et al., 2006; Wilcock, et al., 2004a). Is it important to mention that some have even reported the reversal of memory deficits with no reduction in plaque load, further asserting the fact that plaque burden and behavioral deficits are not correlated (Dodart et al., 2002). Moreover, most mouse models in which an amelioration of behavioral deficits is reported, are APP overexpressing or enzymatic mutation of APP related models, reflecting more cases of familial AD than those of sporadic AD.

We were able to achieve a reversal of spatial reference memory deficits in the Tg4-42 homozygous mice after passive immunization with the NT4X antibody and its Fab fragment. The preventative treatment, allowed for mice to maintain an intact spatial reference memory, as one exhibited in the pre-symptomatic phase (Fig 3.28). This goes in line with the direction of on-going clinical trials where most passive immunization trials are now focused on prevention and very early treatment of AD (Lemere, 2013).

\subsubsection{Mechanism of NT4X passive immunotherapy}

The cornerstone theory of $A \beta$ engagement, suggested that antibodies may act catalytically to prevent $A \beta$ aggregation or dissolve its preformed aggregates (Solomon et al., 1997). This was later on supported by the first active immunization trials which demonstrated plaque removal in response to immunization with $A \beta_{1-42}$ aggregates, allowing the immune system to develop anti- $A \beta$ antibodies (Schenk et al., 1999). Though active immunization per-say was abandoned due to life-threatening side effects, the field still moved forward in research 
concerning removal of deposited amyloid peptides. It is estimated that less than $1 \%$ of antibody injected in passive immunization crosses the BBB to reach its target, treatment effects have nonetheless been positive (Lemere, 2013). Bapineuzumab was the first humanized antibody in clinical trials, its murine predecessor 3D6 target full length $A \beta_{1-42}$. It failed however to improve clinical outcomes in a phase III placebo-controlled study of patients with mild to moderate $A D$ (Salloway et al., 2014). Studies have even suggested that the solubilization of fibrillar $A \beta$ may have a noxious effect (Benilova et al., 2012; Haass et al., 1994). In this study, we circumvent this issue by the use of the Tg4-42 model, which does not exhibit $A \beta$ deposits in the form of plaques, and allows for target engagement of the NT4X antibody without the repercussions faced by other passive immunotherapy studies which employed models harboring plaque pathology.

A different hypothesis for antibody $A \beta$ clearance, the peripheral sink hypothesis, does not require the penetration of the BBB. It has been shown that $A \beta$ can be rapidly transported to the periphery (Ghersi-Egea et al., 1996; Shibata et al., 2000). In this light, it has been proposed that a shift in $A \beta$ equilibrium, driving a higher efflux from the central nervous system would allow peripherally circulating antibodies to facilitate $\mathrm{A} \beta$ clearance (Bacskai et al., 2002; Das et al., 2003). In reality however, reports have been contradictory. While some studies utilizing the murine predecessor of Solanezumab, the m266 antibody, have reported an $\mathrm{A} \beta / \mathrm{m} 266$ complex in the plasma and cerebrospinal fluid of treated PDAPP mice, thus supporting the peripheral sink hypothesis (Dodart et al., 2002b). Other studies have reported that the m266 neutralizes intracerebral rather than peripheral A $\beta$ (Yamada et al., 2009).

Microglial activation in immunotherapy has been suggested as a key player in the clearance of $A \beta$ (Wang et al., 2011). The mechanism proposed that the clearance of amyloid deposits occur via an interaction of the Fc receptor on microglia cells with the Fc art of the 
therapeutic antibody bound to $A \beta$ (Bard et al., 2000). Results obtained in this study, do not support this hypothesis, as the passive immunization with the Fab fragment of the NT4X antibody, resulted in the same therapeutic effect of the full length antibody itself in mitigating neuron loss and reversing spatial reference memory deficits (Fig 3.29 and Fig 3.28). Along those lines, another study using Tg2576 APP mice that were further engineering as $\mathrm{Fc}$ receptor-gamma chain knock-outs, still demonstrated an effect of anti-A $\beta$ antibodies on $A \beta$ deposition (Das et al., 2003), disproving the need for Fc receptor mediated phagocytosis.

This study has been able to discuss several aspects of the treatment mechanism in $\mathrm{AD}$ passive immunotherapy. Primarily, we show that mouse models of AD needn't harbor plaque pathology and that the Tg4-42 mouse model presents a chance to tackle soluble $A \beta_{4-}$ 42 aggregates of as possible therapeutic targets. We have introduced another paradigm in terms of measurable pre-clinical outcome for passive immunotherapy; neuron loss, and have demonstrated that the Fab fragments of antibodies are viable options for therapy.

\subsection{Outlook in Immunotherapy}

\subsubsection{Autoantibodies against $A \beta$}

The presence of natural antibodies against $A \beta$ has been reported in plasma samples and the cerebrospinal fluid of both AD patients and healthy controls (Britschgi et al., 2009). One such antibody presently in clinical trials is Aducanumab (Biogen). The most recent developments at the AD/PD conference (March 2015) reported interim analysis of first data sets from Aducanumab (Biogen). Developed from aged, cognitively healthy, donors using reverse translational medicine, it is a fully human IgG1 monoclonal antibody against a conformational epitope found on $A \beta$. Results have so far been promising with a dose dependent reduction in amyloid deposition in six cortical regions. Results communicated in the Alzheimer's 
Association International Conference (AAIC) in August 2015, the 6 $\mathrm{mg} / \mathrm{kg}$ immunotherapy group was numerically reported to be closer to the $1 \mathrm{mg} / \mathrm{kg}$ than the 3 or $10 \mathrm{mg} / \mathrm{kg}$ group, in the mini-mental state examination (MMSE), but overall dose dependence remained significant. Phase III trials began in August 2015 and are set to run till 2022 (Alzforum.org).

\subsubsection{Passive immunotherapy and vascular pathology}

A diet deficient in folate and vitamins B6and B12, has been reported to cause vascular cognitive impairment in WT mice (Sudduth et al., 2013). APP/PS1 mice, on a similar diet as previously mentioned, had a remarkable redistribution of $A \beta$ to the vasculature from the parenchyma, although total $A \beta$ levels remained unchanged. The mice also worsened as compared to control groups, in a radial arm maze (Sudduth et al., 2014). This has raised questions regarding the co-morbidity effect of passive immunotherapy and vascular pathology. A $\beta$-related imaging abnormalities (ARIA), which have been linked to vasogenic edema, were part of the demise of the Bapineuzumab program, and are being investigated in the ongoing trials with Aducanumab as well (Alzforum.org).

\subsubsection{Intrabodies in immunotherapy}

Intracellular antibodies, or Intrabodies, are small, usually single-chain antibodies that are able to penetrate cells through the use of viral or other types of vectors. They are designed to designed to bind and inactivate target molecules inside cells (Chen et al., 1994).

The use of protein engineering, has further allowed the targeting of intrabodies to specific subcellular compartments. By adding a KDEL amino acid motif, targeting the antibody to the endoplasmic reticulum, the scFvA13 intrabody, which only recognizes $A \beta$ in a sequence and confirmation selective manner, a study has been able to decrease the production of $\mathrm{A} \beta$ oligomers in 7PA2 cells expressing the 
antibody (Meli et al., 2014). It was previously shown that 7PA2 cells produce large quantities of $A \beta_{x-42}$ and exports various forms of the peptide out of the cell (Walsh et al., 2005). Meli and colleagues are now investigating, using in vivo experiments, the targeting of the scFvA13 intrabody to the hippocampus of AD mouse models (Alzforum.org).

\subsection{Crystallization of NT4X Fab and Target Peptide}

\subsubsection{Generation of Fab fragment}

In order to study the antibody: antigen binding properties of the NT4X antibody, the Fab fragment of the antibody had to be generated and ensured to be functional. Antibody subclasses exhibit diverse physical properties and show a substantial difference in their susceptibility to cleavage sites. Experimental parameters must be examined and adjusted for each individual subclass to ensure a complete digestion and more importantly a homogenous one. Antibody fragments have been routinely obtained by papain digestion. It has been suggested that the monitoring of antibody papain digestion by electrospray ionization mass spectrometry is of benefit (Bennett et al., 1997). Initial results from antibody digestion with papain resulted in a heterogeneous mix of Fab subtypes and that of over digested products (Fig 3.5). The separation of resulting fragments was not possible via size exclusion chromatography nor through ion exchange chromatography (Fig 3.6).

Although it was believed that the digestion of antibody fragments using pre-activated papain will result in the generation of $\mathrm{F}\left(\mathrm{ab}^{\prime}\right) 2$ fragment $(100 \mathrm{kDa})$, it was later suggested that a closer monitoring of digestion conditions with regard to antibody subtype can result in a homogenous digestion resulting in an Fab fragment using pre-activated papain (Adamczyk et al., 2000). Our results are in agreement with this, as digestion with pre-activated papain resulted in 
a homogenous digestion of the NT4X antibody, resulting in a more pure Fab fragment (Fig 3.8).

\subsubsection{Fab functional in vitro and in vivo}

In order to ensure the Fab fragment of the NT4X antibody has the same binding and functional properties as its full-length counterpart, our collaborators in Synaging have performed in vitro and in vivo toxicity rescue assays. The in vitro cellular toxicity assay using the Fab fragment, demonstrates the capability of the Fab fragment to bind and rescue the toxicity caused by $A \beta_{4-42}$ in a dose dependent manner (Fig 3.21). On the other hand, an in vivo assay has demonstrated the Fab's ability to rescue an $A \beta_{4-42}$ induced working memory deficit in WT mice, as tested by a Y-maze alteration assay (Fig 3.21b).The experiments demonstrate that the NT4X Fab is functional and exhibits similar binding capabilities as the full-length antibody. We have also used the Fab in passive immunization of the Tg4-42 mice where it has demonstrated an ability to bind its target in an AD mouse model and rescue both neuronal loss and spatial reference memory deficits (Antonios et al., 2015).

\subsubsection{Crystallization conditions}

To examine the structural basis of NT4X binding to $A \beta$, we endeavored to isolate the NT4X as a Fab fragment in complex to the Ntruncated $A \beta_{4-19}$ peptide and went further to crystallize the complex. Initial screening for crystallization conditions tackled both matters of appropriate conditions and that of protein concentration (Chayen $\&$ Saridakis, 2008). Initial crystals obtained were of the unconjugated Fab fragment of the NT4X (Fig 3.12) and SDS-PAGE followed by silver staining confirmed that crystals observed were of respective size corresponding to a Fab fragment (Fig 3.13). 
We next pursued the crystallization of the Fab: $A \beta_{4-x}$ peptides complex. Several $A \beta C$-terminal lengths were tested, including: $A \beta_{4-10}$, $A \beta_{4-19}$ and $A \beta_{4-22}$. Crystallization was successful using the Fab: $A \beta_{4-19}$ complex. The corresponding peptide sequence of $A \beta_{4-19}$ is the following:

$\mathrm{Phe}^{4}$ - Arg - His - Asp - Ser - Gly - Tyr - Glu - Val - His His - Gln - Lys - Leu - Val - Phe ${ }^{19}$

Initial crystals of the Fab: $A \beta_{4-19}$ complex grew in PEG 2000 MME. Though some were amorphous in shape (Fig 3.14b,c), others were overlapping crystals (Fig 3.14a) of a distinct nature that were used to develop screening grids in conjunction with seeding. Seeding in crystallization, is used to bypass excess nucleation. By introducing ready-made nuclei directly into the metastable zone, the presence of a limited number of nuclei may ensure growth into larger single crystals (Bergfors, 2003; Chayen, 2003.) Our results demonstrate the previous by (Fig 3.15 and Fig 3.16). We also report an improvement in the diffraction potential of crystals, where successive rounds of seeding have improved the diffraction resolution limit from $9 \AA \hat{A}$ (Fig 3.15a) and $5 \AA$ (Fig $3.15 b$ ) to $2.8 \AA \AA$ (Fig 3.16b). It is worth noting that all crystals from respective seeding rounds grew in very similar conditions consisting of PEG $(3000,6000$ or 8000$)$ as precipitant and $(0.1 \mathrm{M}, \mathrm{pH}$ $=4.6$ ) sodium acetate trihydrate.

The crystallization conditions of the NT4X Fab: A $\beta_{4-19}$ complex, is very comparable to previously published data. Crystals of the WO2 antibody, the first anti-A $\beta$ antibody to be crystallized complexed with $\mathrm{A} \beta$, was crystallized in 25\% PEG 400, $100 \mathrm{mM}$ MES pH 6.5 (Wun et al., 2008). Later on, Bapineuzumab, the first anti-A $\beta$ antibody to go into $\mathrm{AD}$ passive immunotherapy, was crystallized in complex with $\mathrm{A} \beta 1-28$ in 20\% PEG 3350, 0.2 M sodium formate (Crespi et al., 2014). 


\subsubsection{Crystallization of clinically relevant antibodies}

It is the future objective of this work, to determine the molecular basis of the $A \beta$ recognition of NT4X. In context of clinical relevance, this will allow the development and humanization of the NT4X in a way which enhances its binding to its target. A report has previously demonstrated the conservation of antigen contact residues and conformation of antigen recognized between the 3D6 antibody and its humanized counterpart Bapineuzumab (Feinberg et al., 2014). It has been previously demonstrated that the introduction of mutations to an antibody, following information gathered from its crystallographic analysis, induced a 500 fold improvement in affinity for a helical peptide ligand. The mutated residues did not actually interact with the ligand directly, it was rather through subtle changes in the framework surrounding the binding sites (Zahnd et al., 2004). Moreover, the crystal structure of a Bapineuzumab Fab-A $\beta$ peptide complex revealed that it captured $A \beta$ in a monomeric helical conformation at the $N$ terminus (Miles et al., 2013). Furthermore, the mobilization of toxic A $\beta$ species from inert plaque material, might partially explain the failure of Bapineuzumab in clinical trials (Salloway et al., 2014).

A recent study suggested that amino acids that interacted with $\mathrm{A} \beta$ in both the Solanezumab and Crenezumab antibodies had nearly the same sequence, suggesting they bind $A \beta$ in the same way (Crespi et al., 2015), although reports had other suggested that they recognize different forms of $A \beta$ (Table 4.1). 
Table 4.1. Conformational binding properties of some clinically relevant $A \beta$ antibodies.

\begin{tabular}{|c|c|c|c|c|c|c|}
\hline \multirow[t]{2}{*}{ Antibody } & \multirow[t]{2}{*}{ Epitope } & \multirow{2}{*}{$\begin{array}{l}\text { Epitope } \\
\text { Structure }\end{array}$} & \multicolumn{3}{|c|}{ Conformations Recognized } & \multirow[t]{2}{*}{ Aria-E } \\
\hline & & & Monomer & Oligomer & Fibril & \\
\hline Solanezumab* & AA $16-26$ & Helix - $\beta$ coil & Yes & Unknown & Unknown & Low \\
\hline Crenezumab* & AA $16-26$ & Helix - $\beta$ coil & Yes & Yes & Yes & Low \\
\hline Bapineuzumab* & AA $1-7$ & Helix & Yes & Unknown & Yes & High \\
\hline Gantenerumab* & AA $1-11$ & Linear & Unknown & Yes & Yes & Low \\
\hline Aducanumab* & AA 3-6 & Linear & No & Unknown & Yes & High \\
\hline
\end{tabular}

Adolfsson and colleagues have reported that, unlike Solanezumab, Crenezumab binds aggregated forms of $A \beta$ (Adolfsson et al., 2012). On the other hand, we have recently shown that, both antibodies showed a very similar staining profile in formalin-fixed and paraffin-embedded tissue and fresh frozen tissue and were able to detect plaques and $\mathrm{CAA}$ in humans in addition to plaques and intraneuronal $A \beta$ in mice (Bouter et al., 2015). This goes to show the importance of structural studies of antibody-A $\beta$ recognition, as IHC, though an important basis for diagnostic pathology, might not reflect antibody efficacy or action in vivo.

Issues with antibody-target engagement in terms of affinity, species and conformation of $A \beta$ bound may be dealt with before going to a clinical setting, with the help of information arising from the crystal structure of the NT4X Fab: $A \beta_{4-x}$ complex. 


\section{CHAPTER 5}

\section{Summary \& Conclusions}

The NT4X antibody has been raised against the human $A \beta_{4-40}$ peptide. We present here its characterization data as an antibody which recognizes both $A \beta_{4-x}$ and $A \beta_{p E 3-x} N$-truncated peptides in reducing and native conditions in PAGE where the NT4X is used as a primary antibody. Further analysis demonstrates that the phenylalanine at positon 4 of $A \beta$ is essential for binding its target. Having previously shown that the $A \beta_{4-42}$ peptide is toxic in vitro and in vivo, we now demonstrate that the NT4X antibody is able to rescue the peptide's toxicity

In this study, we have endeavored to present a new target for $A \beta$ passive immunotherapy. In an $\mathrm{AD}$ mouse model, the Tg4-42, $\mathrm{A} \beta_{4-42}$ expression leads to a progressive neuronal loss in the CA1 region. This is accompanied by a gradual loss of spatial reference memory from moderate ( 5 months) to severe at 6 months of age, in the homozygous line. This short timeframe allowed us to perform a preventative therapeutic passive immunization trials do commence before neuronal loss and reference memory deficits begin and to stop when they are severe. NT4X and its Fab fragment demonstrated a significant mitigation of neuron loss and rescue of spatial reference memory deficits in this treatment paradigm. In this regards, we also present neuronal loss in the Tg4-42 model as an alternative, more relevant, measurable clinical outcome.

In light of failures in translation from pre-clinical studies to the clinic, our work has strived to present a wholesome picture of the therapeutic tool being used in complex to its target. We have been successful in co-crystallizing the NT4X Fab and the $A \beta_{4-19}$ peptide. Our collaborators at the Macromolecular crystallography group (Max Planck for Biophysical Chemistry) are currently working on solving the crystal structure of the NT4X Fab:A $\beta_{4-19}$ complex. Subsequent information may 
be used to support the humanization process of the NT4X currently underway at MRC Technology. 


\section{CHAPTER 6}

\section{Bibliography}

Adamczyk, M., Gebler, J. C., \& Wu, J. (2000). Papain digestion of different mouse IgG subclasses as studied by electrospray mass spectrometry. Journal of Immunological Methods, 237(1-2), 95-104. http://doi.org/ 10.1016/S0022-1759(00)00135-6

Adolfsson, O., Pihlgren, M., Toni, N., Varisco, Y., Buccarello, A. L., Antoniello, K., Lohmann, S., Piorkowska, K., Gafner, V., Atwal, J K., Maloney, J., Chen, M., Gogineni, A., Weimer, R M., Mortensen, D L., Friesenhahn, M., Ho, C., Paul, R., Pfeifer, A., Muhs, A., \& Watts, R. J. (2012). An effector-reduced anti- $\beta$-amyloid $(A \beta)$ antibody with unique $A \beta$ binding properties promotes neuroprotection and glial engulfment of $A \beta$. The Journal of Neuroscience, 32(28), 9677-89. http://doi.org/10.1523/ JNEUROSCI.4742-11.2012

Alafuzoff, I., Pikkarainen, M., Arzberger, T., Thal, D. R., Al-Sarraj, S., Bell, J., Bodi, Istvan., Budka, H., Capetillo-Zarate, E., Ferrer, I., Gelpi, E., Gentleman, S., Giaccone, G., Kavantzas, N., King, A., Korkolopoulou, P., Kovács, G., Meyronet, D., Monoranu, C., Parchi, P., Patsouris, E., Roggendorf, W., Stadelmann, C., Streichenberger, N., Tagliavini, F., \& Kretzschmar, H. (2008). Inter-laboratory comparison of neuropathological assessments of beta-amyloid protein: a study of the BrainNet Europe consortium. Acta Neuropathologica, 115(5), 533-46. http:/ / doi.org/10.1007/s00401-008-0358-2

Alonso, A., Zaidi, T., Novak, M., Grundke-Iqbal, I., \& Iqbal, K. (2001). Hyperphosphorylation induces self-assembly of tau into tangles of paired helical filaments/straight filaments. Proceedings of the National Academy of Sciences of the United States of America, 98(12), 6923-8. http:/ / doi.org / 10.1073/pnas.121119298

Anderson, J. P., Esch, F. S., Keim, P. S., Sambamurti, K., Lieberburg, I., \& Robakis, N. K. (1991). Exact cleavage site of Alzheimer amyloid precursor in neuronal PC-12 cells. Neuroscience Letters, 128(1), 126-8. 
Antonios, G., Borgers, H., Richard, B. C., Brauß, A., Meißner, J., Weggen, S., Pena, V., Pillot, T., Davies, S L., Bakrania, P., Matthews, D., Brownlees, J., Bouter, Y., \& Bayer, T. A. (2015). Alzheimer therapy with an antibody against N-terminal Abeta 4-X and pyroglutamate Abeta 3-X. Scientific Reports, 5, 17338. http://doi.org/10.1038/srep17338

Antonios, G., Saiepour, N., Bouter, Y., Richard, B. C., Paetau, A., Verkkoniemi-Ahola, A., Lannfelt, L., Ingelsson, M., Kovacs, G., Pillot, T., Wirths, O., \& Bayer, T. A. (2013). N-truncated Abeta starting with position four: early intraneuronal accumulation and rescue of toxicity using NT4X-167, a novel monoclonal antibody. Acta Neuropathologica Communications, 1(1), 56. http://doi.org/10.1186/ 2051-5960-1-56

Bacskai, B. J., Kajdasz, S. T., McLellan, M. E., Games, D., Seubert, P., Schenk, D., \& Hyman, B. T. (2002). Non-Fc-mediated mechanisms are involved in clearance of amyloid-beta in vivo by immunotherapy. The Journal of Neuroscience., 22(18), 7873-8.

Bard, F., Barbour, R., Cannon, C., Carretto, R., Fox, M., Games, D., ... Yednock, T. (2003). Epitope and isotype specificities of antibodies to beta -amyloid peptide for protection against Alzheimer's disease-like neuropathology. Proceedings of the National Academy of Sciences of the United States of America, 100(4), 2023-8.

Bard, F., Cannon, C., Barbour, R., Burke, R. L., Games, D., Grajeda, H., ... Yednock, T. (2000). Peripherally administered antibodies against amyloid beta-peptide enter the central nervous system and reduce pathology in a mouse model of Alzheimer disease. Nature Medicine, 6(8), 916-9.

Bayer, T. A., \& Wirths, O. (2010). Intracellular accumulation of amyloid-Beta - a predictor for synaptic dysfunction and neuron loss in Alzheimer's disease. Frontiers in Aging Neuroscience, 2, 8.

Bayer, T. A., \& Wirths, O. (2014). Focusing the amyloid cascade hypothesis on N-truncated Abeta peptides as drug targets against Alzheimer's disease. Acta Neuropathologica, 127(6), 787-801. http://doi.org/ $10.1007 / \mathrm{s} 00401-014-1287-\mathrm{x}$ 
Behl, C., Davis, J. B., Lesley, R., \& Schubert, D. (1994). Hydrogen peroxide mediates amyloid beta protein toxicity. Cell, 77(6), 817-27.

Benilova, I., Karran, E., \& De Strooper, B. (2012). The toxic A $\beta$ oligomer and Alzheimer's disease: an emperor in need of clothes. Nature Neuroscience, 15(3), 349-57. http://doi.org/10.1038/nn.3028

Bennett, K. L., Smith, S. V, Truscott, R. J., \& Sheil, M. M. (1997). Monitoring papain digestion of a monoclonal antibody by electrospray ionization mass spectrometry. Analytical Biochemistry, 245(1), 17-27. http:/ / doi.org/ 10.1006/abio.1996.9904

Berchtold, N. C., \& Cotman, C. W. (1998). Evolution in the Conceptualization of Dementia and Alzheimer's Disease: Greco-Roman Period to the 1960s. Neurobiology of Aging, 19(3), 173-89. http://doi.org/10.1016/S01974580(98)00052-9

Bergfors, T. (2003). Seeds to crystals. Journal of Structural Biology, 142(1), 66-76.

Bertram, L., Lill, C. M., \& Tanzi, R. E. (2010). The genetics of Alzheimer disease: back to the future. Neuron, 68(2), 270-81.

Bien, J., Jefferson, T., Causević, M., Jumpertz, T., Munter, L., Multhaup, G., Weggen, S., Becker-Pauly, C., \& Pietrzik, C. U. (2012). The metalloprotease meprin $\beta$ generates amino terminal-truncated amyloid $\beta$ peptide species. The Journal of Biological Chemistry, 287(40), 33304-13. http://doi.org/10.1074/ jbc.M112.395608

Birks, J., \& Harvey, R. J. (2006). Donepezil for dementia due to Alzheimer's disease. The Cochrane Database of Systematic Reviews, (1), CD001190. http:/ / doi.org/ 10.1002/14651858.CD001190.pub2

Blennow, K., de Leon, M. J., \& Zetterberg, H. (2006). Alzheimer's disease. Lancet, 368(9533), 387-403. http://doi.org/10.1016/S01406736(06)69113-7

Bohrmann, B., Baumann, K., Benz, J., Gerber, F., Huber, W., Knoflach, F., ... Loetscher, H. (2012). Gantenerumab: a novel human anti-A $\beta$ antibody demonstrates sustained cerebral amyloid- $\beta$ binding and elicits cell-mediated removal of human amyloid- $\beta$. Journal of Alzheimer's Disease : JAD, 28(1), 49-69. http://doi.org/10.3233/JAD-2011-110977 
Bonin-Guillaume, S., Zekry, D., Giacobini, E., Gold, G., \& Michel, J.-P. (2005). Impact économique de la démence. La Presse Médicale, 34(1), 35-41. http://doi.org/10.1016/S0755-4982(05)83882-5

Bottino, C. M. C., Castro, C. C., Gomes, R. L. E., Buchpiguel, C. A., Marchetti, R. L., \& Neto, M. R. L. (2002). Volumetric MRI measurements can differentiate Alzheimer's disease, mild cognitive impairment, and normal aging. International Psychogeriatrics / IPA, 14(1), 59-72.

Bouter, Y., Noguerola, J. S. L., Tucholla, P., Crespi, G. A. N., Parker, M. W., Wiltfang, J., Miles, L A., \& Bayer, T. A. (2015). Abeta targets of the biosimilar antibodies of Bapineuzumab, Crenezumab, Solanezumab in comparison to an antibody against $\mathrm{N}$-truncated Abeta in sporadic Alzheimer disease cases and mouse models. Acta Neuropathologica. http://doi.org/ 10.1007/s00401-015-1489-x

Bouter, Y., Dietrich, K., Wittnam, J. L., Rezaei-Ghaleh, N., Pillot, T., PapotCouturier, S., Lefebvre, T., Sprenger, F., Wirths, O., Zweckstetter, M., \% \& Bayer, T. A. (2013). N-truncated amyloid $\beta$ (Aß) 4-42 forms stable aggregates and induces acute and long-lasting behavioral deficits. Acta Neuropathologica, 126(2), 189-205. http://doi.org/ 10.1007/s00401013-1129-2

Braak, H., \& Braak, E. (1991). Neuropathological stageing of Alzheimerrelated changes. Acta Neuropathologica., 82(4), 239-59.

Britschgi, M., Olin, C. E., Johns, H. T., Takeda-Uchimura, Y., LeMieux, M. C., Rufibach, K., Rajadas, J., Zhang, H., Tomooka, B., Robinson, W H., Clark, C M., Fagan, A M., Galasko, D R., Holtzman, D M., Jutel, M., Kaye, J A., Lemere, C A., Leszek, J., Li, G., Peskind, E R., Quinn, J F., Yesavage, J A., Ghiso, J A., \& Wyss-Coray, T. (2009). Neuroprotective natural antibodies to assemblies of amyloidogenic peptides decrease with normal aging and advancing Alzheimer's disease. Proceedings of the National Academy of Sciences of the United States of America, 106(29), 12145-50. http://doi.org/10.1073/pnas.0904866106

Broadbent, N. J., Squire, L. R., \& Clark, R. E. (2004). Spatial memory, recognition memory, and the hippocampus. Proceedings of the National Academy of Sciences of the United States of America, 101(40), 14515-20. http:/ / doi.org/ 10.1073/pnas.0406344101 
Brookmeyer, R., Johnson, E., Ziegler-Graham, K., \& Arrighi, H. M. (2007). Forecasting the global burden of Alzheimer's disease. Alzheimer's \& Dementia, 3(3), 186-91. http://doi.org/10.1016/j.jalz.2007.04.381

Bullock, R., Touchon, J., Bergman, H., Gambina, G., He, Y., Rapatz, G., ... Lane, R. (2005). Rivastigmine and donepezil treatment in moderate to moderately-severe Alzheimer's disease over a 2-year period. Current Medical Research and Opinion, 21(8), 1317-27.

Bussiere, T., Bard, F., Barbour, R., Grajeda, H., Guido, T., Khan, K., ... Buttini, M. (2004). Morphological characterization of Thioflavin-Spositive amyloid plaques in transgenic Alzheimer mice and effect of passive Abeta immunotherapy on their clearance. The American Journal of Pathology, 165(3), 987-95.

Casas, C., Sergeant, N., Itier, J. M., Blanchard, V., Wirths, O., van der Kolk, N., Vingtdeux, V., van de Steeg, E., Ret, G., Canton, T., Drobecq, H., Clark, A., Bonici, B., Delacourte, A., Benavides, J., Schmitz, C., Tremp, G., Bayer, T A., Benoit, P., \& Pradier, L. (2004). Massive CA1/2 neuronal loss with intraneuronal and N-terminal truncated Abeta42 accumulation in a novel Alzheimer transgenic model. The American Journal of Pathology, 165(4), 1289-300.

Chapman, P. F., White, G. L., Jones, M. W., Cooper-Blacketer, D., Marshall, V. J., Irizarry, M., Younkin, L., Good, M A., Bliss, T V., Hyman, B T., Younkin, S G., \& Hsiao, K. K. (1999). Impaired synaptic plasticity and learning in aged amyloid precursor protein transgenic mice. Nature Neuroscience, 2(3), 271-6.

Chayen, N. E. (2003). Protein crystallization for genomics: throughput versus output. Journal of Structural and Functional Genomics, 4(2-3), 115-20. http://doi.org/10.1023/A:1026174727482

Chayen, N. E., \& Saridakis, E. (2008). Protein crystallization: from purified protein to diffraction-quality crystal. Nature Methods, 5(2), 147-53. http://doi.org/10.1038/nmeth.f.203

Chen, S. Y., Bagley, J., \& Marasco, W. A. (1994). Intracellular antibodies as a new class of therapeutic molecules for gene therapy. Human Gene Therapy, 5(5), 595-601. http://doi.org/10.1089/hum.1994.5.5-595 
Citron, M. (2010). Alzheimer's disease: strategies for disease modification. Nature Reviews. Drug Discovery, 9(5), 387-98. http://doi.org/ $10.1038 / \operatorname{nrd} 2896$

Citron, M., Teplow, D. B., \& Selkoe, D. J. (1995). Generation of amyloid beta protein from its precursor is sequence specific. Neuron, 14(3), 661-70.

Corder, E. H., Saunders, A. M., Strittmatter, W. J., Schmechel, D. E., Gaskell, P. C., Small, G. W., Roses, A D., Haines, J., \& LPericak-Vance, M. A. (1993). Gene dose of apolipoprotein E type 4 allele and the risk of Alzheimer's disease in late onset families. Science (New York, N.Y.), 261(5123), 921-3.

Crespi, G. A. N., Ascher, D. B., Parker, M. W., \& Miles, L. A. (2014). Crystallization and preliminary X-ray diffraction analysis of the Fab portion of the Alzheimer's disease immunotherapy candidate bapineuzumab complexed with amyloid- $\beta$. Acta Crystallographica Section F Structural Biology Communications, 70(3), 374-77. http://doi.org/ 10.1107/S2053230X14001642

Crespi, G. A. N., Hermans, S. J., Parker, M. W., \& Miles, L. A. (2015). Molecular basis for mid-region amyloid- $\beta$ capture by leading Alzheimer's disease immunotherapies. Scientific Reports, 5, 9649. http:// doi.org/10.1038/ srep09649

Das, P., Howard, V., Loosbrock, N., Dickson, D., Murphy, M. P., \& Golde, T. E. (2003). Amyloid-beta immunization effectively reduces amyloid deposition in FcRgamma-/- knock-out mice. The Journal of Neuroscience, 23(24), 8532-8.

De Strooper, B., Vassar, R., \& Golde, T. (2010). The secretases: enzymes with therapeutic potential in Alzheimer disease. Nature Reviews. Neurology, 6(2), 99-107. http://doi.org/10.1038/nrneurol.2009.218

DeMattos, R. B., Lu, J., Tang, Y., Racke, M. M., Delong, C. A., Tzaferis, J. A., ... Hutton, M. L. (2012). A plaque-specific antibody clears existing betaamyloid plaques in Alzheimer's disease mice. Neuron, 76(5), 908-20.

De-Paula, V. J., Radanovic, M., Diniz, B. S., \& Forlenza, O. V. (2012). Alzheimer's disease. Subcellular Biochemistry, 65, 329-52. 
Dickson, D. W. (1997). The pathogenesis of senile plaques. Journal of Neuropathology and Experimental Neurology, 56(4), 321-39.

Dodart, J.-C., Bales, K. R., Gannon, K. S., Greene, S. J., DeMattos, R. B., Mathis, C., Hole, J T., Forster, B M., McDonnell, P C., Liu, F., Kinley, R D., Jordan, W H., \& Paul, S. M. (2002). Immunization reverses memory deficits without reducing brain Abeta burden in Alzheimer's disease model. Nature Neuroscience, 5(5), 452-7. http: //doi.org/10.1038/nn842

Duce, J. A., Tsatsanis, A., Cater, M. A., James, S. A., Robb, E., Wikhe, K., ... Bush, A. I. (2010). Iron-export ferroxidase activity of $\beta$-amyloid precursor protein is inhibited by zinc in Alzheimer's disease. Cell, 142(6), 857-67. http://doi.org/10.1016/j.cell.2010.08.014

Duyckaerts, C., Delatour, B., \& Potier, M. C. (2009). Classification and basic pathology of Alzheimer disease. Acta Neuropathologica, 118(1), 5-36.

Duyckaerts, C., Potier, M. C., \& Delatour, B. (2008). Alzheimer disease models and human neuropathology: similarities and differences. Acta Neuropathologica, 115(1), 5-38.

Edmundson, A., Shan, L., Fan, Z., Guddat, L., Hanson, B., \& Andersen, K. (1996). Crystallographic Analysis of Antigen-Antibody Complexes: Endon Insertion of Ligands in Antibodies-CDR3 Loops as Arbiters. Methods, 9(3), 542-58.

EFSA. (2008). Safety of aluminium from dietary intake[1] - Scientific Opinion of the Panel on Food Additives, Flavourings, Processing Aids and Food Contact Materials (AFC) | European Food Safety Authority.

Feinberg, H., Saldanha, J. W., Diep, L., Goel, A., Widom, A., Veldman, G. M., Weis, W I., Schenk, D., \& Basi, G. S. (2014b). Crystal structure reveals conservation of amyloid- $\beta$ conformation recognized by 3D6 following humanization to bapineuzumab. Alzheimer's Research \& Therapy, 6(3), 31. http://doi.org/10.1186/alzrt261

Ferini-Strambi, L., Smirne, S., Garancini, P., Pinto, P., \& Franceschi, M. (1990). Clinical and Epidemiological Aspects of Alzheimer's Disease with Presenile Onset: A Case Control Study. Neuroepidemiology, 9(1), 39-49. http://doi.org/10.1159/000110750 
Ferrer, I., Boada Rovira, M., Sanchez Guerra, M. L., Rey, M. J., \& CostaJussa, F. (2004). Neuropathology and pathogenesis of encephalitis following amyloid-beta immunization in Alzheimer's disease. Brain Pathology, 14(1), 11-20.

Fiandaca, M. S., Mapstone, M. E., Cheema, A. K., \& Federoff, H. J. (2014). The critical need for defining preclinical biomarkers in Alzheimer's disease. Alzheimers and Dementia, 10(3 Suppl), 196-212.

Frost, J. L., Le, K. X., Cynis, H., Ekpo, E., Kleinschmidt, M., Palmour, R. M., Ervin, F R., Snigdha, S., Cotman, C W., Saido, T C., Vassar, R J., St George-Hyslop, P., Ikezu, T., Schilling, S., Demuth, H U., \& Lemere, C. A. (2013). Pyroglutamate-3 amyloid-beta deposition in the brains of humans, non-human primates, canines, and Alzheimer disease-like transgenic mouse models. American Journal of Pathology, 183(2), 36981.

Frost, J. L., Liu, B., Kleinschmidt, M., Schilling, S., Demuth, H. U., \& Lemere, C. A. (2012). Passive immunization against pyroglutamate-3 amyloid-beta reduces plaque burden in Alzheimer-like transgenic mice: a pilot study. Neurodegenerative Diseases, 10(1-4), 265-70.

Fryer, J. D., Taylor, J. W., DeMattos, R. B., Bales, K. R., Paul, S. M., Parsadanian, M., \& Holtzman, D. M. (2003). Apolipoprotein E markedly facilitates age-dependent cerebral amyloid angiopathy and spontaneous hemorrhage in amyloid precursor protein transgenic mice. The Journal of Neuroscience, 23(21), 7889-96.

Games, D., Adams, D., Alessandrini, R., Barbour, R., Berthelette, P., Blackwell, C., Carr, T., Clemens, J., Donaldson, T., \& Gillespie, F. (1995). Alzheimer-type neuropathology in transgenic mice overexpressing V717F beta-amyloid precursor protein. Nature, 373(6514), 523-7.

Ghersi-Egea, J. F., Gorevic, P. D., Ghiso, J., Frangione, B., Patlak, C. S., \& Fenstermacher, J. D. (1996). Fate of cerebrospinal fluid-borne amyloid beta-peptide: rapid clearance into blood and appreciable accumulation by cerebral arteries. Journal of Neurochemistry, 67(2), 880-83. 
Gilman, S., Koller, M., Black, R. S., Jenkins, L., Griffith, S. G., Fox, N. C., ... Orgogozo, J.-M. (2005). Clinical effects of Abeta immunization (AN1792) in patients with AD in an interrupted trial. Neurology, 64(9), 1553-62. http://doi.org/10.1212/01.WNL.0000159740.16984.3C

Gomez-Isla, T., Hollister, R., West, H., Mui, S., Growdon, J. H., Petersen, R. C., Parisi, J E., \& Hyman, B. T. (1997). Neuronal loss correlates with but exceeds neurofibrillary tangles in Alzheimer's disease. Annals of Neurology, 41(1), 17-24.

Gomez-Isla, T., Price, J. L., McKeel, D. W., Morris, J. C., Growdon, J. H., \& Hyman, B. T. (1996a). Profound loss of layer II entorhinal cortex neurons occurs in very mild Alzheimer's disease. The Journal of Neuroscience, 16(14), 4491-500.

Gomez-Isla, T., West, H. L., Rebeck, G. W., Harr, S. D., Growdon, J. H., Locascio, J. J., Perls, T T., Lipsitz, L A., \& Hyman, B. T. (1996b). Clinical and pathological correlates of apolipoprotein E epsilon 4 in Alzheimer's disease. Annals of Neurology, 39(1), 62-70. http://doi.org/10.1002/ana.410390110

Gouras, G. K., Tsai, J., Naslund, J., Vincent, B., Edgar, M., Checler, F., Greenfield, J P., Haroutunian, V., Buxbaum, J D., Xu, H., Greengard, P., \& Relkin, N. R. (2000). Intraneuronal Abeta42 accumulation in human brain. American Journal of Pathology, 156(1), 15-20.

Grundke-Iqbal, I., Iqbal, K., Tung, Y. C., Quinlan, M., Wisniewski, H. M., \& Binder, L. I. (1986). Abnormal phosphorylation of the microtubuleassociated protein tau (tau) in Alzheimer cytoskeletal pathology. Proceedings of the National Academy of Sciences of the United States of America, 83(13), 4913-7.

Gustafson, D. R., Backman, K., Waern, M., Ostling, S., Guo, X., Zandi, P., ... Skoog, I. (2009). Adiposity indicators and dementia over 32 years in Sweden. Neurology, 73(19), 1559-1566. http://doi.org/10.1212/ WNL.0b013e3181c0d4b6

Guzman, E. A., Bouter, Y., Richard, B. C., Lannfelt, L., Ingelsson, M., Paetau, A. A., Verkkoniemi-Ahola, A., Wirths, O., \& Bayer, T. A. (2014). Abundance of Abeta5-X like immunoreactivity in transgenic 5XFAD, 
APP/PS1KI and 3xTG mice, sporadic and familial Alzheimer's disease. Molecular Neurodegeneration, 9, 13.

Gyure, K. A., Durham, R., Stewart, W. F., Smialek, J. E., \& Troncoso, J. C. (2001). Intraneuronal abeta-amyloid precedes development of amyloid plaques in Down syndrome. Archives of Pathology and Laboratory Medicine, 125(4), 489-92.

Haass, C., Hung, A. Y., Schlossmacher, M. G., Teplow, D. B., \& Selkoe, D. J. (1993). beta-Amyloid peptide and a 3-kDa fragment are derived by distinct cellular mechanisms. The Journal of Biological Chemistry, 268(5), 3021-4.

Haass, C., Koo, E. H., Teplow, D. B., \& Selkoe, D. J. (1994). Polarized secretion of beta-amyloid precursor protein and amyloid beta-peptide in MDCK cells. Proceedings of the National Academy of Sciences of the United States of America, 91(4), 1564-8.

Haass, C., \& Selkoe, D. J. (2007). Soluble protein oligomers in neurodegeneration: lessons from the Alzheimer's amyloid beta-peptide. Nature Reviews Molecular Cell Biology, 8(2), 101-12.

Hardy, J. A., \& Higgins, G. A. (1992). Alzheimer's disease: the amyloid cascade hypothesis. Science, 256(5054), 184-5.

Hartmann, T. (1999). Intracellular biology of Alzheimer's disease amyloid beta peptide. European Archives of Psychiatry and Clinical Neuroscience, 249(6), 291-8.

Hirokawa, N., Funakoshi, T., Sato-Harada, R., \& Kanai, Y. (1996). Selective stabilization of tau in axons and microtubule-associated protein $2 \mathrm{C}$ in cell bodies and dendrites contributes to polarized localization of cytoskeletal proteins in mature neurons. The Journal of Cell Biology, 132(4), 667-79.

Howard, G. C., \& Kaser, M. R. (2013). Making and Using Antibodies: A Practical Handbook, Second Edition. CRC Press.

Howell, S., Nalbantoglu, J., \& Crine, P. (1995). Neutral endopeptidase can hydrolyze beta-amyloid(1-40) but shows no effect on beta-amyloid precursor protein metabolism. Peptides, 16(4), 647-52. 
Hsiao, K., Chapman, P., Nilsen, S., Eckman, C., Harigaya, Y., Younkin, S., ... Cole, G. (1996). Correlative memory deficits, Abeta elevation, and amyloid plaques in transgenic mice. Science, 274(5284), 99-102.

Jan, A., Gokce, O., Luthi-Carter, R., \& Lashuel, H. A. (2008). The ratio of monomeric to aggregated forms of Abeta40 and Abeta42 is an important determinant of amyloid-beta aggregation, fibrillogenesis, and toxicity. The Journal of Biological Chemistry, 283(42), 28176-89.

Janus, C., Pearson, J., McLaurin, J., Mathews, P. M., Jiang, Y., Schmidt, S. D., Chishti, M A., Horne, P., Heslin, D., French, J., Mount, H T., Nixon, R A., Mercken, M., Bergeron, C., Fraser, P E., St George-Hyslop, P., \& Westaway, D. (2000). A beta peptide immunization reduces behavioural impairment and plaques in a model of Alzheimer's disease. Nature, 408(6815), 979-82.

Jarrett, J. T., Berger, E. P., \& Lansbury, P. T. (1993). The carboxy terminus of the beta amyloid protein is critical for the seeding of amyloid formation: implications for the pathogenesis of Alzheimer's disease. Biochemistry, 32(18), 4693-7.

Jawhar, S., Trawicka, A., Jenneckens, C., Bayer, T. A., \& Wirths, O. (2012). Motor deficits, neuron loss, and reduced anxiety coinciding with axonal degeneration and intraneuronal Abeta aggregation in the 5XFAD mouse model of Alzheimer's disease. Neurobiology of Aging, 33(1), 29-40.

Kadowaki, H., Nishitoh, H., Urano, F., Sadamitsu, C., Matsuzawa, A., Takeda, K., Masutani, H., Yodoi, J., Urano, Y., Nagano, T., \& Ichijo, H. (2005). Amyloid beta induces neuronal cell death through ROSmediated ASK1 activation. Cell Death and Differentiation, 12(1), 19-24. http://doi.org/10.1038/sj.cdd.4401528

Kalaria, R. N. (2010). Vascular basis for brain degeneration: faltering controls and risk factors for dementia. Nutrition Reviews, 68 Suppl 2(suppl 2), S74-87. http://doi.org/10.1111/j.1753-4887.2010.00352.x

Kaneko, N., Yamamoto, R., Sato, T. A., \& Tanaka, K. (2014). Identification and quantification of amyloid beta-related peptides in human plasma using matrix-assisted laser desorption/ionization time-of-flight mass spectrometry. Proceedings of the Japan Acaddemy, Ser. B, Physical and 
Biological Sciences, 90(3), 104-17.

Kelly, P. H., Bondolfi, L., Hunziker, D., Schlecht, H. P., Carver, K., Maguire, E., Abramowski, D., Wiederhold, K H., Sturchler-Pierrat, C., Jucker, M., Bergmann, R., Staufenbiel, M., \& Sommer, B. (2003). Progressive agerelated impairment of cognitive behavior in APP23 transgenic mice. Neurobiol. Aging, 24(2), 365-78.

Kidd, M. (1963). Paired Helical Filaments in Electron Microscopy of Alzheimer's Disease. Nature, 197(4863), 192-3. http://doi.org/ $10.1038 / 197192 \mathrm{b0}$

Kobayashi, D. T., \& Chen, K. S. (2005). Behavioral phenotypes of amyloidbased genetically modified mouse models of Alzheimer's disease. Genes, Brain, and Behavior, 4(3), 173-96. http://doi.org/10.1111/j.1601183X.2005.00124.x

Kril, J. J., Hodges, J., \& Halliday, G. (2004). Relationship between hippocampal volume and CA1 neuron loss in brains of humans with and without Alzheimer's disease. Neuroscience Letters, 361(1-3), 9-12.

Kuo, Y. M., Emmerling, M. R., Bisgaier, C. L., Essenburg, A. D., Lampert, H. C., Drumm, D., \& Roher, A. E. (1998). Elevated low-density lipoprotein in Alzheimer's disease correlates with brain abeta 1-42 levels. Biochemical and Biophysical Research Communications, 252(3), 711-5. http:/ / doi.org/ 10.1006/bbrc. 1998.9652

Kuusisto, J., Koivisto, K., Kervinen, K., Mykkanen, L., Helkala, E.-L., Vanhanen, M., Vanhanen, M., Hanninen, T., Pyorala, K., Kesaniemi, Y A., Riekkinen, P., \& Laasko, M. (1994). Association of apolipoprotein E phenotypes with late onset Alzheimer's disease: population based study. British Medical Journal, 309(6955), 636-8. http://doi.org/10.1136/ bmj.309.6955.636

La Porte, S. L., Bollini, S. S., Lanz, T. a., Abdiche, Y. N., Rusnak, A. S., Ho, W. H., ... Pons, J. (2012). Structural basis of C-terminal $\beta$-amyloid peptide binding by the antibody ponezumab for the treatment of Alzheimer's disease. Journal of Molecular Biology, 421(4-5), 525-36. http:/ / doi.org/10.1016/j.jmb.2011.11.047 
Lambert, J. C., Ibrahim-Verbaas, C. A., Harold, D., Naj, A. C., Sims, R., Bellenguez, C., ... Amouyel, P. (2013). Meta-analysis of 74,046 individuals identifies 11 new susceptibility loci for Alzheimer's disease. Nature Genetics, 45(12), 1452-8. http://doi.org/10.1038/ng.2802

Lannfelt, L., Relkin, N. R., \& Siemers, E. R. (2014). Amyloid- $\beta$-directed immunotherapy for Alzheimer's disease. Journal of Internal Medicine, 275(3), 284-95.

Lee, A. Y. (2011). Vascular dementia. Chonnam Medical Journal, 47(2), 6671. http:/ / doi.org/10.4068/cmj.2011.47.2.66

Lee, V. M., Balin, B. J., Otvos, L., \& Trojanowski, J. Q. (1991). A68: a major subunit of paired helical filaments and derivatized forms of normal Tau. Science, 251(4994), 675-8.

Leibson, C. L., Rocca, W. A., Ganson, V. A., Cha, R., Kokmen, R., O’brien, P. C., \& Palumbo, P. J. (1997). The Risk of Dementia among Persons with Diabetes Mellitus: A Population-Based Cohort Study. Annals of the New York Academy of Sciences, 826 (1 Cerebrovascul), 422-7. http://doi.org/10.1111/j.1749-6632.1997.tb48496.x

Leissring, M. A., Lu, A., Condron, M. M., Teplow, D. B., Stein, R. L., Farris, W., \& Selkoe, D. J. (2003). Kinetics of amyloid beta-protein degradation determined by novel fluorescence- and fluorescence polarization-based assays. The Journal of Biological Chemistry, 278(39), 37314-20. http:/ / doi.org/10.1074/jbc.M305627200

Lemere, C. A. (2013). Immunotherapy for Alzheimer's disease: hoops and hurdles. Molecular Neurodegeneration, 8(1), 36. http://doi.org/10.1186/ 1750-1326-8-36

Levites, Y., Das, P., Price, R. W., Rochette, M. J., Kostura, L. A., McGowan, E. M., Reed, D K., Rosenberry, T L., Das, P., \& Golde, T. E. (2006). AntiAbeta42- and anti-Abeta40-specific mAbs attenuate amyloid deposition in an Alzheimer disease mouse model. Journal of Clinical Investigation, $116(1), 193-201$.

Lipton, S. A. (2006). Paradigm shift in neuroprotection by NMDA receptor blockade: memantine and beyond. Nature Reviews. Drug Discovery, 5(2), 160-70. http://doi.org/10.1038/nrd1958 
Lopez, O. L., Becker, J. T., Wahed, A. S., Saxton, J., Sweet, R. A., Wolk, D. A., Klunk, W., \& Dekosky, S. T. (2009). Long-term effects of the concomitant use of memantine with cholinesterase inhibition in Alzheimer disease. Journal of Neurology, Neurosurgery, and Psychiatry, 80(6), 600-7. http://doi.org/10.1136/jnnp.2008.158964

Lord, A., Gumucio, A., Englund, H., Sehlin, D., Sundquist, V. S., Soderberg, L., Moller, C., Gellerfors, P., Lannfelt, L., Pettersson, F E., \& Nilsson, L. N. (2009). An amyloid-beta protofibril-selective antibody prevents amyloid formation in a mouse model of Alzheimer's disease. Neurobiol. Dis., 36(3), 425-34.

Luchsinger, J. A. (2001). Diabetes Mellitus and Risk of Alzheimer's Disease and Dementia with Stroke in a Multiethnic Cohort. American Journal of Epidemiology, 154(7), 635-41. http://doi.org/10.1093/aje/154.7.635

Lukiw, W. J., Percy, M. E., \& Kruck, T. P. (2005). Nanomolar aluminum induces pro-inflammatory and pro-apoptotic gene expression in human brain cells in primary culture. Journal of Inorganic Biochemistry, 99(9), 1895-8. http://doi.org/10.1016/j.jinorgbio.2005.04.021

Masliah, E., Sisk, A., Mallory, M., Mucke, L., Schenk, D., \& Games, D. (1996). Comparison of neurodegenerative pathology in transgenic mice overexpressing V717F beta-amyloid precursor protein and Alzheimer's disease. The Journal of Neuroscience, 16(18), 5795-811.

Masters, C. L., Simms, G., Weinman, N. A., Multhaup, G., McDonald, B. L., \& Beyreuther, K. (1985). Amyloid plaque core protein in Alzheimer disease and Down syndrome. Proceedings of the National Academy of Sciences of the United States of America, 82(12), 4245-9.

Mattson, M. P., \& Goodman, Y. (1995). Different amyloidogenic peptides share a similar mechanism of neurotoxicity involving reactive oxygen species and calcium. Brain Research, 676(1), 219-24.

Mayeux, R., Ottman, R., Maestre, G., Ngai, C., Tang, M.-X., Ginsberg, H., ... Shelanski, M. (1995). Synergistic Effects of Traumatic Head Injury and Apolipoprotein-epsilon4 in Patients With Alzheimer's Disease. Neurology, 45(3), 555-7. http://doi.org/10.1212/WNL.45.3.555 
Meli, G., Lecci, A., Manca, A., Krako, N., Albertini, V., Benussi, L., ... Cattaneo, A. (2014). Conformational targeting of intracellular A $\beta$ oligomers demonstrates their pathological oligomerization inside the endoplasmic reticulum. Nature Communications, 5, 3867. http://doi.org/ 10.1038/ncomms4867

Michikawa, M. (2003). Cholesterol paradox: is high total or low HDL cholesterol level a risk for Alzheimer's disease? Journal of Neuroscience Research, 72(2), 141-6. http://doi.org/10.1002/jnr.10585

Miles, L. A., Crespi, G. A. N., Doughty, L., \& Parker, M. W. (2013). Bapineuzumab captures the N-terminus of the Alzheimer's disease amyloid-beta peptide in a helical conformation. Scientific Reports, 3, 1-6. http://doi.org/10.1038/srep01302

Miller, B. R., Dorner, J. L., Shou, M., Sari, Y., Barton, S. J., Sengelaub, D. R., Kennedy, R T., \& Rebec, G. V. (2008). Up-regulation of GLT1 expression increases glutamate uptake and attenuates the Huntington's disease phenotype in the R6/2 mouse. Neuroscience, 153(1), 329-37.

Miravalle, L., Calero, M., Takao, M., Roher, A. E., Ghetti, B., \& Vidal, R. (2005). Amino-terminally truncated Abeta peptide species are the main component of cotton wool plaques. Biochemistry, 44(32), 10810-21.

Morris, R. (1984). Developments of a water-maze procedure for studying spatial learning in the rat. The Journal of Neuroscience Methods, 11(1), 47-60.

Moser, M. B., Moser, E. I., Forrest, E., Andersen, P., \& Morris, R. G. (1995). Spatial learning with a minislab in the dorsal hippocampus. Proceedings of the National Academy of Sciences of the United States of America, 92(21), 9697-701.

Muckle, T., \& Roy, J. (1985). High-density lipoprotein cholesterol in differential diagnosis of senile dementia. The Lancet, 325(8439), 1191-3. http://doi.org/10.1016/S0140-6736(85)92866-1

Nicoll, J. A., Wilkinson, D., Holmes, C., Steart, P., Markham, H., \& Weller, R. O. (2003). Neuropathology of human Alzheimer disease after immunization with amyloid-beta peptide: a case report. Nature Medicine, 9(4), 448-52. 
Norfray, J. F., \& Provenzale, J. M. (2004). Alzheimer's disease: neuropathologic findings and recent advances in imaging. AJR. American Journal of Roentgenology, 182(1), 3-13. http://doi.org/ 10.2214/ajr.182.1.1820003

Oakley, H., Cole, S. L., Logan, S., Maus, E., Shao, P., Craft, J., GuillozetBongaarts, A., Ohno, M., Disterhoft, J., Van Eldik, L., Berry, R., \& Vassar, R. (2006). Intraneuronal beta-amyloid aggregates, neurodegeneration, and neuron loss in transgenic mice with five familial Alzheimer's disease mutations: potential factors in amyloid plaque formation. The Journal of Neuroscience, 26(40), 10129-40.

Pike, C. J., Overman, M. J., \& Cotman, C. W. (1995). Amino-terminal deletions enhance aggregation of beta-amyloid peptides in vitro. The Journal of Biological Chemistry, 270(41), 23895-8.

Pillot, T., Drouet, B., Queillé, S., Labeur, C., Vandekerchkhove, J., Rosseneu, M., Pinçon-Raymond, M., \& Chambaz, J. (1999). The nonfibrillar amyloid beta-peptide induces apoptotic neuronal cell death: involvement of its C-terminal fusogenic domain. Journal of Neurochemistry, 73(4), 1626-34.

Pimplikar, S. W. (2009). Reassessing the amyloid cascade hypothesis of Alzheimer's disease. The International Journal of Biochemistry and Cell Biology, 41(6), 1261-8.

Portelius, E., Zetterberg, H., Dean, R. A., Marcil, A., Bourgeois, P., Nutu, M., Andreasson, U., Siemers, E., Mawuenyega, K G., Sigurdson, W C., May, P C., Paul, S M., Holtzman, D M., Blennow, K., \& Bateman, R. J. (2012). Amyloid-beta(1-15/16) as a marker for beta-secretase inhibition in Alzheimer's disease. Journal of Alzheimers Disease, 31(2), 335-41.

Priller, C., Bauer, T., Mitteregger, G., Krebs, B., Kretzschmar, H. A., \& Herms, J. (2006). Synapse formation and function is modulated by the amyloid precursor protein. The Journal of Neuroscience, 26(27), 721221. http://doi.org/10.1523/JNEUROSCI.1450-06.2006

Rasmusson, D. X., Brandt, J., Martin, D. B., \& Folstein, M. F. (2009). Head injury as a risk factor in Alzheimer's disease. Brain Injury. 
Razay, G. (2005). Obesity in middle age and future risk of dementia: Midlife obesity increases risk of future dementia. BMJ, 331(7514), 455. http://doi.org/10.1136/bmj.331.7514.455

Reitz, C., \& Mayeux, R. (2014). Alzheimer disease: epidemiology, diagnostic criteria, risk factors and biomarkers. Biochemical Pharmacology, 88(4), 640-51. http://doi.org/10.1016/j.bcp.2013.12.024

Richard, B. C., Kurdakova, A., Baches, S., Bayer, T. A., Weggen, S., \& Wirths, O. (2015). Gene Dosage Dependent Aggravation of the Neurological Phenotype in the 5XFAD Mouse Model of Alzheimer's Disease. Journal of Alzheimers Disease, 45(4).

Rijal Upadhaya, A., Scheibe, F., Kosterin, I., Abramowski, D., Gerth, J., Kumar, S., Kumar, S., Liebau, S., Yamaguchi, H., Walter, J., Staufenbiel, M., \& Thal, D. R. (2013). The type of Abeta-related neuronal degeneration differs between amyloid precursor protein (APP23) and amyloid beta-peptide (APP48) transgenic mice. Acta Neuropathologica Communications, 1(1), 77.

Rockenstein, E. M., McConlogue, L., Tan, H., Power, M., Masliah, E., \& Mucke, L. (1995). Levels and alternative splicing of amyloid beta protein precursor (APP) transcripts in brains of APP transgenic mice and humans with Alzheimer's disease. The Journal of Biological Chemistry, 270(47), 28257-67.

Rüfenacht, P., Guntert, A., Bohrmann, B., Ducret, A., \& Dobeli, H. (2005). Quantification of the A beta peptide in Alzheimer's plaques by laser dissection microscopy combined with mass spectrometry. Journal of Mass Spectrometry, 40(2), 193-201.

Rumble, B., Retallack, R., Hilbich, C., Simms, G., Multhaup, G., Martins, R., Hockey, A., Montgomery, P., Beyreuther, K., \& Masters, C. L. (1989). Amyloid A4 protein and its precursor in Down's syndrome and Alzheimer's disease. New England Journal of Medicine, 320(22), 144652.

Russo, C., Violani, E., Salis, S., Venezia, V., Dolcini, V., Damonte, G., Benatti, U., D'Arrigo, C., Patrone, E., Carlo, P., \& Schettini, G. (2002). Pyroglutamate-modified amyloid beta-peptides--AbetaN3(pE)--strongly 
affect cultured neuron and astrocyte survival. Journal of Neurochemistry, 82(6), 1480-9.

Salloway, S., Sperling, R., Fox, N. C., Blennow, K., Klunk, W., Raskind, M., Sabbagh, M., Honig, L S., Porsteinsson, A P., Ferris, S., Reichert, M., Ketter, N., Nejadnik, B., Guenzler, V., Miloslavsky, M., Wang, D., Lu, Y., Lull, J., Tudor, I C., Liu, E., Grundman, M., Yuen, E., Black, R., \& Brashear, H. R. (2014). Two phase 3 trials of bapineuzumab in mild-tomoderate Alzheimer's disease. The New England Journal of Medicine, 370(4), 322-33. http://doi.org/10.1056/NEJMoa1304839

Sasaki, A., Shoji, M., Harigaya, Y., Kawarabayashi, T., Ikeda, M., Naito, M., ... Nakazato, Y. (2002). Amyloid cored plaques in Tg2576 transgenic mice are characterized by giant plaques, slightly activated microglia, and the lack of paired helical filament-typed, dystrophic neurites. Virchows Archiv, 441(4), 358-67.

Schenk, D. (2002). Amyloid-beta immunotherapy for Alzheimer's disease: the end of the beginning. Nature Reviews Neuroscience, 3(10), 824-8.

Schenk, D., Barbour, R., Dunn, W., Gordon, G., Grajeda, H., Guido, T., ... Seubert, P. (1999). Immunization with amyloid-beta attenuates Alzheimer-disease-like pathology in the PDAPP mouse. Nature, 400(6740), 173-7.

Schupf, N., \& Sergievsky, G. H. (2002). Genetic and host factors for dementia in Down's syndrome. The British Journal of Psychiatry, 180, 405-10.

Selkoe, D. J. (1989). Biochemistry of altered brain proteins in Alzheimer's disease. Annual Review of Neuroscience, 12, 463-90. http://doi.org/ 10.1146/annurev.ne.12.030189.002335

Sergeant, N., Bombois, S., Ghestem, A., Drobecq, H., Kostanjevecki, V., Missiaen, C., Wattez, A., David, J P., Vanmechelen, E., Sergheraert, C., $\&$ Delacourte, A. (2003). Truncated beta-amyloid peptide species in preclinical Alzheimer's disease as new targets for the vaccination approach. Journal of Neurochemistry, 85(6), 1581-91.

Shibata, M., Yamada, S., Kumar, S. R., Calero, M., Bading, J., Frangione, B., Holtzman, D M., Miller, C A., Strickland, D K., Ghiso, J., \& Zlokovic, B. 
V. (2000). Clearance of Alzheimer's amyloid-ss(1-40) peptide from brain by LDL receptor-related protein-1 at the blood-brain barrier. Journal of Clinical Investigation, 106(12), 1489-99.

Shih, R. A., Glass, T. A., Bandeen-Roche, K., Carlson, M. C., Bolla, K. I., Todd, A. C., \& Schwartz, B. S. (2006). Environmental lead exposure and cognitive function in community-dwelling older adults. Neurology, 67(9), 1556-62. http://doi.org/10.1212/01.wn1.0000239836.26142.c5

Sisodia, S. S. (1992). Beta-amyloid precursor protein cleavage by a membrane-bound protease. Proceedings of the National Academy of Sciences of the United States of America, 89(13), 6075-9.

Sisodia, S. S., Koo, E. H., Beyreuther, K., Unterbeck, A., \& Price, D. L. (1990). Evidence that beta-amyloid protein in Alzheimer's disease is not derived by normal processing. Science, 248(4954), 492-5.

Small, G. W. (1998). The pathogenesis of Alzheimer's disease. The Journal of Clinical Psychiatry, 59 Suppl 9, 7-14.

Snowdon, D. A. (2003). Healthy aging and dementia: findings from the Nun Study. Annals of Internal Medicine, 139(5 Pt 2), 450-4.

Solomon, B., Koppel, R., Frankel, D., \& Hanan-Aharon, E. (1997). Disaggregation of Alzheimer beta-amyloid by site-directed mAb. Proceedings of the National Academy of Sciences of the United States of America, 94(8), 4109-12.

Sousa, R. M., Ferri, C. P., Acosta, D., Albanese, E., Guerra, M., Huang, Y., ... Prince, M. (2009). Contribution of chronic diseases to disability in elderly people in countries with low and middle incomes: a 10/66 Dementia Research Group population-based survey. Lancet, 374(9704), 1821-30. http: / doi.org/10.1016/S0140-6736(09)61829-8

Sousa, R. M., Ferri, C. P., Acosta, D., Guerra, M., Huang, Y., Jacob, K., ... Prince, M. (2010). The contribution of chronic diseases to the prevalence of dependence among older people in Latin America, China and India: a 10/66 Dementia Research Group population-based survey. BMC Geriatrics, 10, 53. http://doi.org/10.1186/1471-2318-10-53

Stepanichev, M. Y., Moiseeva, Y. V, Lazareva, N. A., Onufriev, M. V, \& Gulyaeva, N. V. (2003). Single intracerebroventricular administration of 
amyloid-beta (25-35) peptide induces impairment in short-term rather than long-term memory in rats. Brain Research Bulletin, 61(2), 197-205.

Sturchler-Pierrat, C., Abramowski, D., Duke, M., Wiederhold, K. H., Mistl, C., Rothacher, S., Ledermann, B., Burki, K., Frey, P., Paganetti, P A., Waridel, C., Calhoun, M E., Jucker, M., Probst, A., Staufenbiel, M., \& Sommer, B. (1997). Two amyloid precursor protein transgenic mouse models with Alzheimer disease-like pathology. Proceedings of the National Academy of Sciences of the United States of America, 94(24), 13287-92.

Su, J. H., Cummings, B. J., \& Cotman, C. W. (1998). Plaque biogenesis in brain aging and Alzheimer's disease. II. Progressive transformation and developmental sequence of dystrophic neurites. Acta Neuropathologica, 96(5), 463-71.

Sudduth, T. L., Powell, D. K., Smith, C. D., Greenstein, A., \& Wilcock, D. M. (2013). Induction of hyperhomocysteinemia models vascular dementia by induction of cerebral microhemorrhages and neuroinflammation. Journal of Cerebral Blood Flow and Metabolism, 33(5), 708-15. http://doi.org/10.1038/jcbfm.2013.1

Sudduth, T. L., Weekman, E. M., Brothers, H. M., Braun, K., \& Wilcock, D. M. (2014). $\beta$-amyloid deposition is shifted to the vasculature and memory impairment is exacerbated when hyperhomocysteinemia is induced in APP/PS1 transgenic mice. Alzheimer's Research \& Therapy, 6(3), 32. http://doi.org/10.1186/alzrt262

Tang, Y.-J., Ohashi, R., \& Hamel, J.-F. P. (2007). Perfusion culture of hybridoma cells for hyperproduction of $\operatorname{IgG}(2 \mathrm{a})$ monoclonal antibody in a wave bioreactor-perfusion culture system. Biotechnology Progress, 23(1), 255-64. http://doi.org/10.1021/bp060299a

Tucker, S. M., Borchelt, D. R., \& Troncoso, J. C. (2008). Limited clearance of pre-existing amyloid plaques after intracerebral injection of Abeta antibodies in two mouse models of Alzheimer disease. Journal of Neuropathology and Experimantal Neurology, 67(1), 30-40.

Turner, P. R., O'Connor, K., Tate, W. P., \& Abraham, W. C. (2003). Roles of amyloid precursor protein and its fragments in regulating neural 
activity, plasticity and memory. Progress in Neurobiology, 70(1), 1-32. http://doi.org/10.1016/S0301-0082(03)00089-3

Tyas, S. L. (1996). Are tobacco and alcohol use related to Alzheimer's disease? A critical assessment of the evidence and its implications. Addiction Biology, 1(3), 237-54. http:/ /doi.org/10.1080/1355621961000124856

Vassar, R., Bennett, B. D., Babu-Khan, S., Kahn, S., Mendiaz, E. A., Denis, P., Teplow, D B., Ross, S., Amarante, P., Loeloff, R., Luo, Y., Fisher, S., Fuller, J., Edenson, S., Lile, J., Jarosinski, M A., Biere, A L., Curran, E., Burgess, T., Louis, J C., Collins, F., Treanor, J., Rogers, G., \& Citron, M. (1999). Beta-secretase cleavage of Alzheimer's amyloid precursor protein by the transmembrane aspartic protease BACE. Science, 286(5440), 735-41.

Walsh, D. M., Klyubin, I., Shankar, G. M., Townsend, M., Fadeeva, J. V, Betts, V., Podlisny, M B., Cleary, J P., Ashe, K H., Rowan, M J., \& Selkoe, D. J. (2005). The role of cell-derived oligomers of Abeta in Alzheimer's disease and avenues for therapeutic intervention. Biochemical Society Transactions, 33(Pt 5), 1087-90. http://doi.org/10.1042/ BST20051087

Walsh, D. M., \& Selkoe, D. J. (2007). A beta oligomers - a decade of discovery. Journal of Neurochemistry, 101(5), 1172-84. http:// doi.org/10.1111/ j.1471-4159.2006.04426.x

Wang, A., Das, P., Switzer, R. C., Golde, T. E., \& Jankowsky, J. L. (2011). Robust amyloid clearance in a mouse model of Alzheimer's disease provides novel insights into the mechanism of amyloid-beta immunotherapy. The Journal of Neuroscience, 31(11), 4124-36. http://doi.org/10.1523/JNEUROSCI.5077-10.2011

Waring, S. C., \& Rosenberg, R. N. (2008). Genome-wide association studies in Alzheimer disease. Archives of Neurology, 65(3), 329-34. http://doi.org/ 10.1001/archneur.65.3.329

Webb, R. L., \& Murphy, M. P. (2012). $\beta$-Secretases, Alzheimer's Disease, and Down Syndrome. Current Gerontology and Geriatrics Research, 2012, 362839. http://doi.org/10.1155/2012/362839 
Webster, S. J., Bachstetter, A. D., \& Van Eldik, L. J. (2013). Comprehensive behavioral characterization of an APP/PS-1 double knock-in mouse model of Alzheimer's disease. Alzheimer's Research \& Therapy, 5(3), 28. http://doi.org/10.1186/alzrt182

Weishaupt, J. (2003). Inhibition of CDK5 is protective in necrotic and apoptotic paradigms of neuronal cell death and prevents mitochondrial dysfunction. Molecular and Cellular Neuroscience, 24(2), 489-502. http://doi.org/10.1016/S1044-7431(03)00221-5

West, M. J. (1993). Regionally specific loss of neurons in the aging human hippocampus. Neurobiology of Aging, 14(4), 287-93.

Westerman, M. A., Cooper-Blacketer, D., Mariash, A., Kotilinek, L., Kawarabayashi, T., Younkin, L. H., Carlson, G A., Younkin, S G., \& Ashe, K. H. (2002). The relationship between Abeta and memory in the Tg2576 mouse model of Alzheimer's disease. The Journal of Neuroscience, 22(5), 1858-67.

Wilcock, D. M., Alamed, J., Gottschall, P. E., Grimm, J., Rosenthal, A., Pons, J., Ronan, V., Symmonds, K., Gordon, M N., \& Morgan, D. (2006). Deglycosylated anti-amyloid-beta antibodies eliminate cognitive deficits and reduce parenchymal amyloid with minimal vascular consequences in aged amyloid precursor protein transgenic mice. The Journal of Neuroscience, 26(20), 5340-6.

Wilcock, D. M., Munireddy, S. K., Rosenthal, A., Ugen, K. E., Gordon, M. N., \& Morgan, D. (2004a). Microglial activation facilitates Abeta plaque removal following intracranial anti-Abeta antibody administration. Neurobiology of Disease, 15(1), 11-20.

Wilcock, D. M., Rojiani, A., Rosenthal, A., Levkowitz, G., Subbarao, S., Alamed, J., Wilson, D., Wilson, N., Freeman, M J., Gordon, M N., \& Morgan, D. (2004b). Passive amyloid immunotherapy clears amyloid and transiently activates microglia in a transgenic mouse model of amyloid deposition. The Journal of Neuroscience, 24(27), 6144-51.

Wilcock, D. M., Rojiani, A., Rosenthal, A., Subbarao, S., Freeman, M. J., Gordon, M. N., \& Morgan, D. (2004c). Passive immunotherapy against Abeta in aged APP-transgenic mice reverses cognitive deficits and 
depletes parenchymal amyloid deposits in spite of increased vascular amyloid and microhemorrhage. Journal of Neuroinflammation, 1(1), 24.

Wiltfang, J., Esselmann, H., Bibl, M., Smirnov, A., Otto, M., Paul, S., Schmidt, B., Klafki, H W., Maler, M., Dyrks, T., Bienert, M., Beyermann, M., Ruther, E., \& Kornhuber, J. (2002). Highly conserved and diseasespecific patterns of carboxyterminally truncated Abeta peptides 1$37 / 38 / 39$ in addition to 1-40/42 in Alzheimer's disease and in patients with chronic neuroinflammation. Journal of Neurochemistyr, 81(3), 48196.

Wirths, O., Erck, C., Martens, H., Harmeier, A., Geumann, C., Jawhar, S., Kumar, S., Multhaup, G., Walter, J., Ingelsson, M., DegermanGunnarsson, M., Kalimo, H., Huitinga, I., Lannfelt, L., \& Bayer, T. A. (2010). Identification of low molecular weight pyroglutamate Abeta oligomers in Alzheimer disease: a novel tool for therapy and diagnosis. The Journal of Biological Chemistry, 285(53), 41517-24.

Wirths, O., Multhaup, G., \& Bayer, T. A. (2004). A modified beta-amyloid hypothesis: intraneuronal accumulation of the beta-amyloid peptide-the first step of a fatal cascade. Journal of Neurochemistry, 91(3), 51320. http://doi.org/10.1111/j.1471-4159.2004.02737.x

Wittnam, J. L., Portelius, E., Zetterberg, H., Gustavsson, M. K., Schilling, S., Koch, B., Demuth, H U., Blennow, K., Wirths, O., \& Bayer, T. A. (2012). Pyroglutamate amyloid beta aggravates behavioral deficits in transgenic amyloid mouse model for Alzheimer disease. The Journal of Biological Chemsitry., 287(11), 8154-62.

Wun, K. S., Miles, L. A, Crespi, G. A N., Wycherley, K., Ascher, D. B., Barnham, K. J., Cappai, Roberto., Beyreuther, Konrad., Masters, Colin L., Parker, Michael W., \& McKinstry, W. J. (2008). Crystallization and preliminary X-ray diffraction analysis of the Fab fragment of WO2, an antibody specific for the Abeta peptides associated with Alzheimer's disease. Acta Crystallographica. Section F, Structural Biology and Crystallization Communications, 64(Pt 5), 438-41. http:// doi.org/10.1107/ S1744309108011718

Yamada, K., Yabuki, C., Seubert, P., Schenk, D., Hori, Y., Ohtsuki, S., ... Iwatsubo, T. (2009). Abeta immunotherapy: intracerebral sequestration 
of Abeta by an anti-Abeta monoclonal antibody 266 with high affinity to soluble Abeta. The Journal of Neuroscience, 29(36), 11393-8. http://doi.org/10.1523/JNEUROSCI.2021-09.2009

Yamaguchi, H., Hirai, S., Morimatsu, M., Shoji, M., \& Ihara, Y. (1988). A variety of cerebral amyloid deposits in the brains of the Alzheimer-type dementia demonstrated by beta protein immunostaining. Acta Neuropathologica, 76(6), 541-9.

Yoshikai, S., Sasaki, H., Doh-ura, K., Furuya, H., \& Sakaki, Y. (1990). Genomic organization of the human amyloid beta-protein precursor gene. Gene, 87(2), 257-63. http://doi.org/10.1016/0378$1119(90) 90310-\mathrm{N}$

Youssef, I., Florent-Béchard, S., Malaplate-Armand, C., Koziel, V., Bihain, B., Olivier, J. L., Leininger-Muller, B., Kriem, B., Oster, T., \& Pillot, T. (2008). N-truncated amyloid-beta oligomers induce learning impairment and neuronal apoptosis. Neurobiology of Aging, 29(9), 1319-33. http://doi.org/10.1016/j.neurobiolaging. 2007.03.005

Zahnd, C., Spinelli, S., Luginbühl, B., Amstutz, P., Cambillau, C., \& Plückthun, A. (2004). Directed in vitro evolution and crystallographic analysis of a peptide-binding single chain antibody fragment ( $\mathrm{scFv}$ ) with low picomolar affinity. The Journal of Biological Chemistry, 279(18), 18870-7. http://doi.org/10.1074/jbc.M309169200

Zhang, Y., Thompson, R., Zhang, H., \& Xu, H. (2011). APP processing in Alzheimer's disease. Molecular Brain, 4, 3. http://doi.org/10.1186/ 1756-6606-4-3 


\section{Curriculum Vitae Gregory Antonios}

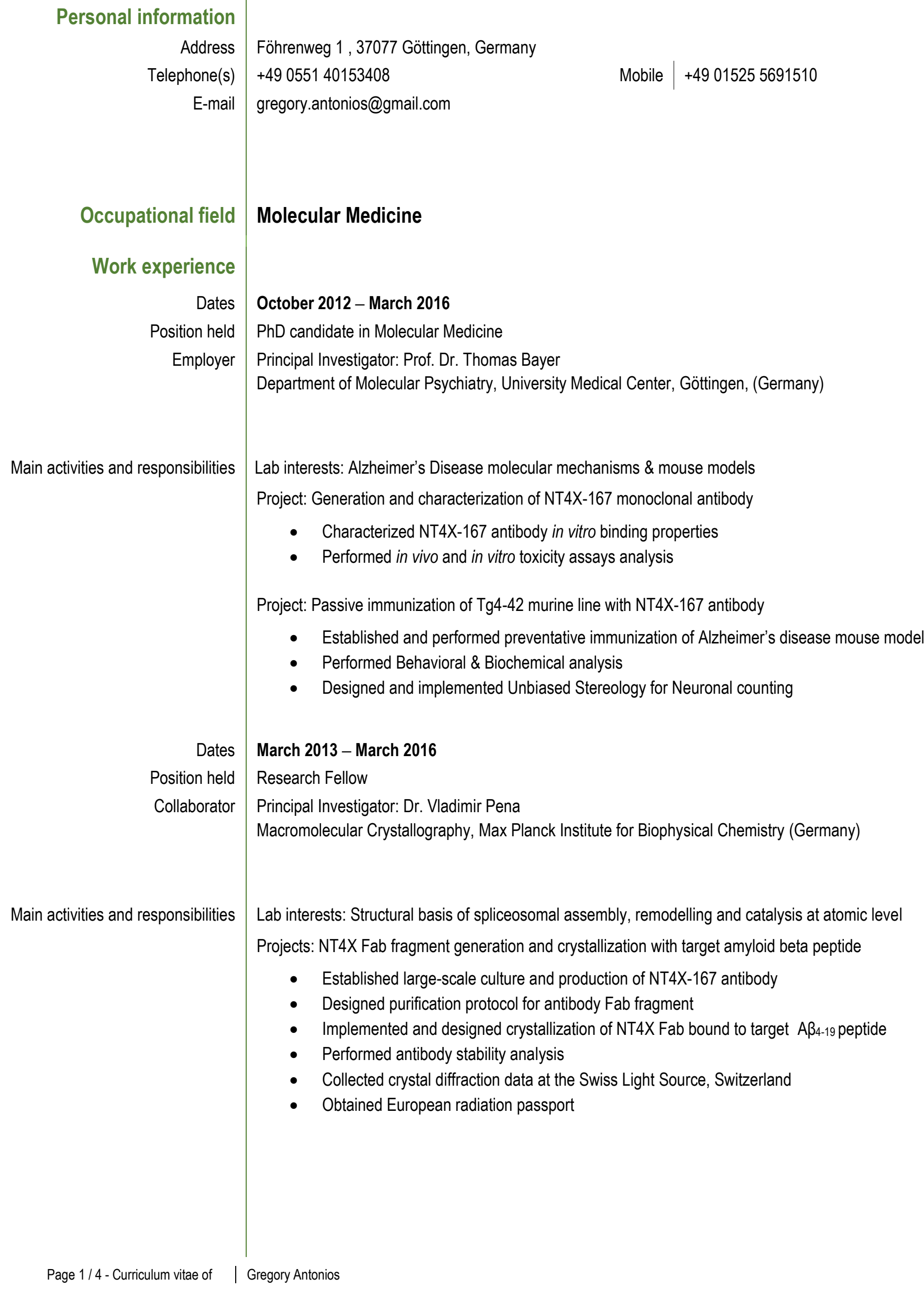


Dates

Position held

Employer

Main activities and responsibilities

Main activities and responsibilities

\section{Teaching \\ Dates \\ Position Held \\ Employer}

Responsibilities

Dates

Position held

Employer

Activities and Responsibilities
July 2011 - August 2012

Research Assistant in Molecular Diagnostics Lab

Principal Investigator: Dr. Rami Mahfouz; Co-Investigator: Dr. Soha Yazbek American University of Beirut - Medical Center (AUBMC), Beirut (Lebanon)

Lab interests: Genetically Inherited Diseases

Project: "Using Microarray Gene Expression Profiling to Uncover Genes and Pathways Involved in the Pathogenesis of Familial Mediterranean Fever"

- Microarray expression profiling of samples from patients clinically and genetically identified with FMF

- Collection of patient samples and consent forms

\section{July 2011 - September 2012}

Research Assistant in Proteomics Lab

Director: Dr. Brigitte Wex

Lebanese American University (LAU), Byblos (Lebanon)

Lab interests: Protein Identification and Sequencing through Matrix Assisted Laser Desorption Ionization (MALDI) Mass Spectrometry

Project: "Effect of Solute Receptor SLC35b4 on cellular O-Glycosylation and its association with glucose production" through protein knock-down (HepG2 cells):

- Purification of glycosylated protein

- 2D gel electrophoresis and protein extraction

- Quantification and MALDI analysis

\section{August 2013 - Present}

Teaching and supervision

Universitätsmedizin Göttingen

Clinical Neurosciences and Higher Brain Functions

- Neuroscience Graduate program course

- Presented and elucidated molecular aspects of neurodegenerative dementias

- Prepared and corrected student exams

Behavioral and neuropathological analysis of transgenic mouse models:

- GGNB Graduate program course

- Prepared and gave lab module in immunohistochemistry

Masters and rotation students:

- $\quad$ Planned long-term projects

- $\quad$ Supervised day-to-day learning and progress

\section{October 2009 - June 2011}

Teaching Assistant

Lebanese American University, Byblos (Lebanon)

Genomics Research Methods Graduate course, Spring 2011:

- Preparation and Assistance in the three Lab Modules

- Molecular Biology, Microbiology \& Cell Biology

Introduction to Biology Undergraduate lab, Fall 2010:

- $\quad$ Preparation of Lab Experiments \& Exams, and Teaching 


\section{Education}

Dates

Degree awarded

Principal subjects

Institution of higher education

Dates

Degree awarded

Principal subjects

Institution of higher education

Dates

Degree awarded

Institution of higher education

\section{Skills and competences}

Organisational skills and competences

Technical skills and competences

Computer skills and competences

Languages

Other language(s)

Self-assessment

European level

English

French

German

Artistic skills and hobbies
October 2012 - Expected February 2016

$\mathrm{PhD}$ in Molecular Medicine

Thesis Project: "Role of N-truncated A $\beta_{4-42}$ peptide in the pathology of Alzheimer's disease"

Georg-August-Universität Göttingen (Germany)

\section{October 2009 - September 2012}

Master of Science in Molecular Biology

Thesis Project: Effect of SLC35b4 Knockdown on Total and O-Glycosylated Cellular Proteins in a HepG2 Cell Line

Lebanese American University (LAU)

(Lebanon)

October 2005 - June 2009

Bachelor of Science Degree in Biology

Notre Dame University (NDU)

Zouk Mosbeh (Lebanon)

Establishment and follow-up on numerous national and international collaborations

Organization of and follow-up on stock availability of lab kits, chemicals, reagents \& consumables Scheduling and follow-up on technical staff timetable and experimental workload

Organization of Conferences and Workshops

Experimental Techniques:

Molecular Biology: PCR, Real-time PCR, Sequencing, PFGE, Transformation, Restriction digestion DNA \& plasmid extraction

Cell Biology: Cell culture \& maintenance, Overexpression and knock-down of proteins,

DNA/RNA/Protein extraction from fresh and FFPE tissues, Western blot and protein quantification, Immunohistochemistry and imaging of cells \& tissues, Live cell imaging, Wound-healing assays, Protein preps

Microbiology: API, Antimicrobial testing, Bacterial isolation, enrichment, culturing \& cryobanking

Proteomics: 2D electrophoresis, protein purification and MALDI data acquisition,

Crystallography: Antibody purification, crystallization, and diffraction data collection

Bioinformatics: Proficient in NCBI, UniProt, Mascot server

Software: Image J, Zeiss Imaging, GraphPad Prism 5, and Microsoft Word, Excel, PowerPoint

Lebanese Arabic (mother tongue)

English, French, German

\begin{tabular}{|l|c|c|c|c|c|c|c|c|c|}
\hline \multicolumn{4}{|c|}{ Understanding } & \multicolumn{4}{c|}{ Speaking } & \multicolumn{2}{c|}{ Writing } \\
\hline \multicolumn{2}{|c|}{ Listening } & \multicolumn{2}{|c|}{ Reading } & Spoken interaction & \multicolumn{2}{c|}{ Spoken production } & \multicolumn{2}{c|}{} \\
\hline C2 & Proficient user & C2 & Proficient user & C2 & Proficient user & C2 & Proficient user & C2 & Proficient user \\
\hline C1 & Proficient user & C1 & Proficient user & C1 & Proficient user & C1 & Proficient user & B2 & Independent user \\
\hline A2 & Basic User & A2 & Basic User & A1 & Basic User & A1 & Basic User & A1 & Basic User \\
\hline
\end{tabular}

Photography, Cooking, Hiking 


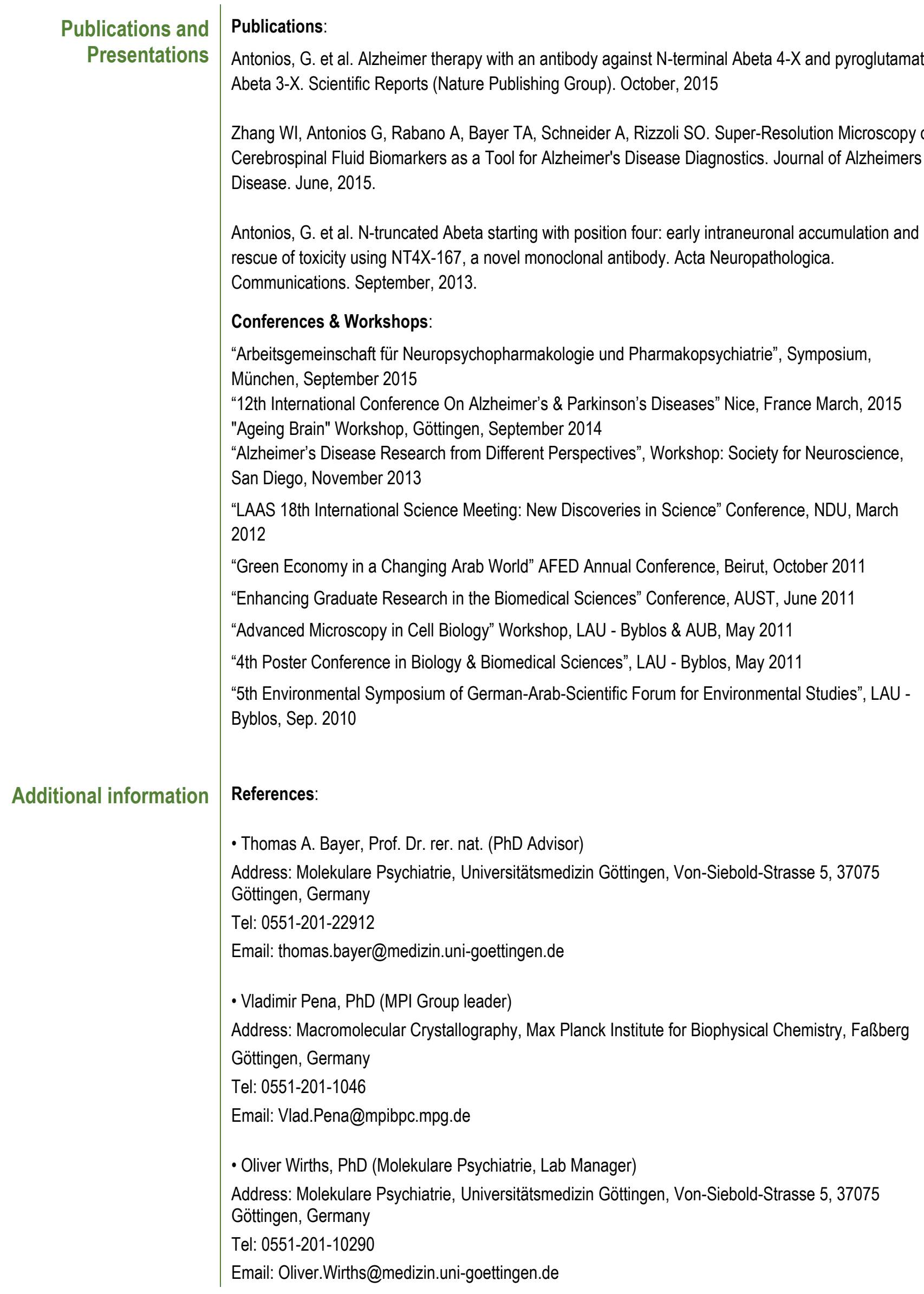

Page 4 / 4 - Curriculum vitae of | Gregory Antonios 